\title{
Mount Mansfield
}

\section{Science and Stewardship Center}

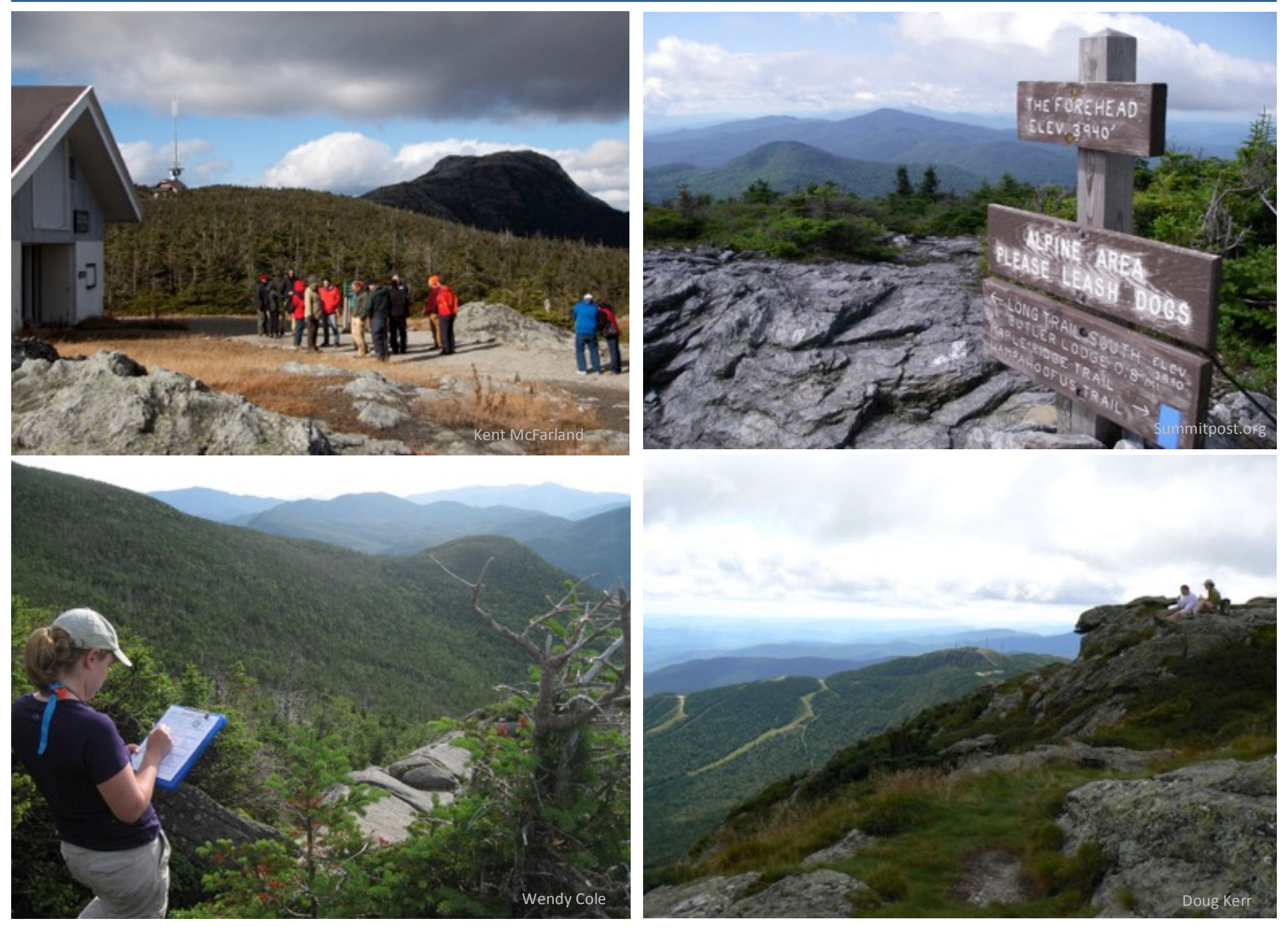

Program, Facilities, and Business Plans

June 2016 


\section{Mount Mansfield Science and Stewardship Center}

Program, Facilities, and Business Plans
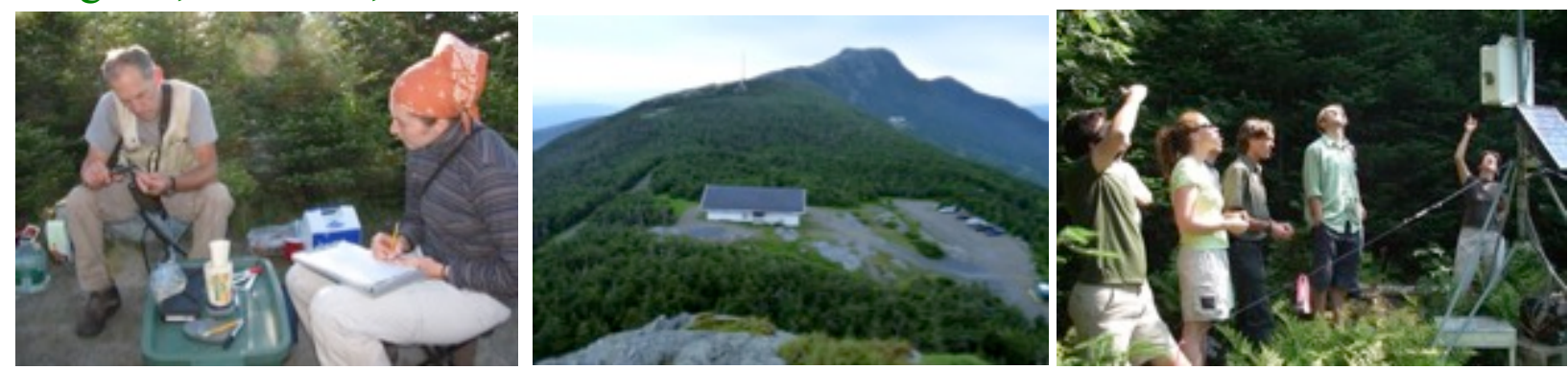

Part 1. Program Plan

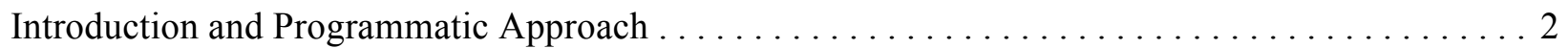

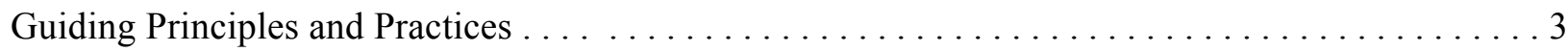

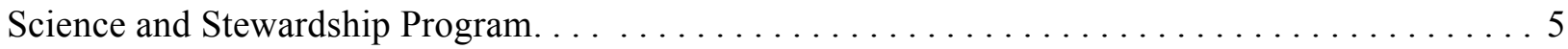

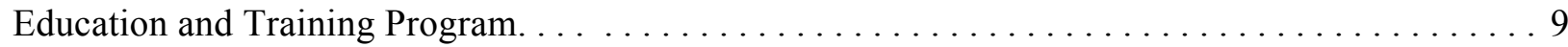

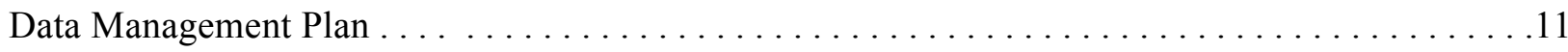

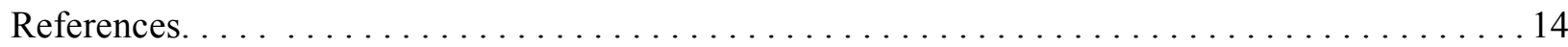

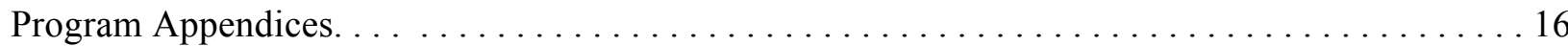

Part 2. Facilities Plan

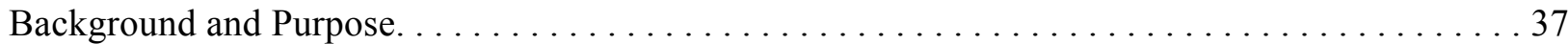

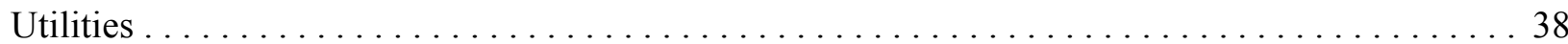

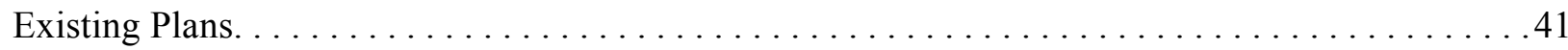

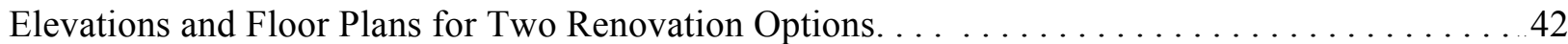

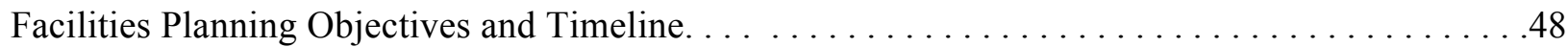

Facilities Appendices. . . . . . . . . . . . . . . . . . . . . . . . . . . . . . . . . . . . .49

Part 3. Business Plan

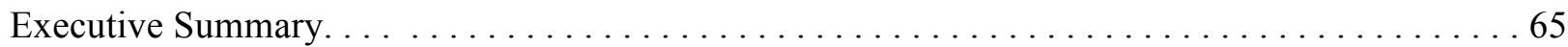

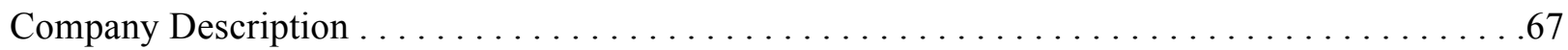

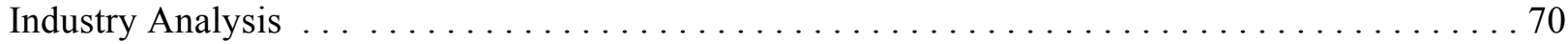

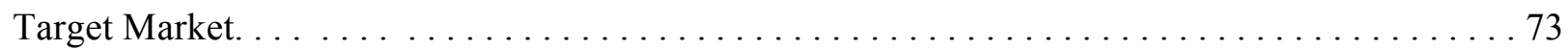

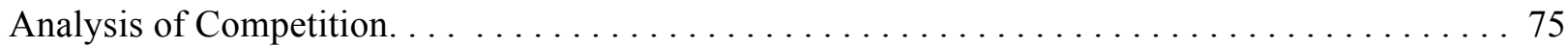

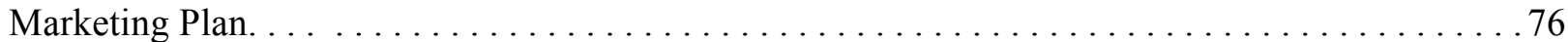

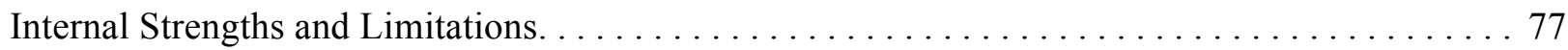

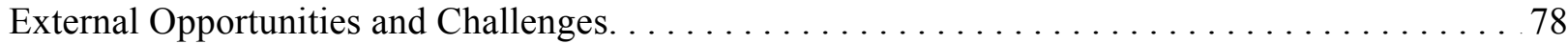

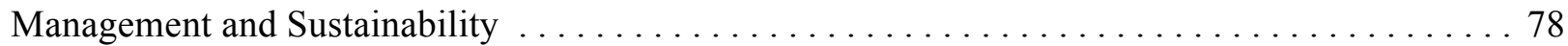

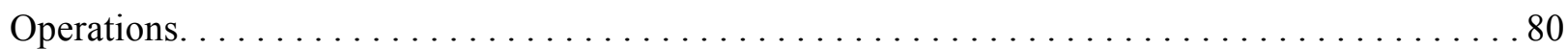

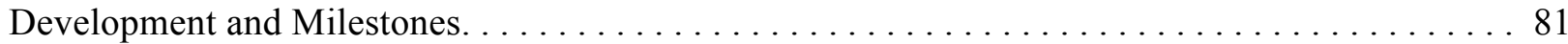

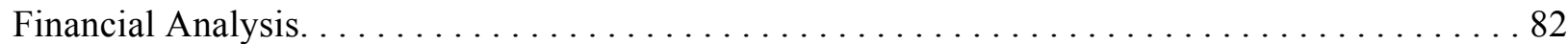

Measuring Performance and Impact $\ldots \ldots \ldots \ldots \ldots \ldots \ldots \ldots \ldots \ldots \ldots \ldots \ldots \ldots \ldots \ldots \ldots \ldots \ldots \ldots \ldots \ldots$

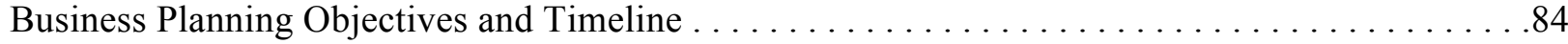

References . . . . . . . . . . . . . . . . . . . . . . . . . . . . . . . . . . . .85

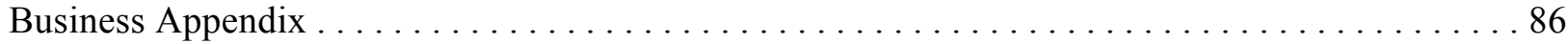

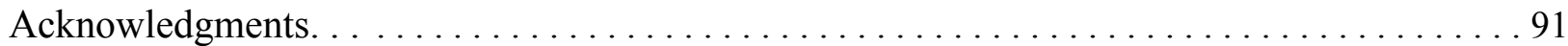




\section{Part 1. Mount Mansfield Science and Stewardship Center Program Plan Introduction and Programmatic Approach}

The University of Vermont is leading an effort to establish a hub of mountain research and conservation in the Mount Mansfield Summit Station, which is located on the forested ridge of Vermont's highest mountain at an elevation of 3,850 ft. Partners in the enterprise include the Vermont Center for Ecostudies, the Vermont Monitoring Cooperative (VMC), the Vermont Department of Forests, Parks and Recreation, and the building's owner, Stowe Mountain Resort. We envision a community of scholars, educators and land stewards working alongside students and visitors to understand and sustain the vitality of mountain ecosystems. The Mount Mansfield Science and Stewardship Center will serve these audiences with a variety of mission-focused programs.

\section{Mission}

The Mansfield Center's mission is to catalyze collaborative science and stewardship for healthy mountains, watersheds, and communities. The foundation for this work consists of: a long-term scientific record that spans air, forest, soil, water, and wildlife; a tradition of information sharing and networking; and a commitment to science-based natural resource policy and management.

Goals

- Build knowledge of mountain ecosystems and changes affecting mountain flora and fauna.

- Advance understanding of relationships among mountains, streams, and lakes.

- Provide place-based education and outreach on mountain ecology, conservation issues, and stewardship.

- Develop, implement, and demonstrate management actions that lead to improved conservation of mountain environments.

- Provide a platform for scholarship and instruction in fields that address social dimensions of mountain environments, such as engineering, human health, economics, education, and the humanities.

- Foster connections among UVM schools and programs and between the University and the Vermont State College system.

Science and Stewardship Approach

Research and monitoring activities will support decisions that promote the health of mountain ecosystems in the face of climate change and other human-induced stressors. The following approach will help ensure integration of science and stewardship.

- Measure natural variability and effects of human activity on mountain ecosystems with observations and experiments conducted across a range of elevations.

- Quantify and model processes that sustain ecosystem function and deliver ecosystem services.

- Evaluate the capacity of plant and animal populations and natural communities to resist, recover from, and adapt to anthropogenic stressors.

- Integrate scientific findings into management decisions, tools, and guidelines that support the health, resilience, and stable transformation of mountain ecosystems. 


\section{Education Approach}

Education programs at the Mansfield Center will serve both individuals and society, in keeping with the University of Vermont's mission as a public research university. The intention is to:

- Provide learning experiences that prepare students to be leaders in environmental science, stewardship, and related fields.

- Foster dedication to healthy social and ecological systems through immersion in cooperative field studies.

- Build technical skills and knowledge by enabling students to participate directly in multiple phases of science and stewardship projects.

- Offer informal science and stewardship education to visitors with exhibits and field demonstrations at the Mansfield Center and at the Smuggler's Notch Visitors Center.

- Deliver outreach programs to area residents.

\section{Approach to Data Management}

Science, stewardship, and education all benefit from efficient exchange of information. We will therefore organize, maintain, and serve Mansfield Center products in a searchable data and document archive to be managed in concert with the Vermont Monitoring Cooperative.

\section{A Foundation for Research and Training}

Mount Mansfield has been the site of research and educational activities for more than 170 years. Since 1990, the Vermont Monitoring Cooperative has coordinated comprehensive environmental monitoring on the mountain, as well as in the Lye Brook Wilderness Area of the Green Mountain National Forest. This long-term record provides a strong foundation for the expansion and integration of current research and training activities, which are summarized in Appendix 1.

\section{Guiding Principles and Practices}

Integration of research, education, and stewardship is needed to sustain ecosystems and their services to society.

- Natural resource managers frame real-world problems, define information needs, and contribute professional insights to the design of science and education programs.

- Scientists design research and monitoring to guide management and policy decisions.

- Students participate in data collection and stewardship activities.

- Educators and scientists communicate findings to targeted audiences, emphasizing the public benefits of science-based stewardship.

- Natural resource managers, stewards, and policy makers incorporate science into decisions and actions.

Strategic collaboration increases the impact of science and conservation by aligning resources, skills, and knowledge.

- Scientists from multiple institutions and disciplines work together to address different dimensions of a complex problem.

- Researchers and stewards participate in regional and global networks to synthesize information and coordinate effort across spatial scales. 
- Cooperators economize on cost through joint use of equipment, personnel, and infrastructure.

- Conflicts in use of common resources are resolved through direct communication, compromise, and accommodation.

Standardized, long-term monitoring and short-term experimentation play essential and complementary roles in science and stewardship. Together, they provide a vital record of the past, reveal ecological patterns and processes, and form a basis for projecting future conditions under different scenarios.

- Scientists and stewards design long-term studies that measure natural variability and reveal interactions among ecosystem components over time.

- Short-term experiments address human dimensions - including anthropogenic stressors and restoration techniques.

- Careful manipulations of ecological patterns and processes provide insights into ecosystem function.

- Cooperators review and coordinate scientific and stewardship activities to minimize conflicts.

Science, stewardship and education must adapt as conditions change and techniques improve.

- Scientists and stewards utilize advancing methods and technologies in their work.

- Program leaders innovate and validate novel approaches to achieve site-specific goals and spur progress in their fields.

- Cooperators address important issues and agents of change as they emerge or become known.

- Cooperators capitalize on short-term funding opportunities to improve infrastructure for long-term studies.

- Effective methods are retained, when possible, to ensure continuity.

Ecological and economic sustainability are fundamental to implementing responsible science, stewardship, and education programs.

- The design of the facility incorporates materials and technologies that minimize visual and environmental impact in the areas of energy use, water supply, and waste management.

- Cooperators use low-impact and leave-no-trace techniques. For example, field programs establish limits on group size and off-trail activity to avoid adverse ecological effects due to trampling, noise, or other agents of disturbance. Site markings and sampling equipment are installed in the field only as necessary and are removed immediately upon project completion.

- Capital assets are protected through regular maintenance and security.

- Financial management conforms to standards of responsible stewardship through maintenance of a balanced budget, capital reserves, and diverse funding streams.

- Environmental and financial practices are regularly and objectively evaluated to assess performance and identify opportunities for improvement.

Cooperative and proficient information management creates valuable opportunities for researchers, educators, and natural resource managers. 
- Cooperators recover, digitize, and make accessible historic information, especially endangered data sets.

- A unified database with standardized fields archives a site-based body of knowledge that extends beyond the life of individual projects and investigators.

- Data are served to diverse users through data sharing agreements that balance the need to protect intellectual property with the benefits of information exchange.

- Annual meetings provide a forum for information exchange and the enrichment of information through development of collaborative ventures.

- Teachers and land stewards draw on historic and recent data to illustrate messages and develop science-based management strategies.

Place-based science, stewardship, and education offer unique advantages over other approaches to building and applying knowledge.

- Educators and mentors provide students direct experiences with their subject matter.

- Scientists build long-term, high-value data sets.

- Land stewards customize management practices to local conditions.

- Cooperators design programs that build connections between people and place, adding meaning to personal, civic, and professional choices that affect the environment.

- Cooperators and visitors engage in activities that foster collaboration and community.

\section{Science and Stewardship Program}

\section{Fundamental Question}

What environmental policy and natural resource management decisions can be made to promote the health of mountain ecosystems in the face of climate change and other human-induced stressors?

\section{Research and Monitoring Domains}

Working in concert with the Vermont Monitoring Cooperative, the Rubenstein Ecosystem Sciences Laboratory at Lake Champlain, and UVM research forests and natural areas, the Mansfield Center will promote advances in and connections among the following research and monitoring domains.

- Reconstruction of the past (paleo-climate/ecology/limnology, historical geology, land use)

- Atmospheric science (atmospheric chemistry and physics, climatology, meteorology)

- Watershed science (stream hydrology, snowpack dynamics, water quality, biogeochemistry)

- Forest science (forest health, primary productivity, carbon fluxes, forestry)

- Biodiversity (genetics, organismal biology, population ecology, community ecology, biogeography)

- Soil science (physical, chemical, and biological properties; soil formation, classification, and mapping)

- Natural resource management (restoration ecology, evaluation of trail/resort/forest management, public interpretation, visitor experiences) 
- Ecosystem services and socio-economy (water regulation and filtration, forest products, local and regional economics)

In addition, the Mansfield Center will afford opportunities for scholarship and instruction in a wide range of related fields, including:

- Engineering (civil/environmental, mechanical/structural, electrical/energy, systems)

- Computer sciences and informatics (biological and geographic data systems)

- Outdoor education (instructional methods, leadership development, risk management)

- Human health and well-being (benefits of physical activity and contact with nature)

- Environmental studies (ethics, planning, journalism, writing, photography)

- Convergence of science and art (environmental design, artistic representations of scientific data, psychological responses to beauty and scientific discovery)

Program Appendices 2 and 3 contain examples of mountain and watershed project ideas that link these domains.

\section{Approach to Science and Stewardship}

* Measure natural variability and effects of human activity on mountain ecosystems with observations and experiments conducted across a range of elevations.

Related questions:

1. What are background or benchmark conditions?

2. What are the stressors and stress responses?

3. What are the relative risks posed by different stressors?

4. Are conservation policy and management actions effective?

5. What state variables or historic conditions explain current patterns?

6. How reliably and to what extent can patterns be modeled across space?

7. What is the rate of change in the status of ecosystem components and processes?

8. How reliably can trends be projected over time?

Possible projects:

1. Measure physical, chemical, and biological variables along elevational transects in order to quantify baseline and future conditions in terms of climate, topography, bedrock, soil, species niches, plant and animal demographics, human use, etc.

2. Obtain, digitize, and compare records of historical conditions to current conditions.

3. Measure physical, chemical, and biological responses to changes in exposure to anthropogenic stressors (e.g, warming, acidification, nitrogen enrichment, changes in moisture regimes, invasive species, forest pests and pathogens, human noise, damage from hiking/biking/skiing/snowshoeing, road traffic, habitat removal or modification, towers/buildings etc.). Address both negative and positive impacts that may result from changes in human behavior or policy.

4. Describe the influence of extreme events on the structure and function of mountain ecosystems. 
5. Investigate the mechanisms that establish treeline in the region. Monitor treeline to determine whether it changes, how it changes, and over what time scales.

6. Identify the location, community composition, duration of snow cover, and timing of snowmelt in alpine snowbed communities.

7. Investigate changes in plant and animal phenology, together with their causes and consequences.

8. Monitor taxa that occur as isolated, disjunct southern populations on the high mountains of the Northeast. Measure environmental conditions so demographic changes can be associated with changing environmental conditions.

9. Measure how characteristics of mountain snowmelt (e.g., timing, volume, chemistry) affect cyanobacteria in lakes.

10. Identify and monitor plant functional traits and their relationship to local conditions.

11. Describe the genetic diversity and structure of high-elevation animal and plant populations.

12. Measure the local and landscape-level effects of forestry and sugar bush management.

* Quantify and model the processes that sustain ecosystem function and deliver ecosystem services.

Related questions:

1. What are the key mechanisms that drive nutrient cycles, population dynamics, community composition, trophic interactions, etc.?

2. To what degree are these mechanisms influenced by different biotic and abiotic factors?

3. How can quantitative measures be applied to a conceptual understanding of mountain ecosystems?

Possible projects:

1. Construct and evaluate quantitative models that describe nutrient and water cycling, energy flow, and community dynamics within and among the major vegetation zones.

2. Conduct observational and experimental studies to establish the mechanistic basis for changes in ecosystem elements and processes.

3. Investigate the effect of area on the composition and rate of change in alpine communities.

4. Measure effects of habitat connectivity on plant and animal demographics (e.g., abundance, age structure, sex ratios, rates of colonization and extinction).

* Evaluate the capacity of populations and natural communities to resist, recover from, and adapt to anthropogenic stressors.

Related questions:

1. Which ecosystem components are resilient to natural and anthropogenic perturbations?

2. What are the self-adaptive attributes that contribute to their resilience (areal extent, mobility, genetic diversity, behavioral or phenotypic plasticity, aspect, slope etc.)?

3. Can these attributes be managed or manipulated to increase resilience?

4. Which ecosystem components are vulnerable to perturbation? 
5. What constraints explain the vulnerability?

6. Can these constraints be alleviated through policy or management actions?

7. Which ecosystem processes are resilient to perturbation?

8. Which are vulnerable?

9. What management and policy options exist to increase the resilience and reduce the vulnerability of ecosystem processes?

10. Do ecological response thresholds exist in northeastern mountain ecosystems?

Possible projects:

1. Conduct observational research to determine if species composition changes in a consistent way along elevational gradients and then identify the indicator species or species groups associated with such change points.

2. Conduct experimental and observational research to identify response thresholds for the principal processes (e.g., water and nutrient cycling) and organizing components (e.g., major natural communities, keystone resources, pests and pathogens) of mountain ecosystems.

* Integrate scientific findings into environmental policy and natural resource management tools and guidelines that support the health, resilience, and stable transformation of mountain ecosystems. Apply, assess, and communicate these measures on Mount Mansfield.

Policy and management applications:

1. Air quality legislation, rules, and regulations

2. Greenhouse gas legislation, rules, and regulations

3. Outreach to recreational resource users

4. Trail construction and treadway management

5. Wildlife habitat management

6. Invasive species and pest control

7. Resort and recreation management

8. Silviculture (including timber and sugar bush management)

9. Regional planning

10. Conservation reserve and easement acquisition

11. Prioritization and resource allocation among conservation initiatives

Possible projects:

1. Review and evaluate the information needs of legislators, regulators, recreation and natural resource managers, planners, and other conservation professionals whose work pertains to northeastern mountain ecosystems.

2. Analyze and rank options for uptake of available scientific information into policy and management decisions that affect mountain environments.

3. Develop specific policy and management recommendations for landowners and other stewards of Mount Mansfield. 
4. Use interpretive displays and demonstration plots to highlight policies or management prescriptions that are adopted on Mount Mansfield.

5. Evaluate the effects of policy and management changes through controlled experiments.

6. Identify communication strategies that reduce hiker impacts.

Science and Stewardship Objectives and Timeline

$\underline{\text { Year } 1}$

1. Assemble teams of collaborators and support their efforts to prepare multi-disciplinary and/or regional research proposals.

2. Develop policies and procedures to ensure compatibility among research activities and to minimize research impacts on natural features and visitor experiences.

$\underline{\text { Year } 2}$

1. Encourage use of the Mansfield Center by scientists and natural resource managers through advertisement of infrastructure, data management, and program offerings.

2. Network with other institutions that specialize in science-policy integration.

Years 3-5

1. Provide basic field station services (shelter, lodging, lab space, equipment storage) to support the launch of new science and stewardship activities.

2. Promote application of mountain research findings to specific environmental policies or decisions.

3. Organize a Northeast Mountain Science Conference to survey frontiers of research and outline regionally coordinated project proposals linking physical, natural, and social sciences.

\section{Education and Training Program}

\section{Education and Training Approach}

The Mansfield Center will capitalize on these existing educational assets to:

- Provide learning experiences that prepare students to be leaders in environmental science, stewardship, and related fields.

- Foster dedication to healthy ecological and social systems through immersion in cooperative field studies.

- Build technical skills and knowledge by enabling students to participate directly in multiple phases of science and stewardship projects.

- Offer informal science and stewardship education to people visiting the Mansfield Center and the Smuggler's Notch Visitors Center.

- Deliver outreach programs to area residents.

\section{Educational Modes}

The following educational modes will be phased in over the first five years of operation. They are presented here in the expected sequence of initiation.

- Exhibits and interpretive displays 
- University field courses and labs

- Internships and mentoring for undergraduates and recent graduates

- Professional training workshops for natural resource managers

- Self-guided tours

- Tours led by researchers and site stewards

- Demonstration sites

- Service-learning

- A mountain studies certificate program

- Outreach to school and community groups

- Smartphone-enabled interpretation

- Internet-based programming

\section{Audiences}

1. Graduate, undergraduate, and advanced-placement high school students participating in field courses or field labs in science, engineering, environmental studies, natural resource management, recreation management, and related fields.

2. Undergraduates, graduate students, and young professionals gaining experience and knowledge through paid or volunteer service on expertly designed projects.

3. Environmental policy makers and natural resource managers.

4. K-12 students (region-wide), local community members, and visitors to the area.

5. Members of groups that are underrepresented in environmental science and stewardship.

Education and Training Objectives and Timeline

Years 1-3

1. Design exhibits for the Mansfield Center and Smuggler's Notch Visitor Center.

2. Develop policies and procedures to: a) ensure the personal safety of guests and program participants; and b) protect sensitive natural features from research and education impacts.

3. Promote use of the Mansfield Center as a platform for research and education.

4. Develop and advertise a calendar of education, training, and service-learning programs.

5. Incorporate hands-on, educational resources (e.g., wet and dry labs, field instruments, and sensor networks) into the Summit Station renovation.

Years 4 and 5

1. Deliver and evaluate off- and on-site education and training programs.

2. Establish an undergraduate internship program in conjunction with VMC cooperators.

3. Create a self-guided science and stewardship tour featuring demonstration sites.

4. Develop proposal for a UVM certificate program in Mountain Studies. 


\section{Data Management Plan}

In order to organize, integrate and maintain the data and associated information generated at the station, this effort will utilize and support cyberinfrastructure currently maintained by the Vermont Monitoring Cooperative and hosted at the University of Vermont. This database and website provide searchable, linked information for over 170 projects, including document archive, data display and visualization, search and download queries, and metadata summaries (e.g. procedural methods, attribute information, related documents and citation and access specifications). The website gives users the power to browse and search, and also makes information about projects, datasets and associated publications visible on the web through search engines such as Google. The back-end database provides a secure archive for data and metadata with access constraints and backup policies.

\section{Data Description}

The data collected by the Mansfield Center's core cooperators and visitors will span a wide range of disciplines (summarized on pages 4 and 5) and encompass results from experimental and observational studies, including data gathered by field personnel during discrete sampling occasions and by continuously operating environmental sensors.

The VMC has been archiving data collected on Mt. Mansfield since the early 1990's. Current data holdings represent the work of state agency scientists, researchers from multiple university, non-profit research and conservation groups, and federal monitoring and research programs. They are a testament to the broad buy-in already in place for this data infrastructure. The extensive data archive encompasses studies of recreational impacts on alpine plant communities, forest bird demographics, and forest canopy conditions, among many others. These data will form the seed for a repository that will serve the needs of researchers and educators as they utilize and contribute to the repository. Because of the flexible metadata format used within the VMC repository and the high quality of documentation in place for these existing data, future integration with other datasets will require much less work than if the data were dispersed in more traditional and isolated data storage systems.

\section{Format}

Data generated by programs sponsored by the Mansfield Center will be managed in two to three stages. The first stage will be data collection by individual researchers or research groups, who will determine the appropriate process for recording, entering, inspecting, and summarizing the information. This will provide researchers with maximum flexibility to format, analyze, and transfer information as circumstances require. One possible exception is data collected through any environmental sensor networks established at the site, as these may be directly fed into the data repository.

In the second stage, digital data will be archived in the station repository for preservation and access by others. A web server running the Linux-Apache-MySQL-PHP stack will provide the needed cyberinfrastructure to input and store tabular data, spatial data, electronic files and associated metadata in a relational database and file system. MySQL is an open-source and wellsupported relational database management system in use across the world. Data and metadata stored in this format can be accessed with a range of free and proprietary software, limiting the risks of data loss to future changes in technology. 
In the third stage, physical samples, specimens and datasheets will be archived onsite in locked cabinets. Containing folders or boxes will be labeled with identification numbers corresponding to metadata record entries in the station repository.

\section{Metadata}

The Vermont Monitoring Cooperative has extended the Ecological Metadata Language (EML) standard (https://knb.ecoinformatics.org/\#external//emlparser/docs/index.html) to document data in its system. This standard provides an extremely flexible set of modules for documenting and sharing metadata, and because of the wide-ranging and diverse data associated with ecological investigations, this flexibility is its biggest asset. No structure is imposed on or expected of the data, instead the standard allows the metadata author to describe all the components of the dataset. For this reason, EML is the preferred standard for the Long-Term Ecological Research Network and data in EML is easily federated to other data cataloging systems through the work of DataOne (http://dataone.org/) and its member-nodes such as the Knowledge Network for Biocomplexity (http://knb.ecoinformatics.org/). Documentation of data in the EML standard provides easy one-click replication to other repositories and discovery through growing datasharing networks such as DataOne.

In addition to EML, VMC uses the Integrated Taxonomic Information System (http://www.itis.gov/) for documenting species information. This system, developed and maintained by a partnership of US, Canadian and Mexican agencies, provides unique identifiers for species and maintains relationships between 'accepted' and 'not accepted' variants for that taxon. This allows identification of species taxa at the time of collection while permitting taxonomic definitions to change in the future without losing the original identification in a given dataset.

Finally, the use of Ecological Metadata Language and the VMC implementation of spatial data are compliant with standards established by the Open Geospatial Consortium, utilizing opensource data formats.

\section{Storage and Backup}

Data are input into the repository through a web portal, or by direct manipulation of the system administrator. Once input into the database and file servers, the station repository will utilize the UVM cyberinfrastructure for its basic hosting and replication needs. The Enterprise Technology Services group at UVM provides redundant database and file servers with multiple physical locations and a rigorous backup and recovery protocol. These systems will provide the first level of reliability for the safe storage and backup of the data.

In addition to the stock services offered by UVM's Enterprise Technology Services, the station repository data will be exported to external media on a monthly basis, with these backups kept for six months. Yearly snapshots of the repository will be saved to external media, such as an external solid-state hard-drive or a series of DVDs, and preserved indefinitely in an offsite location.

Security

All management of data and metadata is done via the VMC web portal. The portal is protected with an industry-standard authentication system. Once authenticated to the system, users have management access to projects (which are collections of datasets) in which they have a role. The project manager can add additional people to a project, and a user cannot access other projects 
without first being added to the project by the project manager. This means that projects are isolated from each other, creating an easily enforceable separation of access for management purposes, and allowing fine-grained control of information access through the web-portal.

Public-facing access to data and information through the web portal is determined by the publishing and licensing parameters set for datasets, files and project-by-project personnel. This allows project managers to restrict information as needed. A site-wide procedure checks the logged-in status of users and their roles and associated permissions for each project before exposing data and files in that project for viewing and download.

Administrator access allows for override of these settings in select cases where data access needs to change due to expired embargoes or the departure of key project personnel with the original access.

\section{Access and Sharing}

The data held in the repository will be available for exploration and download via the Internet, with access constraints determined by the project manager in accordance with the site policy. To label the access constraints for data, the Mansfield Center will utilize the Creative Commons (https://creativecommons.org/) licensing scheme, with a few additional licensing options. The Creative Commons scheme allows authors to declare the allowed uses, whether derivative works are allowed, and attribution requirements. In addition to these levels of licensing, the repository will provide options for "by request" data licensing (data may be accessed upon granting of permission by the dataset owner), "linked data" licensing (the data is in the repository, but the license is determined by an external third party) and "description only" licensing, where the data are not accessible but metadata are available for inspection. This last category is used in rare cases where the data are embargoed or cannot be released.

By default, the data added to the repository will be made immediately accessible, unless the project manager wishes to embargo the data. The anticipated data policy for the station will allow researchers to embargo data for up to two years for the purposes of publishing research based on the data. This embargo period conforms with recommendations made by the National Science Foundation and the National Academy of Sciences. The embargo can be extended upon submission of a request and justification to the Mansfield Center's scientific advisory committee for approval. In rare cases, data can be kept unpublished in the repository when the data are of a sensitive nature, such as the location of rare or endangered species.

\section{Selection and Retention Periods}

Project data from work done at the station will be entered into the repository when they are in a near-final state. This will normally be when the data are ready for analysis and subsequent publication.

Near-real-time data collected through any environmental sensor networks established at the station will be added to the repository on an ongoing basis, and subsequently subjected to $\mathrm{QA} / \mathrm{QC}$ procedures.

\section{Archiving and Preservation}

As described in the "Security" section, data housed in the repository database will be extracted on a monthly basis for storage on external media as a backup. Yearly snapshots of the entire repository will be archived on external media and stored at the Vermont Monitoring Cooperative 
offices. If the VMC ceases to exist, the database and webserver ownership will be transferred to the director of the Mansfield Center for interim stewardship while a new home is sought. The external media of backups and yearly snapshots will be replicated and physically transferred to the Mansfield Center director and assistant director.

\section{Quality Assurance}

Quality assurance will be the responsibility of the individual researchers and research participants. The Mansfield Center scientific advisory committee will provide general oversight of dataset contributions to the repository. QA/QC protocols will be developed for sensor arrays, as they are deployed, using protocols from the VMC Met Station as a model.

\section{Data Management Objectives and Timeline}

Years 1 and 2

1. Incorporate data storage, transfer, and management costs into both capital and research project proposals.

Years 2-5

1. Provide semi-annual training sessions to Mansfield Center cooperators, visitors, and program participants with orientation to data resources and data management protocols.

2. Develop and implement QA/QC protocols for sensor arrays.

Year 5

1. Update the data management plan to reflect the current understanding of audience needs and system requirements.

\section{References}

Billick, I., I. Babb, B. Kloeppel, J. C. Leong, J. Hodder, J. Sanders, and H. Swain. 2013. Field Stations and Marine Laboratories of the Future: A Strategic Vision. National Association of Marine Laboratories and Organization of Biological Field Stations.

Billick, I., and M. V. Price (eds.). 2011. The Ecology of Place. University of Chicago Press. Chicago, IL.

Capers, R. S., Kimball, K. D., McFarland, K.P., Jones, M.T., Lloyd, A.H., Munroe, J.S., Fortin, F., Mattrick, C., Goren, J., Sperduto, D.D., and Paradis, R. 2013. Establishing alpine research priorities in northeastern North America. Northeastern Naturalist 20: 559-577.

Chester, C. C., Hilty, J. A., and Hamilton, L. S. 2013. Mountain gloom and mountain glory revisited: A survey of conservation, connectivity, and climate change in mountain regions. Journal of Mountain Ecology 9: 1-34.

Driscoll, C. T., K. F. Lambert, F.S. Chapin, D. J. Nowake, T. A. Spies, F. J. Swanson, D. B. Kittredge, and C. M. Hart. 2012. Civil and Environmental Engineering. Paper 7.

Hodder, J. 2009. What are undergraduates doing at biological field stations and marine laboratories? BioScience 59: 666-672.

Lindenmayer, D. B., and G. E. Likens. 2010. The science and application of ecological monitoring. Biological Conservation 143: 1317-1328. 
Lohr, S. 2001. An Operations Manual for Field Stations and Marine Laboratories. Organization of Biological Field Station. Available at http://www.obfs.org/assets/docs/operationmanual/obfs-adminhandbook.pdf.

National Research Council. 2014. Enhancing the Value and Sustainability of Field Stations and Marine Laboratories in the 21st Century. National Academy of Sciences Press. Washington, D.C.

Tydecks, L., V. Bremerich, I. Jentschke, G. E. Likens, and K. Tockner. 2016. Biological field stations: A global infrastructure for research, education, and public engagement. Bioscience 66:164-171. 


\section{Program Appendix 1. Scientific and Educational Use of Mount Mansfield}

Since 2010, ecological monitoring, research, and educational activities on the slopes and ridgeline of Mount Mansfield have encompassed a wide variety of subjects (Table 1). These activities have involved close to 1,200 professional research and monitoring days, 630 days of student/public field trips and technical training, plus over 230,000 visitor days (Table 2). An airquality monitoring site located at the base of Mount Mansfield at the Proctor Maple Research Center maintains equipment for numerous institutions and national networks. This Center offers several classes every year, including field trips to the summit. Summit caretakers and volunteers receive annual training on the protection and stewardship of mountain resources. A national meeting of the Forest Guild, held in 2014, offered field training on forest adaptation to climate change on Mount Mansfield. State parks on the east and west slopes of the mountain, which are part of the state forest, provide diverse recreational opportunities and natural history programs to thousands of visitors each year.

Table 1. A selection of scientific and educational activities currently conducted at Mount Mansfield. All monitoring and research activities have been supported and/or coordinated by VMC.

\begin{tabular}{ll}
\hline Activity type & Activity title \\
\hline Class & Ecological restoration \\
Class & Landscape natural history \\
Monitoring & Annual collection of forest cover \& understory metrics on forest health plots \\
Monitoring & Data download \& maintenance of weather stations at 853 m (east \& west) \\
Monitoring & EPA NOx/SOx Field Pilot Program \\
Monitoring & Fall color and leaf-drop monitoring at three elevations \\
Monitoring & Insect pest monitoring at three elevations \\
Monitoring & Long-term monitoring of high-elevation stream flow in an undisturbed watershed \\
Monitoring & Long-term avian population monitoring \\
Monitoring & Long-term sampling of soil and vegetation at three sites \\
Monitoring & Macroinvertebate monitoring at three streams \\
Monitoring & Monitoring water quality at two high-elevation lakes \\
Monitoring & National Atmospheric Deposition Program - Ammonia Monitoring Network \\
Monitoring & National Atmospheric Deposition Program - Atmospheric Mercury Network \\
Monitoring & National Atmospheric Deposition Program - Mercury Deposition Program \\
Monitoring & National Atmospheric Deposition Program - National Trends Network \\
Monitoring & Ozone bioindicator plant monitoring \\
Monitoring & Soil Climate Analysis Network (SCAN) operations and maintenance. \\
Monitoring & Spring phenology of hardwood trees \\
Monitoring & Sugar maple health monitoring plot \\
Monitoring & USDA UVB Monitoring and Research Program \\
Monitoring & Vermont Acid Precipitation Monitoring Program \\
Research & Assessing the vulnerability of Boott's rattlesnake-root to rapid environmental change \\
Research & Forest growth and productivity monitoring \\
Research & Investigating causes of tree mortality in Vermont and adjacent states \\
Research & Long-term avian demographic studies \\
Research & Vermont Bumblebee Survey \\
Training & Field training of biology students \\
Training & Naturalist training on ecology and stewardship \\
\hline
\end{tabular}


Table 2. Summary of user days at Mount Mansfield, 2010-2014

\begin{tabular}{cccccccc}
\hline Year & Research & Monitoring & Classes & $\begin{array}{c}\text { Public } \\
\text { field } \\
\text { trips }\end{array}$ & Trainings & Visitors & $\begin{array}{c}\text { Total } \\
\text { days }\end{array}$ \\
\hline 2010 & 25 & 187 & 16 & 60 & 50 & 41,298 & 41,636 \\
2011 & 28 & 169 & 24 & 48 & 48 & 42,774 & 43,091 \\
2012 & 56 & 186 & 27 & 48 & 52 & 44,908 & 45,277 \\
2013 & 24 & 216 & 13 & 70 & 52 & 49,853 & 50,228 \\
2014 & 29 & 252 & 16 & 60 & 46 & 52,332 & 52,735 \\
Total & $\mathbf{1 6 2}$ & $\mathbf{1 , 0 1 0}$ & $\mathbf{2 8 6}$ & $\mathbf{1 6 2}$ & $\mathbf{2 4 8}$ & $\mathbf{2 3 1 , 1 6 5}$ & $\mathbf{2 3 2 , 9 6 7}$ \\
\hline
\end{tabular}

Figure 1. The VMC has supported long-term monitoring and multi-disciplinary research on Mount Mansfield since 1990. The red star indicates the location of the Summit Station, proposed home of the Mount Mansfield Science and Stewardship Center.

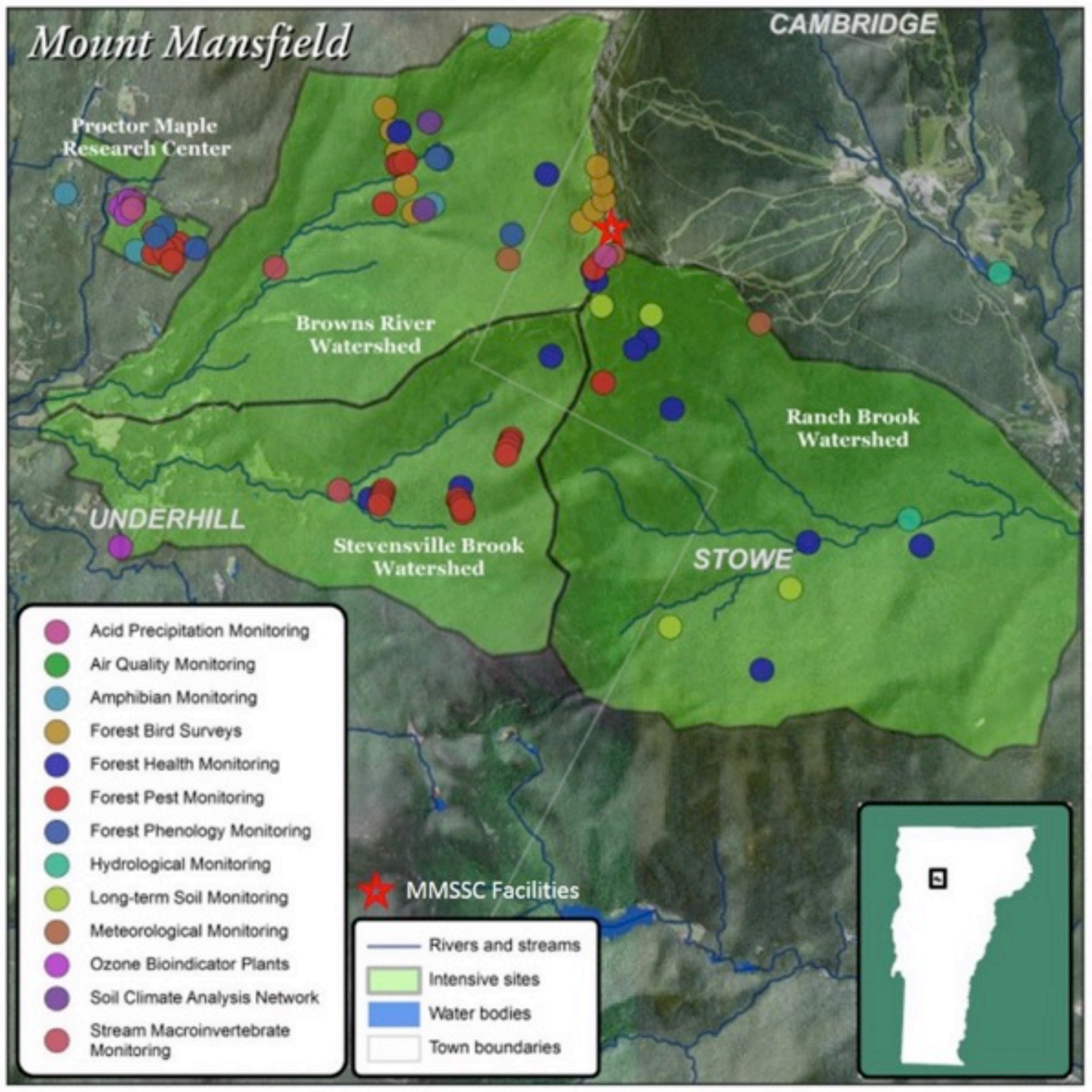


Program Appendix 2. Northeast Mountain Science Conference: Concepts for Collaborative Science and Stewardship

\section{Background}

In April of 2016, the Northeast Mountain Science Conference gathered 45 scientists and natural resource managers at the University of Vermont to plan integrated science and stewardship in northeastern mountain forests and alpine areas. The meeting provided a forum to share and develop ideas for collaborative research programs at sites throughout the region, including the proposed Mount Mansfield Science and Stewardship Center. On the first day, presenters described recent findings, critical information needs, and new lines of inquiry with potential to guide natural resource decisions. Their talks, listed below, spanned the physical, biological, and social sciences and addressed the intersection of mountain ecosystems and society.

Northeast Climate Variability

Eric Kelsey, Mount Washington Observatory and Plymouth State University

Elevational Shifts in Montane Forest Ecotones: Evidence, Causes, and Consequences

Jane Foster, Northeast Climate Science Center and University of Minnesota

Water Quantity and Quality in the Mountain Setting: Lessons from the Mt. Mansfield Paired Watershed Study

Beverley C. Wemple, University of Vermont, and James B. Shanley, U.S. Geological Survey

Distributed Sensor Systems in a Northeastern Alpine Setting

Christian Skalka, University of Vermont

Biodiversity in the Mountains of the Northeast

Steve Trombulak, Middlebury College

Valuing Services Provided by Mountain Social-ecological Systems

Brendan Fisher, University of Vermont

Frameworks for Managing Recreation in the Northeastern Mountains

Robert Manning and Elizabeth Perry, University of Vermont

Alpine Stewardship and Restoration

Julia Goren, Adirondack High Peaks Summit Steward Program, Adirondack Mountain Club

Immersive, Place-based Experiences: Contributions to Learning, Health, Well-being, and Professional Development

Andrea Charest and Steve Charest, Petra Cliffs Climbing Center and Mountaineering School

Science Supporting Policy

Michael Snyder, Commissioner, Vermont Department of Forests, Parks and Recreation

On the second day, small multi-disciplinary and multi-organizational teams formed to develop regional research proposals that could enhance the understanding and vitality of mountain ecosystems. Preliminary concepts for the following five projects are compiled in this document.

- Climate Induced Changes in Forest Structure and Function across Elevational Gradients

- Distributed Infrastructure and Network of Automated Mountain Observatories (DINAMO)

- Ecosystem Services of High-Elevation Forests

- Effects of Changing Snowpack Dynamics on Ecosystem Functions

- Understanding and Managing Impacts in Mountain Environments 


\section{Climate Induced Changes in Forest Structure and Function Across Elevational Gradients}

Mike Debonis, Green Mountain Club (mdebonis@greenmountainclub.org)

Jane Foster, Northeast Climate Science Center and University of Minnesota (jrfoster@umn.edu) Jennifer Pontius, University of Vermont Rubenstein School of Environment and Natural Resources and US Forest Service Northern Research Station (jennifer.pontius@uvm.edu)

Shelly A. Rayback, University of Vermont Department of Geography

(shelly.rayback@uvm.edu)

Chris Rimmer, Vermont Center for Ecostudies (crimmer@vtecostudies.org)

Don Ross, University of Vermont Department Department of Plant and Soil Science

(donald.ross@uvm.edu)

Paul G. Schaberg, US Forest Service Northern Research Station (pschaberg@fs.fed.us)

Issue/Need

- Evidence indicates that the structure and function of the northern forest is changing and that climate change may speed or intensify this change.

- These changes are likely to vary among species and elevations.

- These changes will likely also depend on other environmental factors (e.g. past land-use, legacy of acidic deposition, invasive pests...).

- We need further information to understand the nature, extent and possible causes of these changes.

Goals and Research Questions

- Identify changes in the structure of the northern forest (recruitment, growth, mortality, species composition).

- Identify spatial and temporal drivers.

- Can we explain the mechanisms of change by co-examining ecosystem functions and physiological responses across an elevational gradient?

- What are the social and economic impacts (ecosystem services) of these changes?

- How can we use this information to guide management?

Hypotheses

- Certain groups of species will have an increased competitive advantage and certain groups will decline.

- The cause could be extreme events and/or changes in growing season length interacting with other environmental variables.

- These impacts will vary over space and time.

- There will be repercussions that reverberate through the socio-ecological system.

- Management can be used to mitigate those changes.

Methods

- Spatial (GIS/remotes sensing) analysis of species distribution patterns and ancillary environmental data sets (latitude, slope, aspect, ....micro-climate, acid deposition, CL, soil types, disturbance history, geology, land use history)

- Explore the use of FIA data to determine recruitment and mortality patterns

- Dendrochronology in many species at many locations.

- Intensive Monitoring: mechanisms of forest change 


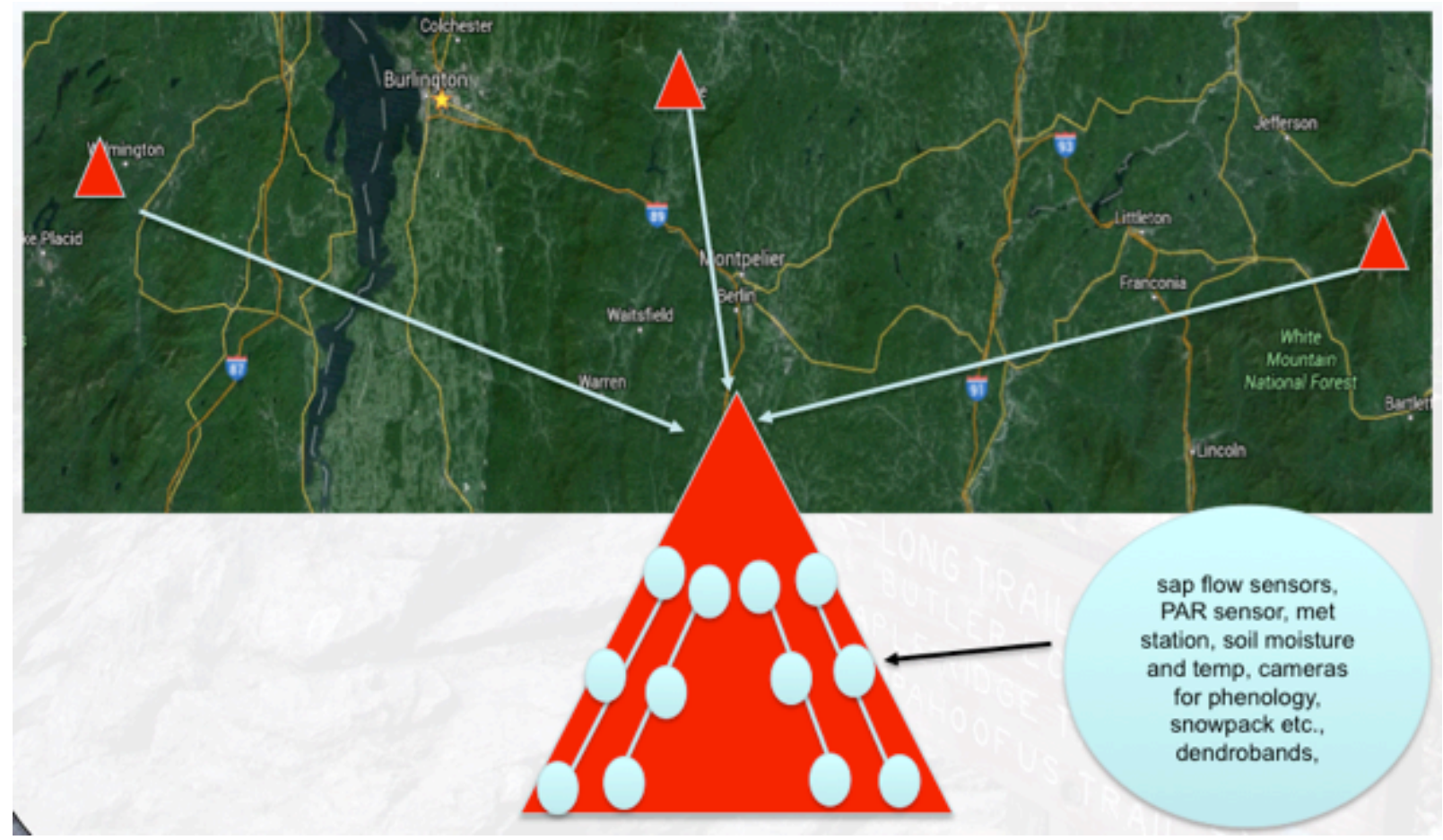

- If funds are available: elevation gradients at Mt. Mansfield, Whiteface and Mt. Washington. If funds are limited: only Mansfield

- Two aspects, two transects with three elevations (12 locations per mountain)

- Instrumented with sap flow sensors, PAR sensor, met station, soil moisture and temp, cameras for phenology, snowpack etc., dendrobands, dendrochronology .

- Other metrics: foliar nutrition, litter quantity and quality (baskets), masting, soil chemistry, soil biology.

- Biota TBD, bridge to other groups?

- Statistical analysis of the data will show that changes in nature and timing of physiological activity can account for species differences in competitive success.

- For example, warming shoulder seasons will explain increased carbon capture and growth of red spruce.

Opportunities to Engage Students and Decision-makers

- Undergraduate or graduate students will be essential for data collection and analysis, data exploration, social media, art.

- Development of K-12 Learning Modules

- Link to other sites: Mansfield, UVM, Whiteface, SUNY, Mt. Washington, PSU, AMC?

- Targeted outreach to management communities: SAF, VT FPR, GMNF, GMC

- Targeted outreach to Legislature (communicate potential impacts to ski industry, maple syrup, lumber industry, alternative energy policy)

Infrastructure and Equipment Requirements

- Summit Station for ease of access

- At each of the 12 plots:

- sap flow sensors,

- PAR sensor, 
- met station,

- soil moisture and temp,

- cameras for phenology, snowpack, cloud immersion, etc.,

- Dendrobands

- Litter baskets

- (Loggers/Repeaters......transmission of real-time data)

Benefits to Social-Ecological System

- Identify vulnerable species and potential management activities to promote their health.

- Understand how to minimize economic impacts. (ecosystem services)

- Educate public about impacts to the landscape, why they occur, and what can be done.

Prospective Collaborators

- Tony D'Amato, University of Vermont Rubenstein School of Environment and Natural Resources

- Sandy Wilmot, Vermont Department of Forests, Parks and Recreation

- Representatives from institutions / organization associated with all three mountains.

- National Forest System, State Foresters for data collection

- Sensor engineers (integrating sensors and real-time capability)

- $\quad$ Biotic people - LINK TO BIODIVERSITY GROUP

- UVM College of Education (K-12 educational component)

Potential Funding Sources

- NSF

- VMC

- NSRC

- NASA

- NYSERDA

- USDA FS

- NE Climate Science Center

- Foundations

- AIG

Next Steps for Proposal Development

- Prospectus (group members to draft ASAP)

- Fleshing out biotic component (or complement biodiversity approach)

- Outreach to potential collaborators

- Identification of funding source

- Investigate sensor options / opportunities.

- Fall 2016 Submission? 


\section{Distributed Infrastructure and Network for Automated Montane Observatories (DINAMO)}

Chris Skalka, University of Vermont College of Engineering and Mathematical Sciences (skalka@cs.uvm.edu)

James Shanley, US Geological Survey (jshanley@usgs.gov)

Eric Kelsey, Mount Washington Observatory and Plymouth State University (ekelsey2@plymouth.edu)

Paul Casson, Atmospheric Science Research Center - Whiteface Mountain Field Station (pcasson@albany.edu)

Jeff Brown, UC Berkeley Central Sierra Field Research Stations (sagehen@berkeley.edu)

Lindsey Rustad, USDA Forest Service Northern Research Station (lrustad@fs.fed.us)

Lesley-Ann Dupigny-Giroux, University of Vermont Department of Geography (Lesley-

Ann.Dupigny-Giroux@uvm.edu)

Eric Howe, Lake Champlain Basin Program (ehowe@lcbp.org)

Beverley Wemple, University of Vermont Department of Geography (bwemple@uvm.edu)

Breck Bowden, University of Vermont Rubenstein School of Environment and Natural

Resources (breck.bowden@uvm.edu)

Issue/Need

- Montane environments are key economic, environmental, recreational, aesthetic, and spiritual resources for the NE region.

- Climate projections suggest increase in frequency and severity in extreme events across the region, though little is known about the dynamics of extreme events in mountain settings and their consequences.

- Limited observations from the region show distinct extreme event responses in high elevation settings that cannot be predicted from low elevation observations.

- There is a critical need for a distributed network of montane observatories.

Research Questions

- How are the meteorological processes and environmental precursors associated with extreme events documented in the records from existing high elevation observatories in the region different from those in lowland settings?

- How do we anticipate extreme events in mountain settings will change in the future?

- What are the implications of extreme events in mountain settings for the production of water, sediment and nutrients delivered downstream?

- How do these events and their changing dynamic impact downstream beneficiaries (or victims)?

Objective and Hypothesis

Objective: Identify elevational differences in meteorological process (extreme temps, wind, precipitation and intensity) and in environmental precursors.

Hypothesis: Meteorological processes will be different across vertical and horizontal gradients at three mountaintop sites with differences in precipitation quantity and chemistry.

Example: Explain how extreme runoff events will change sediment and solute load in mountain streams.

\section{Methods}

- Inventory existing datasets and resources, and identify data gaps. 
- Preliminary synoptic scale analysis of existing meteorological data to understand meteorological processes associated with extreme events and environmental precursors

- Establish network of digital state-of-the-art wireless stream gage and hydromet monitoring stations on montane watersheds at Whiteface, Washington and Mansfield.

- Develop a strategy for managing and delivering near-real time, high frequency spatiallydistributed data.

Infrastructure and Equipment Requirements

- Stream gages

- Elevational gradient of met stations

- Communications

- Distributed environmental sensors

- LiDAR data availability

- Stable data management/distribution network ("last mile" connection to EPSCoR Northeast Cyberinfrastructure Consortium Network)

- Trained staffing

- Logistical support (vehicles, lodging, etc.)

- Public visualization tools (off- and on-site)

- Phenology tracking by crowdsource (e.g. leaf on/off from selfies)

Opportunities to Engage Students and Decision-makers

- Graduate and undergraduate research and training opportunities

- Real-time data to social media programs

- Arts programs - work with MFA programs

- USGS "hands on" stream gages

- Hubbard Brook - roundtables exercises

- Regional "Montane extreme events" summit

- MWO Nov 2017 Climate Change Science Colloquium

- Public policy events to raise awareness of montane issues

- RT data feeds \& visualization, etc to regional museums, school systems

- Recreational stakeholder engagement

Benefits to Social-Ecological System

- Extreme event forecasting

- Outdoor recreation (snow sports, angling)

- Community resiliency (e.g planning flood forecasting capacity, hard infrastructure (culverts/roads)

- Adaptive management - information to inform adaptive policy

- Inform policy on renewable energy development

- Land use planning information for zoning/smart growth planning

- Potential stakeholder understanding of potential for change in the montane system

Prospective Collaborators

- WILD Center

- ECHO

- Regional universities

- Hubbard Brook

- US Forest Service

- USGS 
- Other government agencies

- Lake Champlain Basin Program

- European montane networks

Potential Funding Sources

- $\quad$ NSRC - forest processes

- $\quad$ NSF - general

- $\quad$ FEMA - flooding/disasters

- $\quad$ LCBP - collaborative opportunities, E\&O

- $\quad$ NOAA (NWS, SeaGrant) climate \& weather research

- USGS - hydrology

- $\quad$ EPA - atmospheric chemistry, nutrient loading

- $\quad$ State agencies - DOTs, Environmental, Emergency Management, utilities, insurance companies

- recreation sector

- NGOs, philanthropic foundations

- Grant Makers for the Arts

- University Development Offices, endowments

- Lease agreements (e.g. transmitters)

Next Steps for Proposal Development

Step 0 - develop Steering Committee (Paul C, Eric K, Beverley W, Jamie S, and/or VMC rep; 3 months timeframe)

Step 1a - Data inventory \& needs analysis, (Paul C, Eric K, Beverley W, Jamie S, and/or VMC rep; 3 months timeframe)

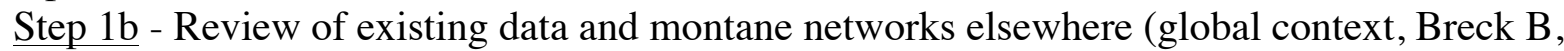
Jamie S, Beverley W; 3 months)

Step 2 - Synoptic-scale analysis of extreme weather events (Eric K, 12-36 months, MS thesis)

Step 3a - feasibility workshop to bring people together from the 3 sites to discuss feasibility and frame proposals (Christian Skalka, Breck B, Eric H, 12 months)

Step 3b - hold summit/symposium to vet ideas/proposals with collaborators and stakeholders Christian Skalka, Breck B, Eric H, 12 months)

Step 4 - write proposals (Dependent on Step 3 - likely 12-18 months) 


\section{Ecosystem Services of High-Elevation Forests}

Stacy McNulty, SUNY College of Environmental Science and Forestry (smcnulty@esf.edu) Nathan Fry, University of Vermont Rubenstein School of Environment and Natural Resources (nathan.e.fry@uvm.edu)

Brendan Fisher, University of Vermont Gund Institute for Ecological Economics (bfisher@uvm.edu)

Allan Strong, University of Vermont Rubenstein School of Environment and Natural

Resources (allan.strong@uvm.edu)

John Lloyd, Vermont Center for Ecostudies (jlloyd@vtecostudies.org)

Issue/Need

The ecosystem services provided by high elevation forests have not been well-studied. To understand the benefits of alpine forests, we will conduct a literature search to collate studies that have been done to date. This information will be used to work with local land managers and planners to help them make decisions on how land use, climate and behavioral changes will affect the provisioning of ecosystem services.

\section{Goals}

- Quantify the provisioning (timber, maple syrup), regulating (water and C-sequestration) and cultural (Skiing, snowmobiling, ice climbing, hiking) ecosystem services that are provided by alpine forests

- Outline the threats to these services

- Convene stakeholders to quantify threats on ecosystem services of value to this group (general and spatially explicit)

- Model predicted effects on key ecosystem services

- Highlight success stories of ecosystem services conservation

Premise

- The community will be more likely to conserve ecosystem services when presented in a more tangible context (e.g., \$s that the ski industry provides to the Vermont economy).

- Mount Mansfield can serve as a starting point for understanding ecosystem services and their threats; the research is scalable to the region or the Northern Forest

Methods

- Literature review

- $\quad$ Enumerate threats

- Focus groups with stakeholders

- Model change scenarios on ecosystem services

- Outreach and interpretation: success stories on Mansfield (art?)

- Opportunities for "paired" design

- Development level

- "Side" of mountain 
Figure 1. Outline of proposed methods

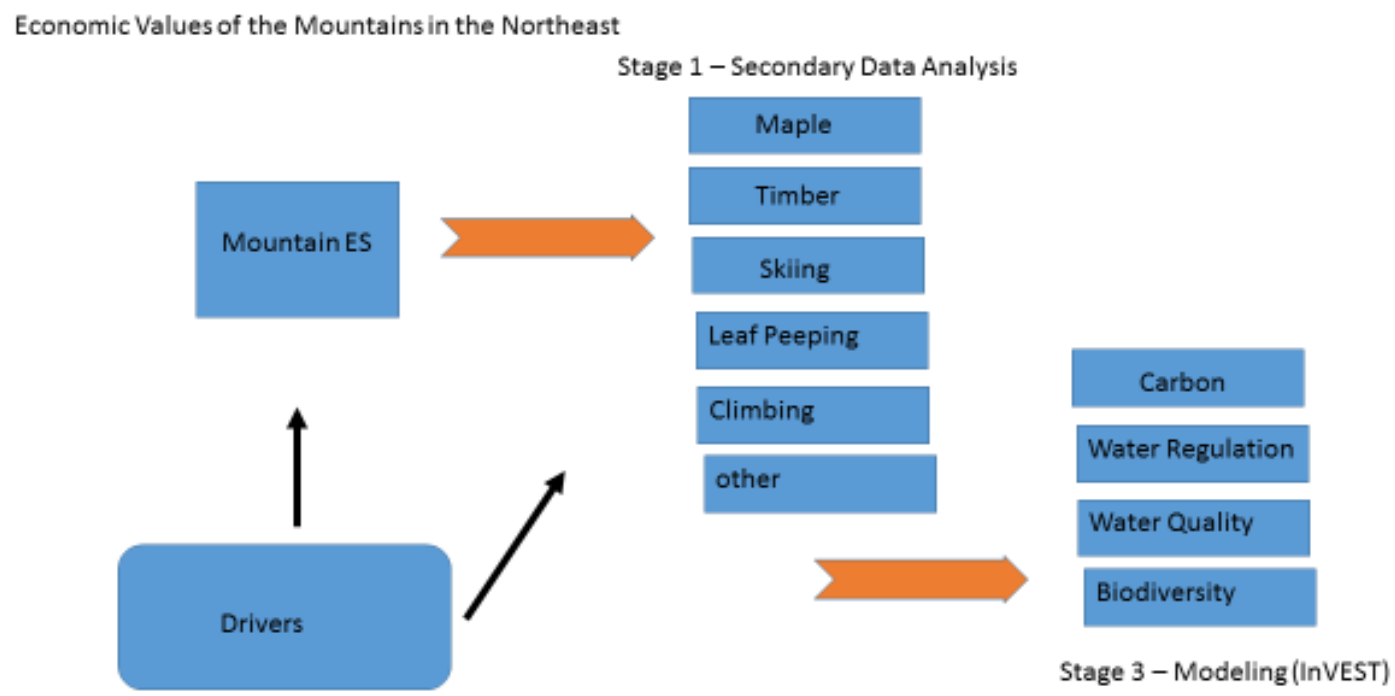

Stage 2 - Drivers of Change - Stakeholder and Modeling Scenario Development

Opportunities to Engage Students and Decision-makers

Students:

- Literature review - Ecosystem services of high elevation forests

- Mine the Gund dataset

- Tell success stories

Decision-makers:

- Scenario designs

- Explicit involvement in focus groups

- On-site - place-based field sites

Benefits to Social-Ecological System

SOCIAL BENEFITS: Put ecosystem services explicitly into the context of what people value; direct stakeholder input

BIOLOGICAL BENEFITS: Maintaining and improving the capacity of the system to provide ecosystem services

OTHER: Increasing social capital and strengthen networks for long-term collaboration

Prospective Collaborators

- Questions about scale (Canada)

- VSAA (local: Stowe, Smugglers, Bolton and regional); Case study partners: (Camel's Hump, Mt. Washington, Whiteface, Katahdin)

- Proctor Maple Research Center

- VAST

- $\quad$ CRAG-Vermont

- GMC, ADK, AMC

- Vermont Chamber of Commerce

- VMC

- VCE 
- $\quad$ Forest Roundtable

- $\quad$ NSRC community (Northern Forest research community)

- Vermont Army National Guard (Property owner and disaster response)

- Focus groups: Landowners, town councils, realtors, planners, legislators

Potential Funding Sources

- NSRC

- McIntire-Stennis

- $\quad \mathrm{NSF}$ - if scaled up

- Gund family

Next Steps for Proposal Development

- Literature review (is there enough to get started; assume yes, GUND dataset)

- Graduate special topics class

- Better understand outputs, spatial resolution of InVEST 


\section{Effects of Changing Snowpack Dynamics on Ecosystem Functions across Elevation Gradients in the US Northeast}

Susan Hindinger, Vermont Center for Ecostudies (shindinger@vtecostudies.org)

Brian Kloeppel, Western Carolina University (bkloeppel@wcu.edu)

Kent McFarland, Vermont Center for Ecostudies (kmcfarland@ vtecostudies.org)

Bill Schuster, Black Rock Forest Consortium (wschuster@blackrockforest.org)

Doug Weihrauch, Appalachian Mountain Club (dweihrauch@outdoors.org)

Sandy Wilmot, Vermont Department of Forests, Parks, and Recreation

(sandy.wilmot@vermont.gov)

Issue/Need

Incomplete understanding of how climate and other drivers of change are affecting ecosystem functions at different elevations

Research Question and Areas of Inquiry

How do changing snowpack dynamics affect ecosystem functions across the elevation gradient from mountaintop to lake bottom?

- Water

- Climate

- Biodiversity

- Economics

- Human health

Hypotheses

- The spatial and temporal extent of snowpack is decreasing at a rate that varies across the elevation gradient.

- There exists an elevational tipping point where snowpack dynamics affect ecosystem function more intensely than at other elevations.

- Snowpack changes are responsible for some phenological mismatches (predator/prey, plants/pollinators, flowering/frost)

- Reduced flow due to decreased snowpack results in warmer water temperatures and impacts on stream biota such as brook trout and macroinvertebrates.

- Temperature dynamics and cyanobacteria growth in Lake Champlain are related to the changing snowpack.

- Snowpack in the alpine zone is a major driver of alpine plant community distribution.

- There will be spatial changes in plant communities due to changing snowpack, over time.

- Changes in tree health in response to snowpack manipulations will be detectable within five years.

- An expanded growing season at lower elevations will promote expansion of invasive plants.

- Tick dynamics are related to snowpack changes.

- Recreation economy will change directionally with changing snowpack.

Methods

1. Establish study areas at multiple elevations between the lake and the mountaintop

2. Conduct monitoring:

a. cameras to capture leaf on/leaf off, NDVI (plant stress, see Phenocam Network) 
b. flower timing for alpine plants, spring ephemerals, dendrometer bands for phenology and growth of trees

c. alpine plant community mapping/monitoring

d. acoustic sensors for arrival dates for birds

e. insect prey availability

f. stream temp, dissolved $\mathrm{O}, \mathrm{F} \& \mathrm{~W}$ may already monitor brook trout, macroinvertebrate monitoring

g. Lake Champlain temperature, bacteria monitoring

h. red backed vole, snowshoe hare

i. monitor an invading species that is near the edge of its range (garlic mustard?)

j. gather economic data related to winter recreation and relate to snowpack depth

3. Experimental approach: snowmaking, snow melting

4. Remote sensing for historical data and to develop models to extrapolate from survey locations across a wider area

5. Citizen science, student involvement

6. Dispersed sensor systems to gather hydrometeorological data and Snowcloud to measure snowpack

7. Conduct the study in parallel at multiple sites around the region.

Opportunities to Engage Students and Decision-makers

- Students could contribute to all elements of this project (elementary-university)

- Field season timing is good for student calendar.

- Citizen scientists can be involved in monitoring.

- Students can be engaged and connected to parts of the gradient away from where they live.

- Artists' interpretations can tell the stories.

- Recreationists can be involved in remotely monitoring snow at the stake, lake $\mathrm{T}$, other relevant parameters.

- State tourism office and chambers of commerce will be office interested in findings related to the recreation economy.

- Health department will be interested in tick findings (and possibly in participating).

- Results will help in risk rating and adaptation decision-making about climate change.

Infrastructure and Equipment Requirements

- Snowcloud Distributed Sensor System network

- Equipment for manipulating snowpack (snowmaking, melting)

- Cyber infrastructure and staffing to manage data

Benefits to Social-Ecological System

- Water availability

- Disease prevention

- Access to recreation

- Adaptation of the recreation economy

- Forest health and productivity

- Job stability

- Supporting data for land use planning 
Prospective Collaborators

- UVM

- VMC

- VT Fish and Wildlife Department

- DEC

- FPR

- VCE

- AMC

- Stowe Mountain Resort

- NWS/NOAA

- Lake Champlain Basin Program

- USGS

- USFS

- VT Dept of Health and Tourism Office

- Public schools

- Towns

- Winooski Valley Park District

Potential Funding Sources

For the broad research program:

- NOAA

- EPA/Clean Water Act

- USFS

- NSRC

- NASA

- EPSCoR

For more discrete projects within the larger program:

- NSF

- VT Ski Areas Association

- VT Community Foundation

- CDC/other health sources

Next Steps for Proposal Development

- Identify funding sources (contact UVM Office of Sponsored Programs for assistance)

- Identify a group of potential collaborators/PIs

- Meet to refine project idea 


\section{Understanding and Managing Human Impacts in Mountain Environments}

Rick Paradis, University of Vermont (richard.paradis@uvm.edu)

Julia Goren, Adirondack Mountain Club (summit@adk.org)

Brad Moskowitz, Johnson State College (brad.moskowitz@jsc.edu)

Andrea Charest, Petra Cliffs Climbing Center (andrea@petracliffs.com)

Stephen Charest, Petra Cliffs Climbing Center (steve@petracliffs.com)

Faerthen Felix, UC Berkeley Sagehen Creek Field Station (ffelix@berkeley.edu)

Issue/Need

- Human activities such as recreation, research, commercial enterprises, and land management are having an impact on mountain environments in northeastern North America

- Such activities are expected to increase over time

- Resource management techniques will need to respond to increased activity and emerging trends

Research Themes

1. Study the four-season impacts of human recreation (backcountry skiing; climbing rock, ice and snow; hiking; mountain biking; and shoulder season use)

2. Explore the impacts of research activities, facilities and infrastructure (consider the development of a research infrastructure policy)

3. Develop a research program that supports regional management decisions and goals

4. Identify and compare techniques and strategies for education and stewardship

5. Understand and manage conflicting land use interests

6. Anticipate future trends in land use (changing demographic, technology, activities)

Goals

- Understand and inform best practices for management, stewardship and education

- Analyze existing management and stewardship techniques and consider new strategies

- Collaborate with stakeholders to develop and execute a research agenda

Methods

- Exploratory Research: communicating with various stakeholders to determine research questions

- Monitoring

- Literature review

- Assessing the effectiveness of current techniques

- Adaptive management

- Citizen science

- Collaboration/partnerships

- Social media

- Public engagement

- Outreach

Opportunities to Engage Students and Decision-makers

- Faculty mentored research

- Funding for research assistantships

- Field courses

- Congressional visits 
- Working with the staff, board of directors, and membership

- Service learning opportunities

- Organized opportunities for service

Infrastructure and Equipment Requirements

- Housing

- Basic lab/office space

- Storage

- Exhibit space

- Data pipeline \& internet connectivity

- Web support

- Signage

- Printed materials

- Winter access vehicle?

Benefits to Social-Ecological System

- A well educated constituency

- Improve visitor understanding of human impacts on fragile ecosystems

- Attitudinal \& behavioral changes leading to sustainable use/practices

- Increased connection between the community and science

- Reduced conflicts between user groups

- Increased health of the ecosystem

Prospective Collaborators

- UVM \& The Rubenstein School

- Johnson State College

- Other Vermont State Colleges

- Other Private/Public Colleges \& Universities

- Green Mountain Club and related organizations (AMC, ADK, etc.)

- NGOs (Access Fund, AAC, CRAG-VT, CTA,)

- Leave No Trace, Inc.

- Vermont Youth Conservation Corps

- State of Vermont: Agency of Natural Resources, Forest Parks \& Recreation, Fish \& Wildlife

- Federal Agencies: NPS, USFWS, USFS, USGS, NRCS, NOAA

- Local Businesses

- Stowe Mountain Resort

- VT Monitoring Cooperative

- VT Center for Ecostudies

- Land Trusts \& Conservation Groups

- Mount Washington Observatory \& Other Field Stations (OBFS)

- Municipal Governments

- Organized citizen science platforms (iNaturalist, eMammal)

Potential Funding Sources

- Local businesses

- Corporate sponsors \& partners

- National Science Foundation

- Northern States Research Cooperative

- The Waterman Fund 
- Crowdsourcing

- The VT Community Foundation

- Federal \& State agencies

- UVM \& the Rubenstein School

- Vermont State Colleges

- Advocacy groups

Next Steps for Proposal Development

- Step 1: Enlist partner organizations to discuss research needs

- Step 2: Further define the project (obtain permits, recruit researchers, etc.)

- Step 3: Locate funding sources

- Step 4: Begin project 
Program Appendix 3. Ranked Alpine Zone Science Projects

The following research and monitoring ideas were generated and ranked by approximately 40 participants in a 2011 regional workshop, held at the Highland Center at Crawford Notch (Capers et al. 2013). Scoring was based on the following scheme: "critically important and urgent" $=1$; "somewhat important and urgent" $=2$; "less important or not urgent" $=3$. Average scores are presented here.

The projects are organized according to the proposed Mansfield Center science and stewardship approach. Project ideas that integrate two or more approaches (e.g., measure effects and model processes) are repeated within each approach.

\section{Measure Natural Variability and Effects of Human Activity}

1. Identify the location, community composition, duration of snow cover and timing of snow melt in snowbed communities. Score $=1.20$

2. Monitor treeline to establish how it changes and over what time scales and to determine the mechanisms that establish treeline in the region. Score $=1.28$

3. Analyze the extent and rate of change in woody species occurrence and abundance, particularly in species exhibiting significant vertical growth. Score $=1.40$

4. Conduct plant surveys on mountains where surveys were previously completed to determine if species richness has changed and to establish improved quantitative baseline study plots for future comparisons with greater resolution than just presence and absence. Score $=1.52$

5. Characterize variation in weather, including: mean, minimum and maximum temperatures; amount ant timing of precipitation; wind speed; cloud immersion; ice accretion and radiation budget. Score $=1.52$.

6. Investigate changes in alpine phenology and their consequences. Score $=1.52$

7. Investigate changes in composition and abundance of lichen and bryophyte communities. Score $=1.60$

8. Assess whether Mount Washington's meteorological and climatic trends are typical or anomalous, considering the magnitude of climate change appears to decline with elevation. Score $=1.64$

9. Monitor vertebrate taxa that occur as isolated, disjunct southern populations on the high mountains of the Northeast. Measure environmental conditions so demographic changes can be associated with changing environmental conditions. Score $=1.71$

10. Investigate the historic importance of anthropogenic influences on alpine peaks, including fire. Score $=1.72$

11. Conduct annual surveys of alpine communities to determine if non-native species are recruiting and, if they are, to investigate whether management strategies exist that could minimize their numbers. Score $=1.96$

12. Monitor productivity, rates of nutrient cycling, and varability in measures of alpine ecosystem function so the effects of species loss can be characterized precisely. Score $=2.04$ 
13. Conduct exploratory research to determine if alpine species composition changes in a consistent way along elevational gradients and then identify the indicator species or species groups associated with such change points. Score $=2.04$

14. Investigate how the effects of meteorological conditions vary with spatial scale. Score $=2.08$

15. Obtain data on how the deposition of clouds' chemical constituents varies with elevation and topography. Score $=2.33$

16. Evaluate the historic influence of ungulate disturbance on alpine plant community structure. Score $=2.56$

17. Analyze the influence of different alpine bedrock types on chemical and physical soil properties and on species and community composition. Score $=2.56$

18. Characterize how alpine soil depth varies with topography and how soil depth influences plant and animal communities. Score $=2.64$

\section{Model Ecosystem Processes}

5. Monitor treeline to establish how it changes and over what time scales and to determine the mechanisms that establish treeline in the region. Score $=1.28$

6. Investigate changes in alpine phenology and their consequences. Score $=1.52$

7. Investigate changes in composition and abundance of lichen and bryophyte communities. Score $=1.60$

8. Monitor vertebrate taxa that occur as isolated, disjunct southern populations on the high mountains of the Northeast. Measure environmental conditions so demographic changes can be associated with changing environmental conditions. Score $=1.71$

9. Investigate the historic importance of anthropogenic influences on alpine peaks, including fire. Score $=1.72$

10. Establish the environmental factors that prevent or limit tree growth and survival in alpine environments. Score $=1.72$

11. Conduct observational and experimental studies to identify the response of individual species to warming, nitrogen enrichment, and the combined effects of both. Score $=1.76$

12. Investigate the effect that area has on the composition and rate of change in alpine communities. Score $=1.80$

13. Analyze demographic variability of three butterflies that are endemic to the Northeast, identifying their host plants, and assessing the effects of changing environmental conditions. Score $=1.83$

14. Conduct observational and manipulative studies to identify controlling factors of ecosystem processes in the alpine and to establish whether changing conditions are affecting rates of productivity, nutrient cycling, and species composition. Score $=2.00$

15. Conduct experimental manipulations to establish the mechanistic basis for changes in alpine plant community composition in response to increased atmospheric nitrogen deposition. Score $=2.12$ 
16. Evaluate the historic influence of ungulate disturbance on alpine plant community structure. Score $=2.56$

\section{Evaluate Resilience}

1. Conduct exploratory research to determine if alpine species composition changes in a consistent way along elevational gradients and then identify the indicator species or species groups associated with such change points. Score $=2.04$

\section{Integrate Science and Policy}

1. Conduct annual surveys of alpine communities to determine if non-native species are recruiting and, if they are, to investigate whether management strategies exist that could minimize their numbers. Score $=1.96$ 


\section{Part 2. Mount Mansfield Science and Stewardship Center Facilities Plan}

\section{Background and Purpose}

The University of Vermont owns and manages 400 acres of mountain forest and alpine tundra along the iconic ridge of Mount Mansfield. Embedded within approximately 40,000 acres of public land, this property is a jewel of the Green Mountain landscape that has supported decades of research and monitoring across many environmental fields. Although the Mount Mansfield Natural Area is visible from campus and accessible by auto road, its potential as a research and education asset has been limited by the lack of nearby classroom, laboratory, and lodging facilities. Educators and scholars from UVM and throughout the Northeast have expressed a strong interest in a field station that could serve as a hub for experiential learning and scientific research at this site. To meet this need, we propose to lease and renovate the Summit Station, a vacant $64 \times 40$ - $\mathrm{ft}$ building situated on a private inholding at an elevation of 3,850 ft, and to establish programs and infrastructure to investigate and sustain the vitality of mountain ecosystems. The Mount Mansfield Science and Stewardship Center will catalyze collaborative science and stewardship to promote healthy mountains, watersheds, and communities.

\section{Renovation of the Summit Station}

The Summit Station is a 1.5-story, concrete-block building located at the terminus of the Mount Mansfield Auto Toll Road in Stowe, Vermont. The structure and the surrounding 20 acres are owned by the Mount Mansfield Company, which operates Stowe Mountain Resort. The building was erected in 1968 as a commercial broadcasting facility and over the years has housed a gift shop, café, restrooms, and interpretive displays. The last of the telecommunications equipment was removed in 2010, leaving most of the building vacant. The Mount Mansfield Company has offered to lease the building to UVM for a nominal fee.

We propose to renovate the building as a state-of-the-art, LEED-certified and/or Net Zero Energy field station that offers safe and affordable accommodations to scientists, educators, and natural resource managers. Once remodeled, the building will offer basic educational and residential infrastructure, as well as laboratory and storage facilities. The main design elements will include: a research laboratory (with wet and dry labs), a multipurpose field lab/classroom space, a kitchen, single-sex bunkrooms, bathrooms, a public reception/exhibit area, and small storage areas. The building will also include private sleeping quarters for the Assistant Director/Caretaker.

Preliminary elevations and schematic plans for two renovation concepts appear on pages $42-47$, following a depiction of existing conditions on page 41. Cost analyses for each concept are included in Facilities Appendix 1 and 2.
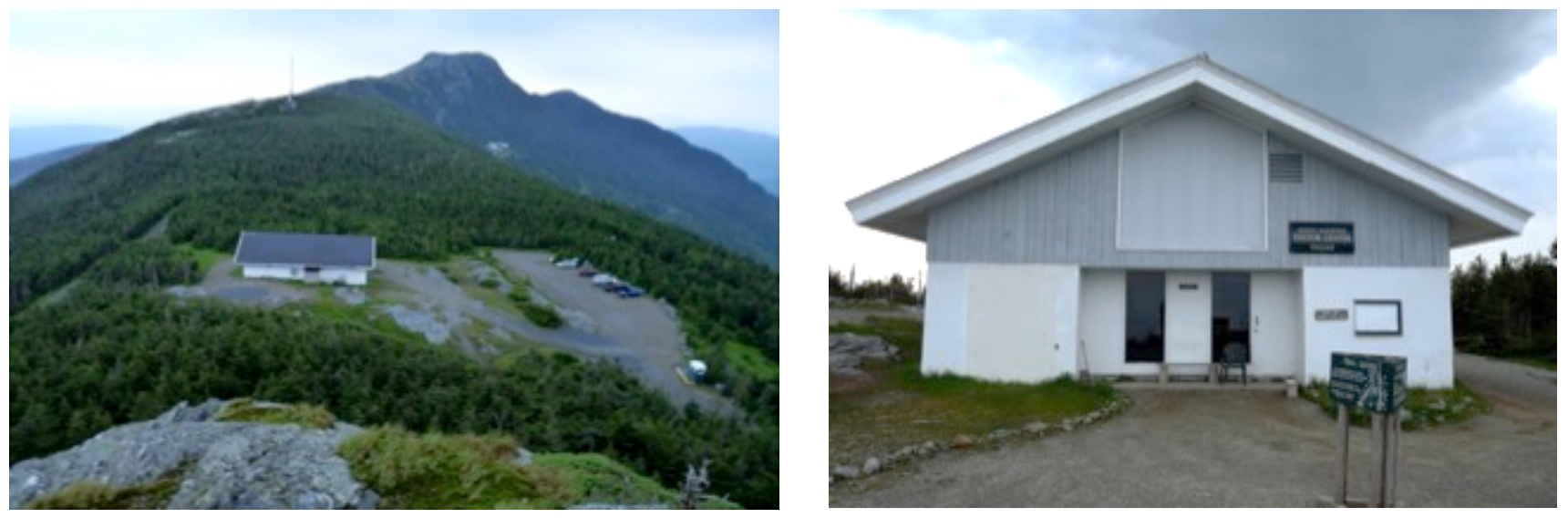

Figure 1. The Mount Mansfield Natural Area and Summit Station 


\section{Overnight Lodging}

The Mansfield Center will accommodate no more than 20 overnight occupants at one time. This level satisfies the needs of most respondents to a December 2015 survey of prospective users (refer to Facilities Appendix 2 for a summary of key findings). Ongoing discussions with project stakeholders may result in a lower cap on the number of bunks and/or adoption of occupancy limits that vary seasonally. We will institute, carefully monitor, and enforce guidelines for use of the building and its environs in order to ensure both safe and productive operation, as well as protection of the site's natural features and remote character. A draft of these guidelines is included as Facilities Appendix 3. For an assessment of off-site lodging options, refer to Facilities Appendix 4.

\section{Field Instrumentation}

In addition to establishing the field station, we aim to gradually enhance the mountain's existing system of field instruments and sensors. Prospective users of the Mansfield Center have indicated interest in the following resources, in order of priority: weather stations, rain gages, snow gages, fixed phenology/forest health cameras, water quality stations, portable webcams, soil sensors, and stream gages. Some of these instruments are already in place at different locations on the mountain.

\section{Safety and Security}

The Mansfield Center will strongly emphasize safety and security in managing the facility and field operations and will abide by all relevant UVM policies. The facility will be outfitted with first aid, lab safety, and mountain rescue equipment. Permanent and seasonal staff will receive health and safety training on an annual basis. A backup generator will be stored onsite in the event of an emergency, and explicit emergency procedures will be readily available throughout the facility. First-time users of the station will be required to view an orientation video, either prior to arrival or after arriving on site. All lab and field equipment, tools, and appliances will be secured, catalogued, serviced and inventoried at regular intervals. No excess inventory will be kept on the premises. To minimize the risk of theft and damage to the facility or its equipment, overnight or regular users of the building will be required to submit a refundable security deposit.

\section{Utilities}

\section{Water Supply}

The Summit Station was once supplied with water from a drilled well. The septic system that used to store and dispose of wastewater no longer functions. The primary technical challenge associated with utility upgrades is to meet the water needs of prospective users with supply and sewage systems that conform to current environmental, public health, and fire safety standards. It is also important to address heating/ventilation needs, although these areas raise fewer technical or regulatory concerns.

The drilled well is located in a vegetated area just east of the parking lot. It is covered by a concrete well cap within an encasement that extends approximately three to four feet below grade. According to a well report submitted to the Vermont Agency of Natural Resources by the H. A. Manosh Corporation, the well yielded one gallon per minute when it was drilled to a depth of 649 feet in 1968. The water supply was sufficient to operate a café with toilets as recently as the 1980 s, however the current yield is unknown. Richard Hamlin, a civil engineer contracted to evaluate the water systems, has advised that a constant-discharge pumping test be conducted to determine the actual well production rate. He also recommended that storage beneath the building or parking area be incorporated into the water supply design, depending on a comparison of demand and yield. Another option is to hook into municipal water at the Octagon Café and Gallery, a Stowe Mountain Resort facility located $0.4 \mathrm{mi}$ down the toll road. 
Figure 2. Conceptual plan for the water-supply system with inset image of the well pump within its concrete encasement (R. Hamlin).

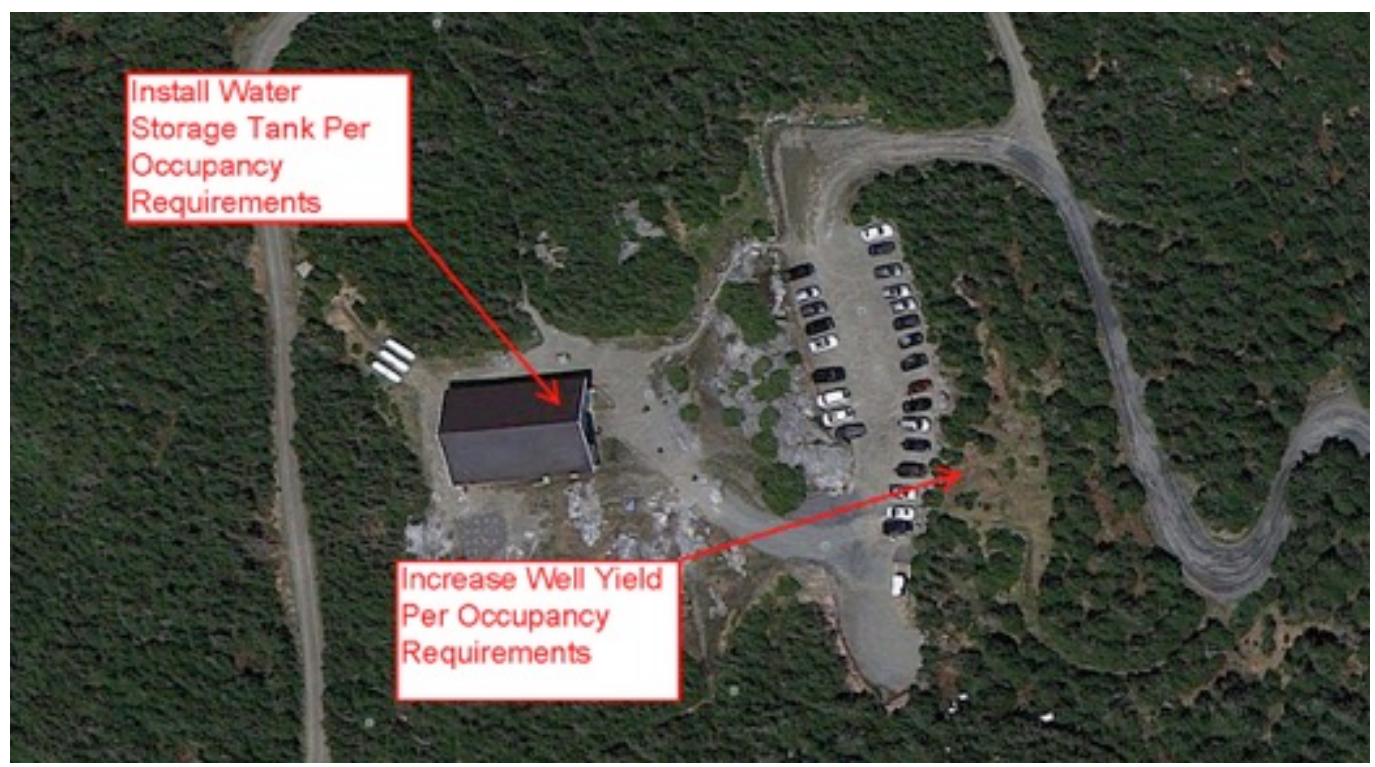

Both the 24-hour pump test and storage tank will be needed to secure a state Potable Water Supply Permit if the number of water users exceeds 10. If the water facility serves more than 24 users for 60 or more days per year, then it is subject to classification as a Public Transient Non-community Water Supply. Such a designation would require a licensed operator as well as systems for inspecting, sampling, and reporting. The Mount Mansfield Company already satisfies these operational requirements at the Octagon Café and Gallery. Mr. Hamlin does not foresee any technical problems related to water supply that cannot be solved, given the level of anticipated use and availability of the existing well. Even a low rate of water yield can be addressed by conservation, storage, hydraulic fracturing, or drilling the well deeper.

Disposing of wastewater presents a more significant challenge because thin soils severely limit the options for on-site treatment. In 1996, the State of Vermont permitted a sand filter septic system (a type of mound system for aberrant soil conditions) to serve a single occupant at the WCAX building. The cost of the project was approximately $\$ 80,000$ (R. Fraser, pers. comm.). Scaling such a system up for the Summit Station is not considered a realistic option due to economic, ecological, and regulatory considerations. Cooperators have also rejected composting toilets because of their cost, sanitary and maintenance issues, and poor performance in cool mountain conditions. Furthermore, neither composting toilets nor portable toilets provide for gray water disposal.

The option recommended by Hamlin and endorsed by participants at an October 2012 planning workshop is offsite disposal via a down-mountain pipe that connects to the Octagon's sewer line, which drains into Stowe's municipal system (Figure 4). The proposed design calls for a new septic tank to be installed behind the Summit Station, but otherwise limits construction disturbance to the existing roadway, where the waste pipe would be buried. Another advantage is that it can handle a high volume of wastewater in all four seasons. 
Figure 4. Conceptual plan for the wastewater system (R. Hamlin).

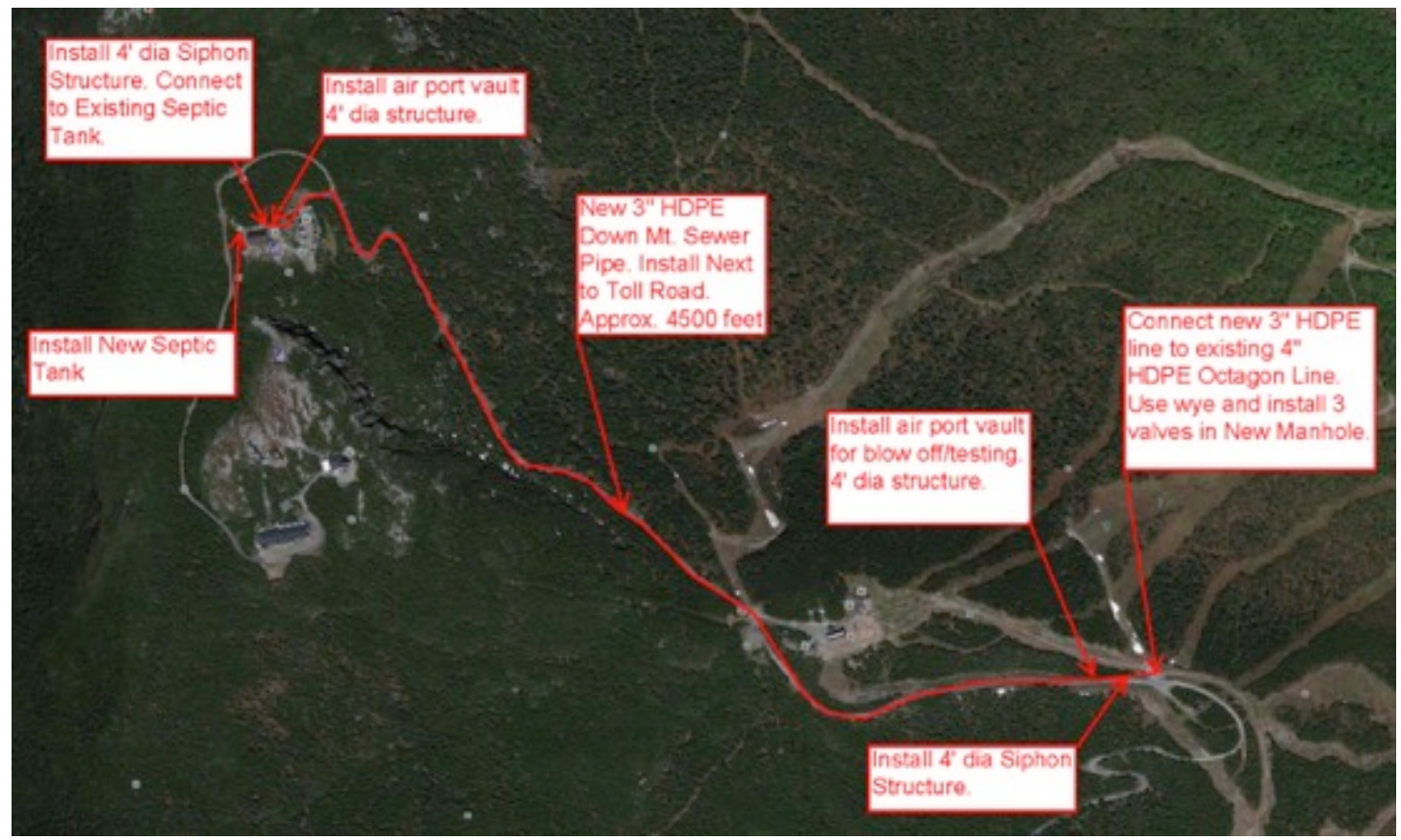

\section{Electrical, Heating, and Ventilation}

A thorough assessment of the Summit Station's electrical, heating, and ventilation systems has not been performed. The building receives AC power from Green Mountain Power and propane heating with aboveground storage tanks located to the northwest of the building. We assume that the electrical infrastructure can meet the anticipated need based on the building's history of energy-intensive telecommunications use. The roof's broad southern exposure and the prevalence of ridge-top wind present the possibility of offsetting consumption of grid energy with solar panels and/or a small, roofmounted windmill. The Summit Station is currently ventilated by industrial-scale fans that do not appear to suit the proposed future use of the building.

\section{Structural Integrity and Advantages of Renovation}

The Summit Station was built to withstand extreme weather conditions and appears to be structurally sound. A preliminary inspection of the exterior and interior by a licensed contractor revealed no more than cosmetic issues. A more thorough review by a structural engineer is needed to adequately assess the condition of the cement-block frame and metal roof and to evaluate whether it would be possible to lower the second floor to accommodate two stories within the existing shell.

Remodeling the Summit Station is the most cost-effective and ecologically sustainable option because such a renovation would make use of the existing structure and materials, while minimizing site disturbance. Still, substantial modifications to the façade and interior configuration will be required to achieve a visually inviting and functional space. Although upgrading the facility will necessitate many material, stylistic, and engineering decisions, the design and construction work is expected to present no extraordinary technical problems.

\section{Internet Access}

We are considering two main options for establishing a high-speed, broadband Internet connection at the Summit Station. First, the fiber optic cable that delivers broadband service to the Octagon could be extended up the Toll Road to the building. The second option that awaits further investigation is satellite Internet service. 


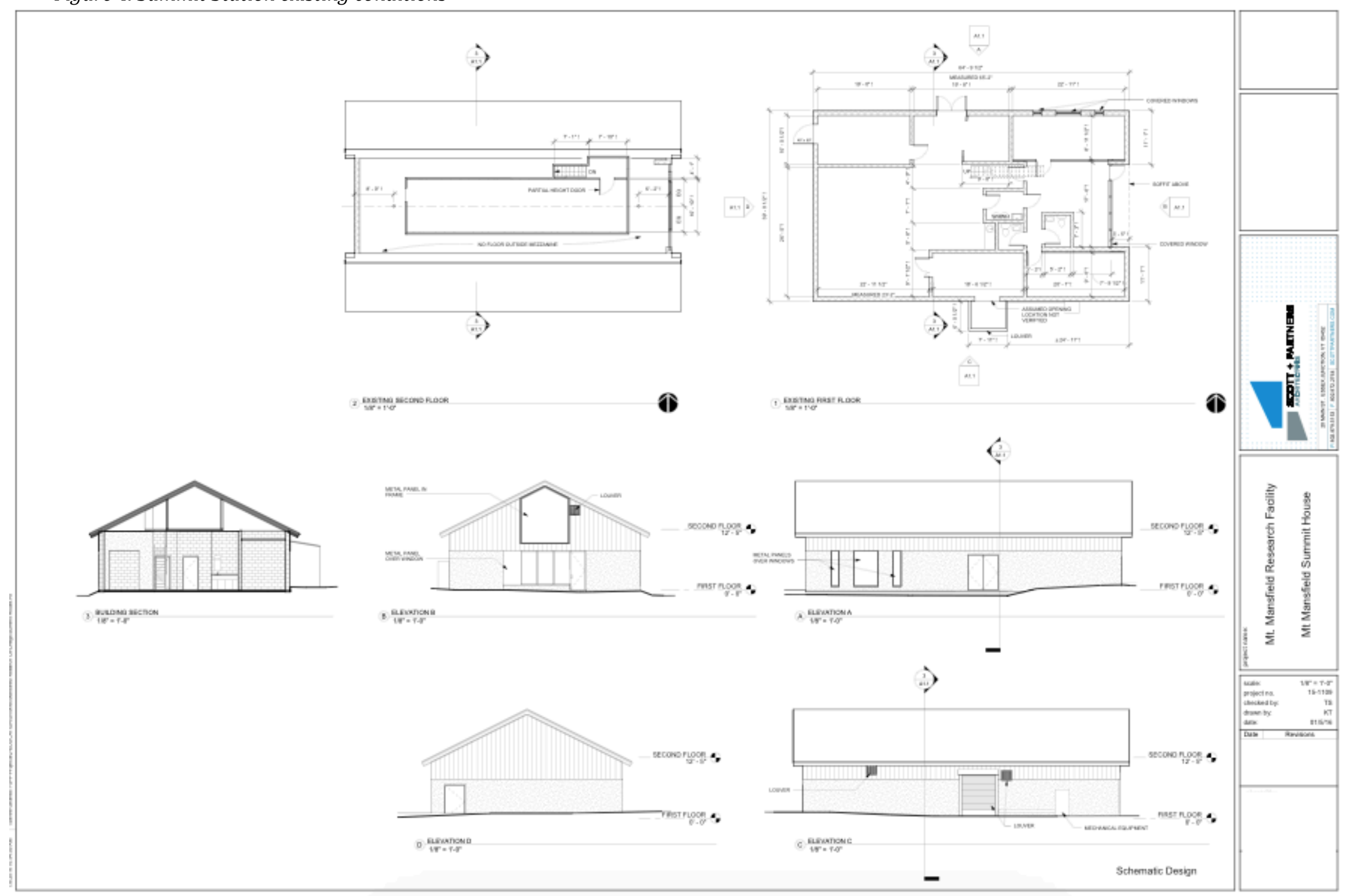


Figure 5. Elevations for renovation concept A (overnight accommodations for up to 20). Note reconstructed roof, addition to front of building, and bump-out to rear.

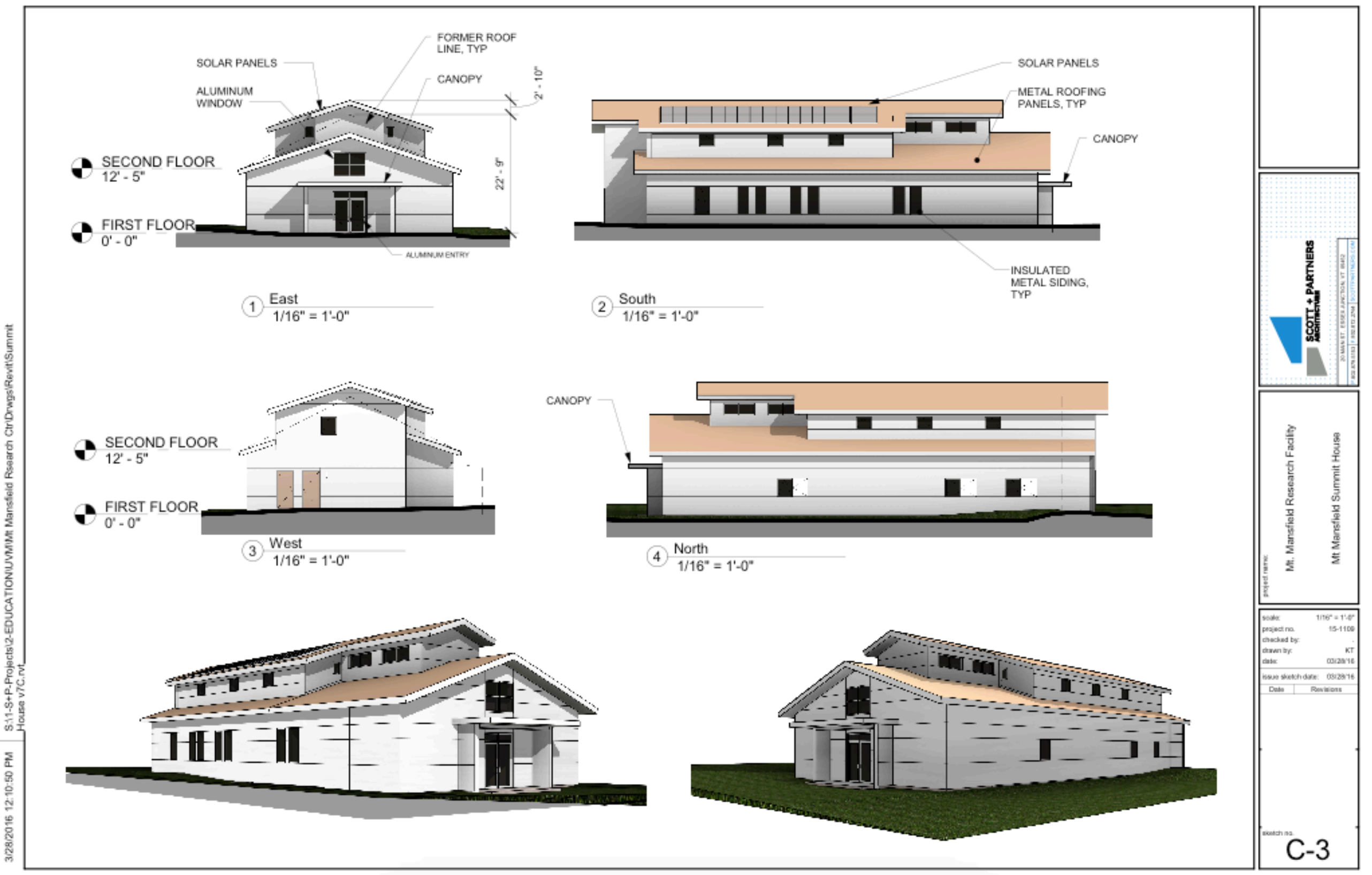


Figure 6. First floor plan for renovation concept $A$

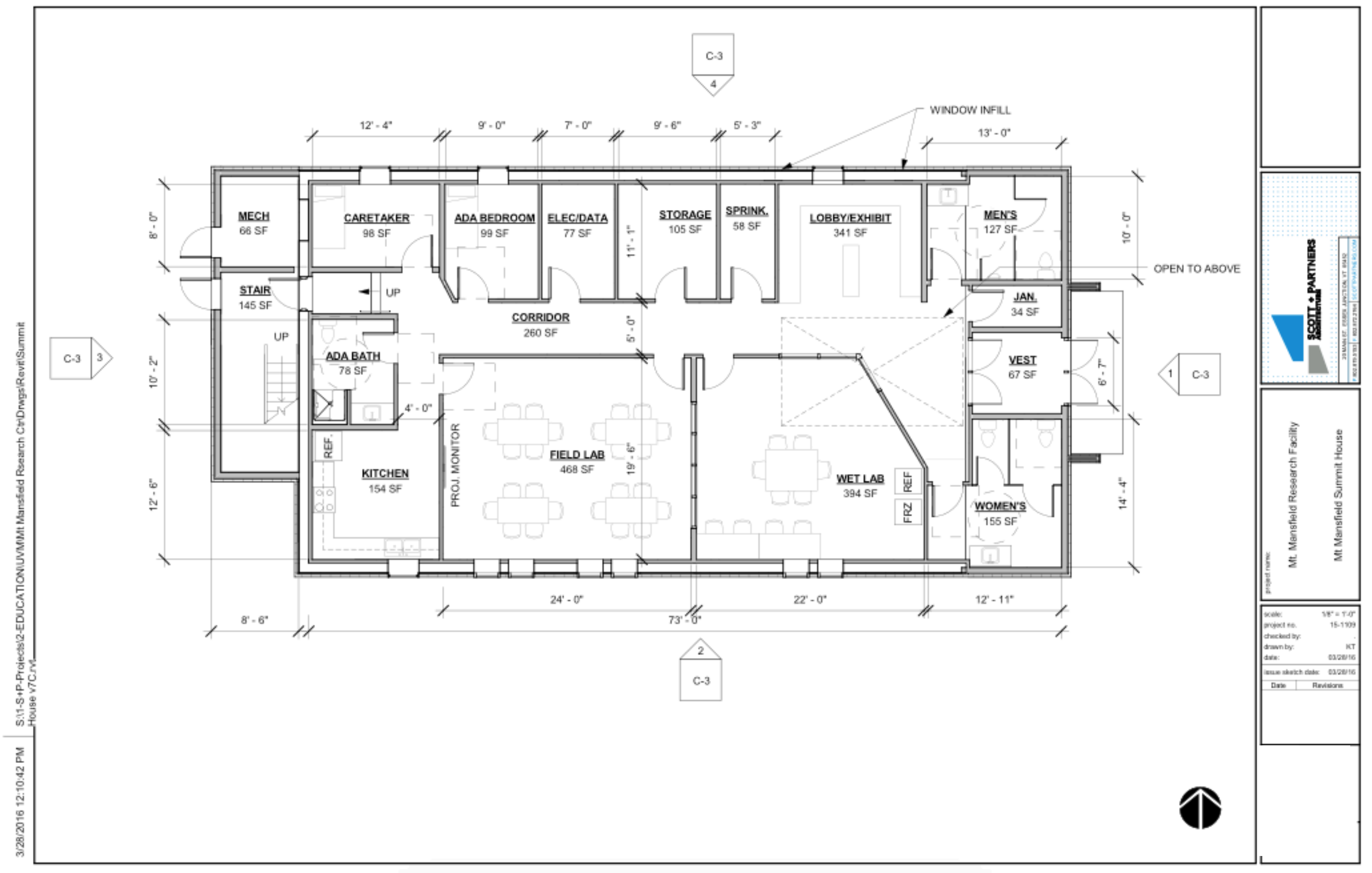


Figure 7. Second floor plan for renovation concept $A$

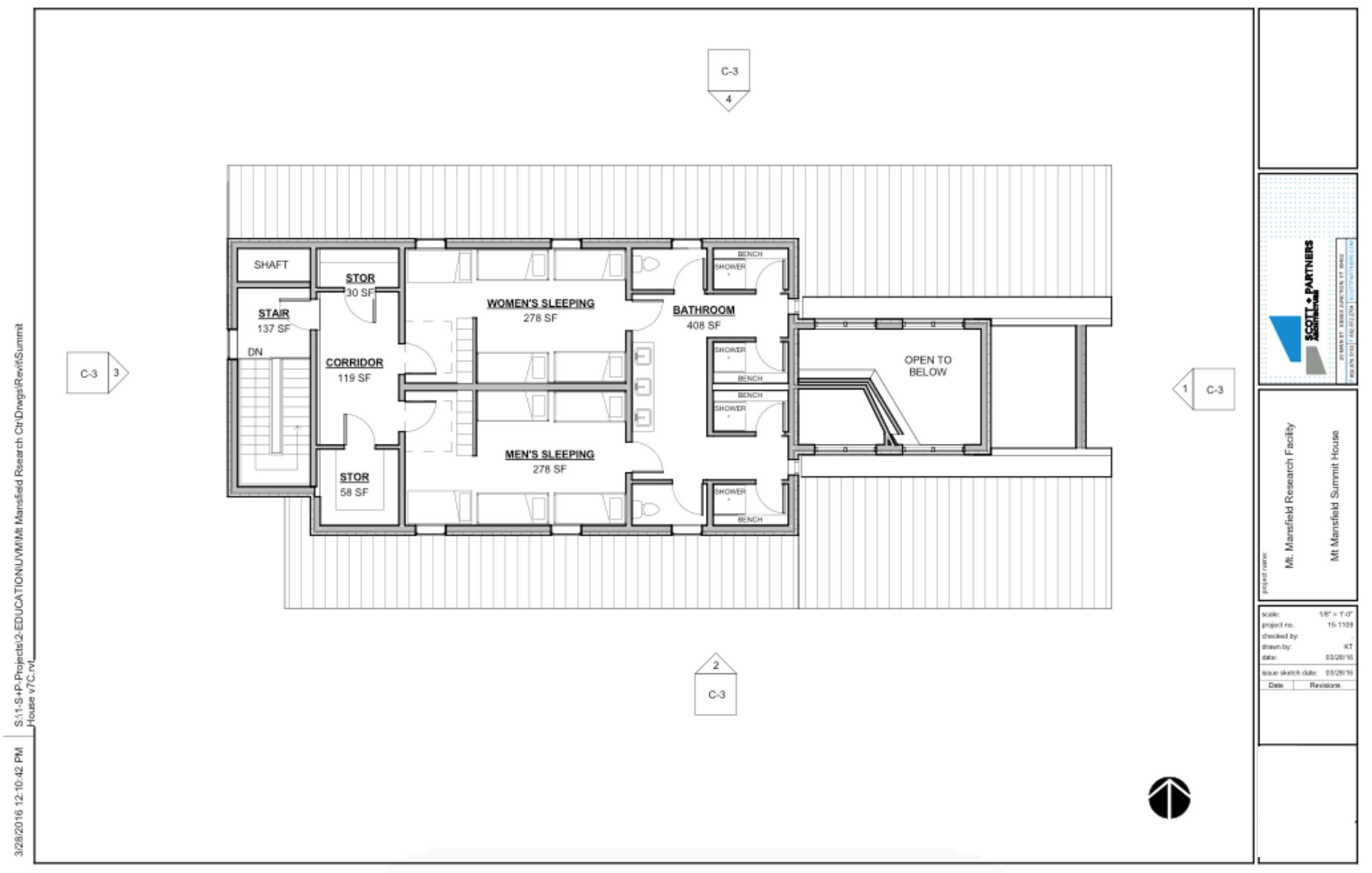


Figure 8. Elevations for renovation concept B, which adheres to the building's original footprint except for the addition of insulated siding and a vestibule. Concept B is currently designed for up to 4 overnight occupants, but up to 8 may be possible in a one-floor renovation.

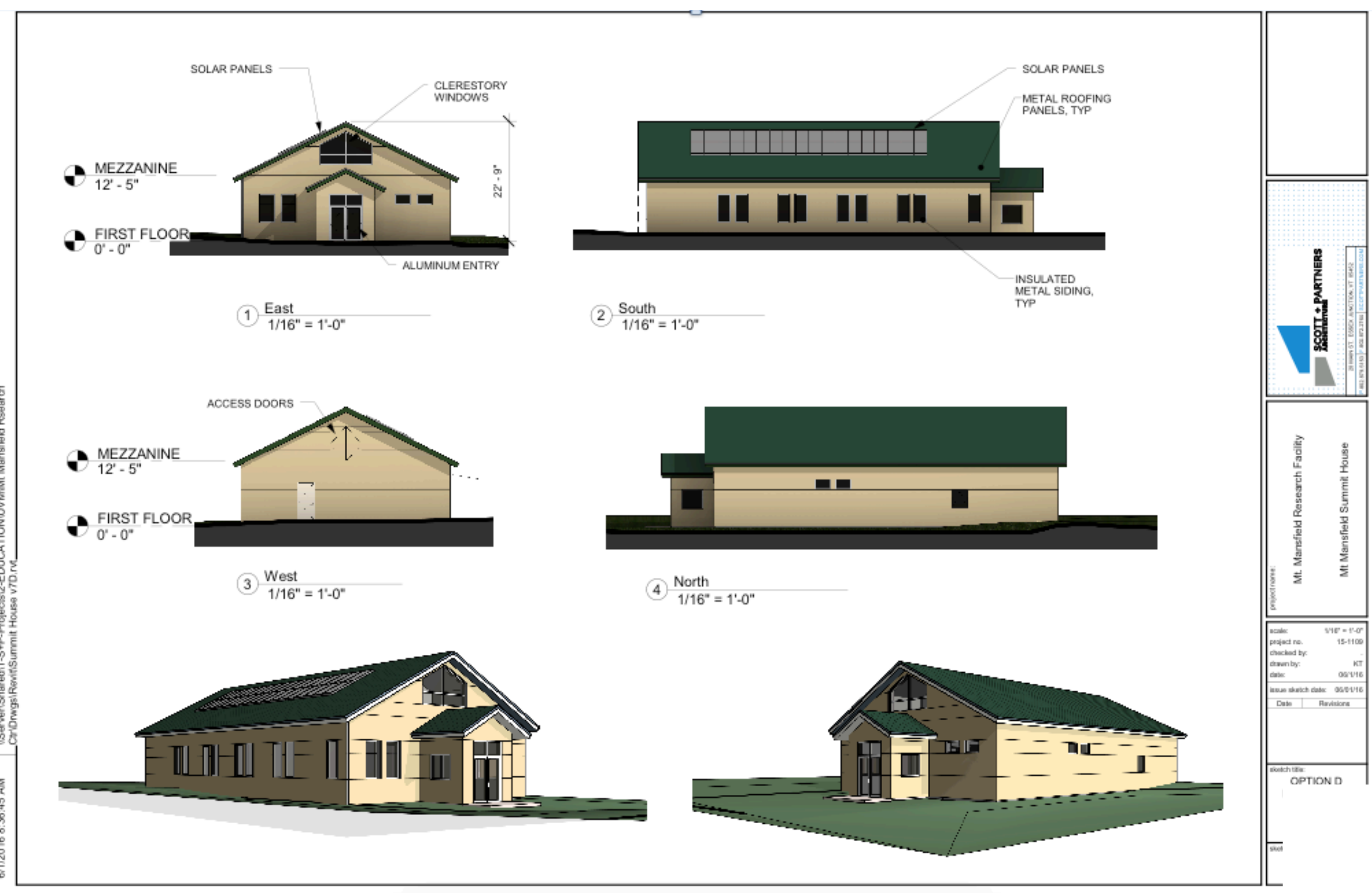




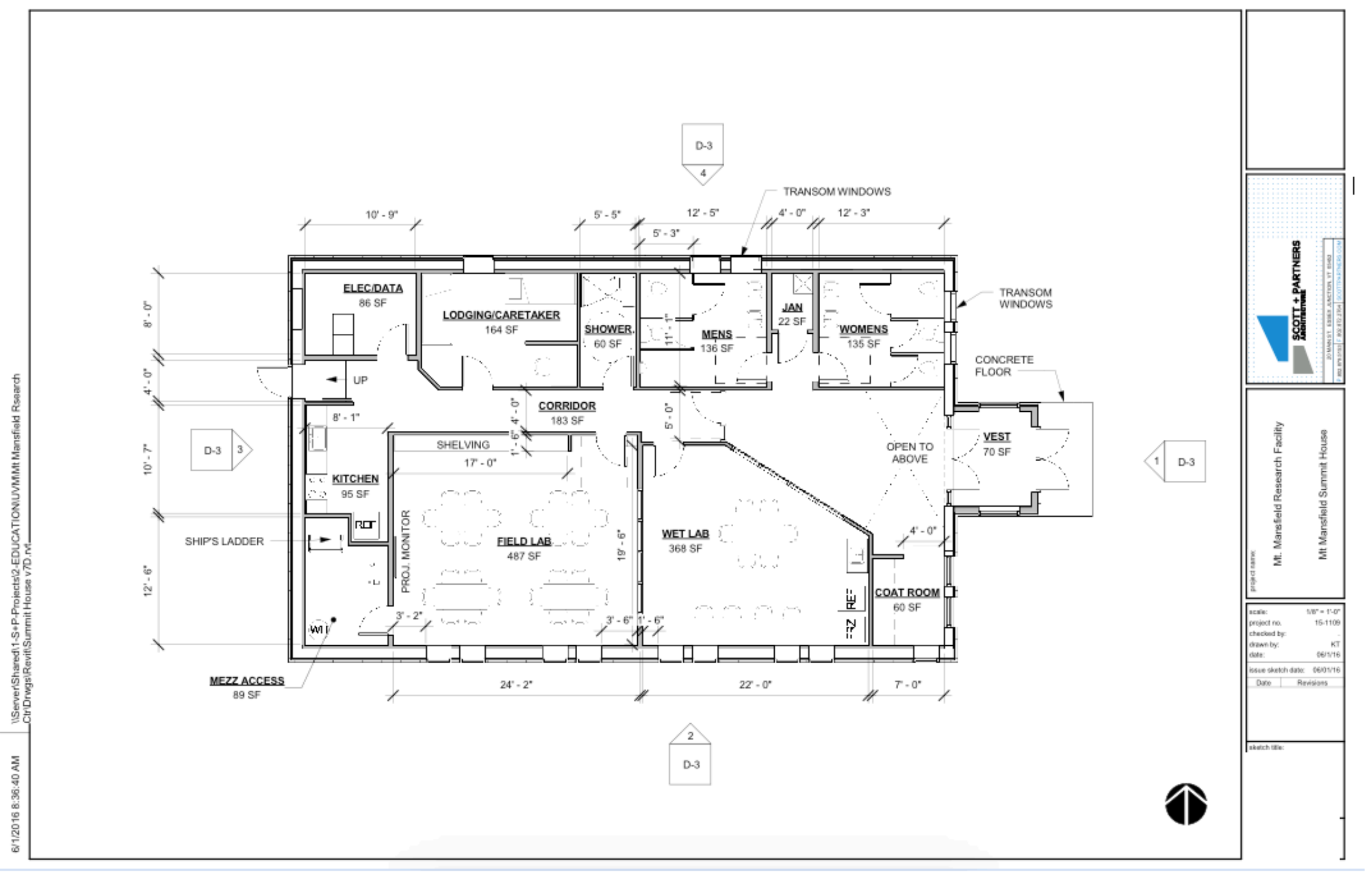


Figure 10. Second floor plan for renovation concept $B$

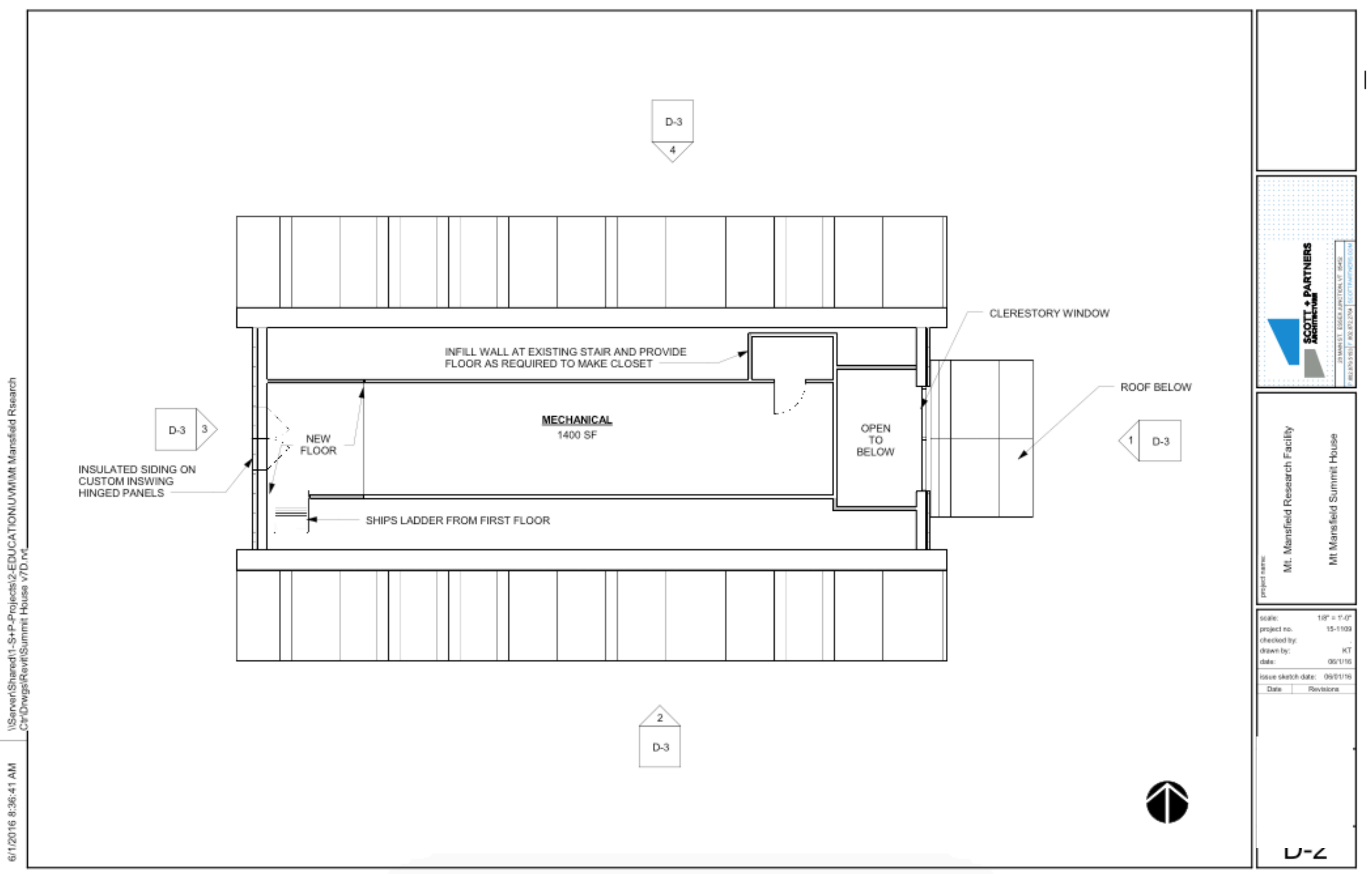




\section{Facilities Planning Objectives and Timeline}

$\underline{\text { Year } 1}$

1. Retain the services of an architect and exhibit designer.

2. Conduct an inventory of field instruments currently deployed on the mountain.

3. Itemize lab and field equipment needs.

4. Engage cooperators in the review and customization of architectural and exhibit design pla

5. Secure the municipal and state permits needed to carry out the renovation.

Years 2 and 3

1. Renovate and fit up the Summit Station.

2. Design and deploy a distributed, wireless network of automated environmental sensors.

3. Develop a registration and orientation system, building use guidelines, personal and environmental safety procedures, and infrastructure security protocols.

Years 4 and 5

1. Implement the systems, policies, and procedures described above.

2. Perform facilities maintenance and inventory activities at regular intervals. 
Facilities Appendix 1. Cost analysis for renovation concept A (accommodating up to 20)

This cost analysis assumes the addition of a sprinkler system, the addition of square footage to the original footprint, roof removal, and height increase to the roofline.

\section{Item}

Building Costs w/construction contingency

Other Project Costs

Other Contingency

Total Project Cost

Square Footage

Cost per Square Foot

\section{Option A}

$\$ 3,878,860$

$\$ 1,111,379$

$\$ 149,707$

$\$ 5,139,946$

4,200

$\$ 1,224$

Facilities Appendix 2. Cost analysis for renovation concept B (accommodating up to 4)

This cost analysis assumes renovation primarily within the existing footprint, except for the addition of an entry vestibule. No change in roof height and no sprinkler system added.

\section{Item}

Building Costs w/construction contingency

Other Project Costs

Other Contingency

Total Project Cost

Square Footage

Cost per Square Foot

\section{Option B}

$\$ 2,736,957$

$\$ 854,984$

$\$ 107,758$

$\$ 3,699,699$

3,280

$\$ 1,128$ 
Facilities Appendix 2 (continued). Cost analysis for renovation concept B (accommodating up to 4) The University of Vermont

Facilities Design and Construction

\section{Project Cost Summary}

Mt. Mansfield Science and Stewardship Center

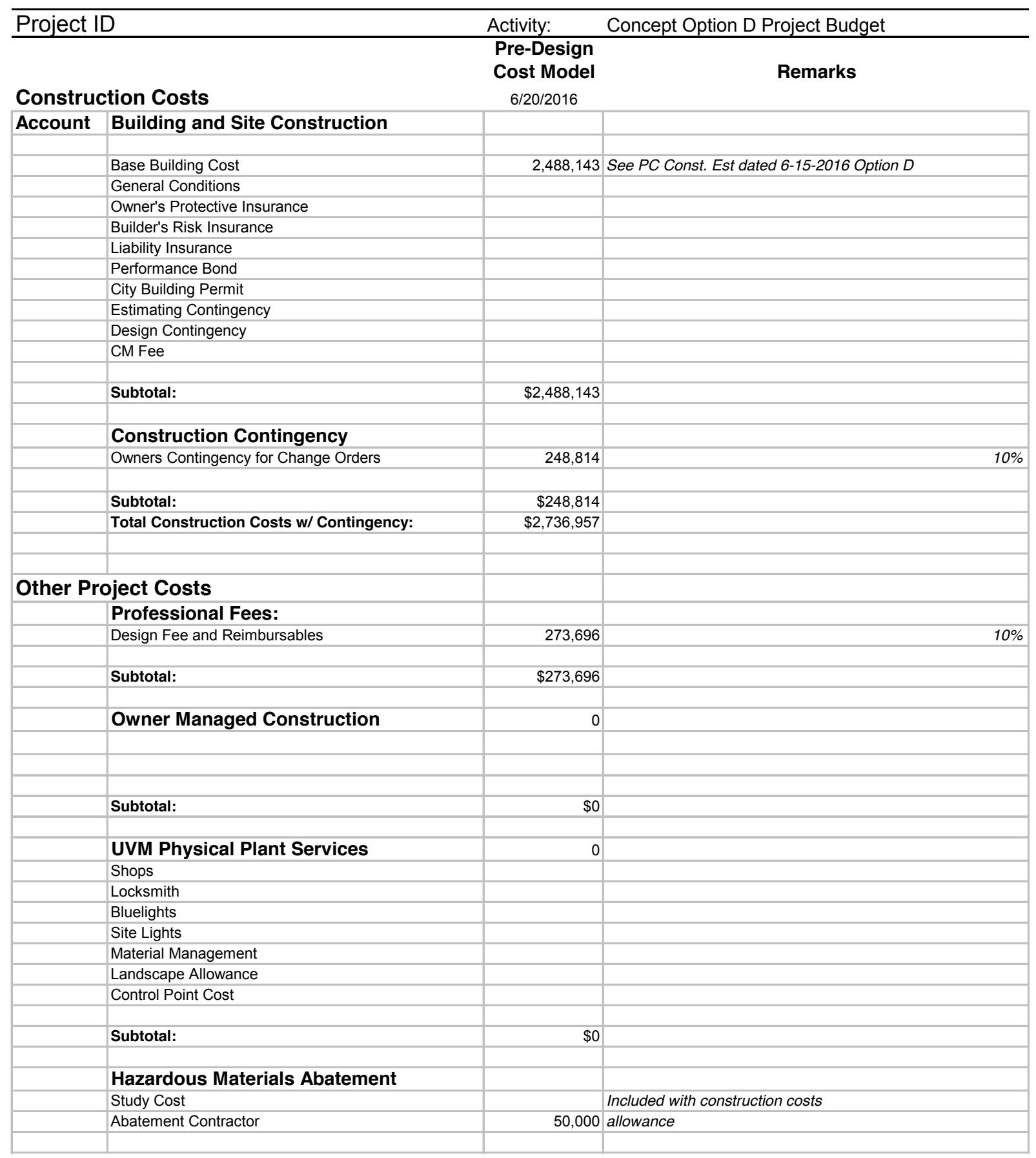


The University of Vermont

Facilities Design and Construction

\section{Project Cost Summary}

Mt. Mansfield Science and Stewardship Center

Project ID
Activity:
Concept Option D Project Budget

Pre-Design

Cost Model

Remarks

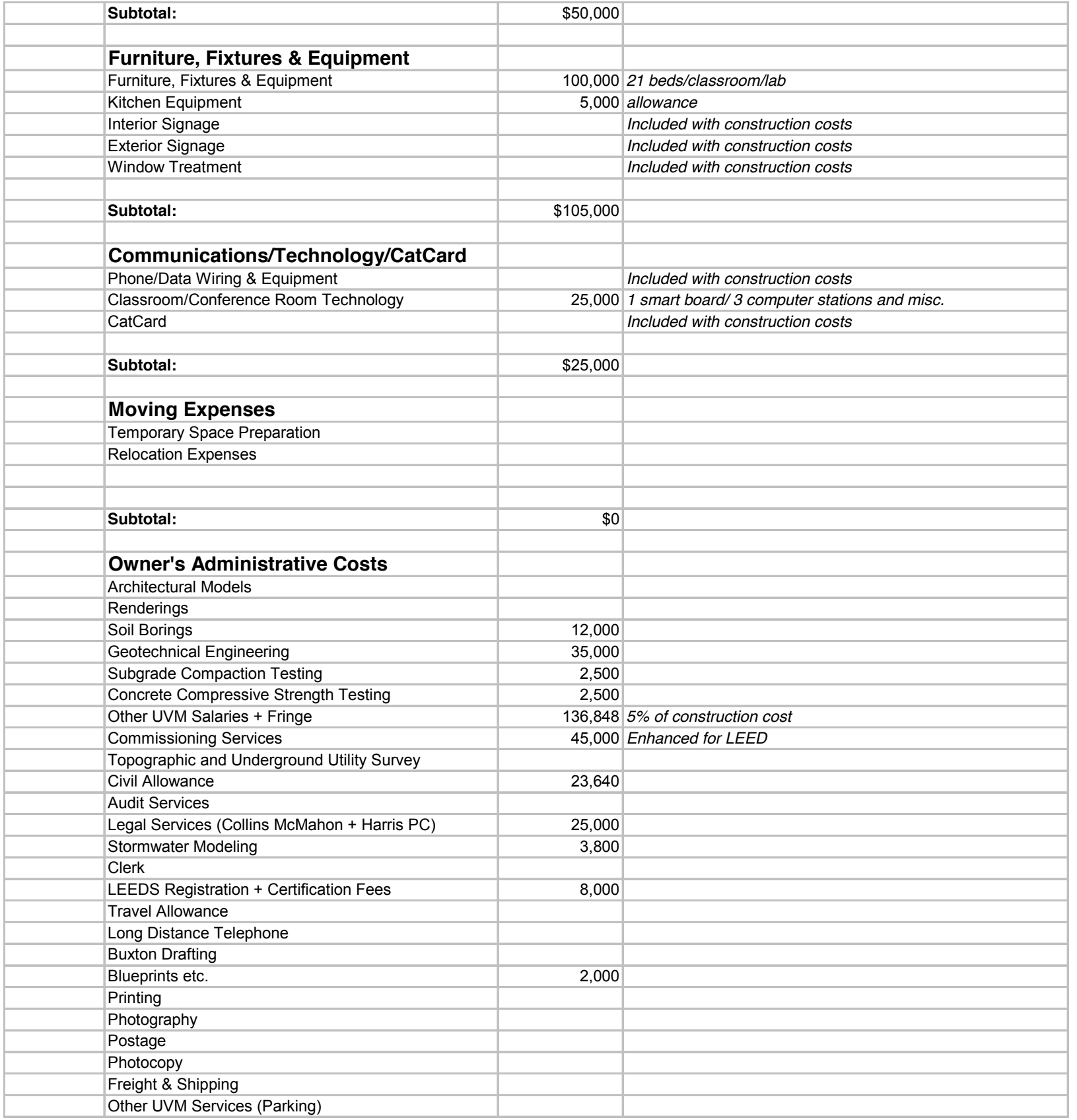


The University of Vermont

Facilities Design and Construction

\section{Project Cost Summary}

Mt. Mansfield Science and Stewardship Center

\begin{tabular}{|c|c|c|c|}
\hline \multirow{2}{*}{\multicolumn{2}{|c|}{ Project ID }} & Activity: & Concept Option D Project Budget \\
\hline & & $\begin{array}{l}\text { Pre-Design } \\
\text { Cost Model }\end{array}$ & Remarks \\
\hline & Consulting Organizations & 5,000 & \\
\hline & Advertising/Publicity & & \\
\hline & Supplies \& Materials & & \\
\hline & Business Meals & & \\
\hline & Job Trailer Phone \& Fax for CM & & \\
\hline & Permit Consultant & 25,000 & \\
\hline & & & \\
\hline & Subtotal: & $\$ 326,288$ & \\
\hline & & & \\
\hline & Permit Costs & & \\
\hline & Stowe Development Review & 75,000 & \\
\hline & Stowe Application Fee & & \\
\hline & Stowe Major Project Fee & & \\
\hline & Stowe Impact Fees & & \\
\hline & Act 250 Permit Fees & & \\
\hline & Occupancy Permit Fee & & \\
\hline & State Water Supply \& Waste Water Permit & & \\
\hline & & & \\
\hline & Subtotal: & $\$ 75,000$ & \\
\hline & & & \\
\hline & Subtotal Other Project Costs: & $\$ 854,984$ & \\
\hline & Project Cost Subtotal: & $\$ 3,591,941$ & \\
\hline & Other Project Cost Contingency: & $\$ 107,758$ & $3 \%$ at concept \\
\hline & Total Project Cost: & $\$ 3,699,699$ & \\
\hline
\end{tabular}


Facilities Appendix 3. Mount Mansfield Science and Stewardship Center 2015 Planning Survey Report

\section{Introduction}

A group of organizations from the public and private sectors has launched an effort to establish a hub of mountain science and stewardship in the northern Green Mountains of Vermont. Cooperators in the enterprise include: the University of Vermont (UVM), the Vermont Center for Ecostudies, the Vermont Department of Forests, Parks and Recreation, the Vermont Monitoring Cooperative (VMC), and the Mount Mansfield Company. The partnering institutions envision the Mount Mansfield Science and Stewardship Center as a community of scholars, educators, and natural resource managers working alongside students and visitors to understand and sustain the vitality of mountain ecosystems.

The Mansfield Center's mission is to promote the health of northeastern mountain ecosystems by catalyzing collaborative science and stewardship on Mount Mansfield. Its goals are:

- to advance interdisciplinary research and long-term monitoring of mountain ecosystems and changes affecting mountain flora and fauna;

- to develop, implement, and demonstrate stewardship actions that lead to improved conservation of mountain environments; and

- to provide place-based education and outreach on mountain ecology, conservation issues, and stewardship.

The foundation for this work consists of: 25 years of VMC monitoring data spanning air, forest, soil, water, and wildlife; UVM research and education programs that extend from the bottom of Lake Champlain to Vermont's highest summit; and a tradition of information-sharing and networking.

Since 2012, Mansfield Center cooperators have held two scoping workshops, completed a feasibility study, and produced an organizing framework for science, stewardship and education programs. They have also discussed the role of a mountain field station with local to international stakeholders, including the Organization of Biological Field Stations and the Global Network of Mountain Observatories. These discussions have led to the initiation of a formal strategic-planning phase that involves the preparation of detailed program, facilities, and business plans.

Each of these documents calls for an accounting of current research, education, and stewardship activities on Mount Mansfield. Planning must also incorporate information about the level of interest, among prospective users, in new programs, services, and facilities currently under consideration. The purpose of the 2015 Planning Survey was to gather information about ongoing and potential uses of the mountain's living laboratory in order to guide the development of a comprehensive, five-year strategic plan.

\section{Survey Methods}

Working in concert with the Mansfield Center Leadership Team, I prepared a 23-question survey for circulation via an online platform (https://www.surveymonkey.com). To develop a survey pool, we drew from a variety of sources, including: the VMC and Mansfield Center contact databases, the OBFS member station database, the contact list from a 2011 workshop to establish alpine research priorities in the Northeast, staff directories for the Vermont Agency of Natural Resources and the US Forest Service, as well as directories for colleges, universities, nature centers, and environmental organizations located primarily in New England and eastern New York. On November $6^{\text {th }}$, we invited 520 scientists, educators, and natural resource managers to participate in the survey. We issued reminders to complete the survey on November $24^{\text {th }}$ and on December $2^{\text {nd }}$ and closed the survey on December $4^{\text {th }}$. 


\section{Profile of Respondents}

During the 29 days when the survey was active, we received 100 responses for a response rate of $19.2 \%$. Of these, 82 responses originated from individuals working in Vermont. As a group, the respondents represent at least 44 different institutions based in five states and the province of Quebec. Approximately half of the respondents (53) are affiliated with a public or private university or college (Table 1). Government agencies and not-for-profit organizations were represented by 23 and 18 respondents, respectively.

Table 1. Organizational affiliations of survey respondents

\begin{tabular}{|l|l|}
\hline Affiliation & Count \\
\hline Public university or college & 43 \\
\hline Independent not-for-profit organization & 18 \\
\hline State agency & 16 \\
\hline Private university or college & 10 \\
\hline Federal agency & 7 \\
\hline Other & 6 \\
\hline
\end{tabular}

Half of the survey participants have led or participated in fieldwork on Mount Mansfield and at least twenty-seven of them are currently involved in projects on the mountain. Approximately half of the respondents work within an hour of Stowe, Vermont, a town located to the east of the mountain from which a toll road ascends to the ridgeline. A large majority of the respondents (84\%) work within two hours of Stowe.

Sixty survey participants identified "Research and/or Monitoring" as one of their primary professional fields. Natural resource management and education were also commonly identified (Table 2).

Table 2. Professional fields identified by survey respondents

\begin{tabular}{|l|l|}
\hline Professional Field & Count \\
\hline Research and/or monitoring & 60 \\
\hline Natural resources management & 46 \\
\hline Education & 44 \\
\hline Environmental regulation & 10 \\
\hline Recreation management & 8 \\
\hline Engineering & 2 \\
\hline Other & 18 \\
\hline
\end{tabular}

\section{Results}

Responses to all questions are summarized in tables and figures appended to this report. Here, I present nine key findings that pertain most directly to program, facilities, and business planning.

1. The expertise of prospective Mansfield Center users spans more than 30 academic and professional disciplines.

Table 3. Top 13 areas of expertise identified by survey respondents

\begin{tabular}{|l|l|}
\hline Area of Expertise & Count \\
\hline Natural resource management & 34 \\
\hline Forest science & 27 \\
\hline Botany or plant ecology & 25 \\
\hline Environmental studies & 25 \\
\hline
\end{tabular}




\begin{tabular}{|l|l|}
\hline Zoology or wildlife ecology & 20 \\
\hline Restoration ecology & 10 \\
\hline Climatology & 10 \\
\hline Education & 10 \\
\hline Organismal biology & 9 \\
\hline Atmospheric chemistry & 8 \\
\hline Geology & 8 \\
\hline Hydrology & 8 \\
\hline Recreation management & 8 \\
\hline
\end{tabular}

2. Interest in basic residential and educational infrastructure is high relative to interest in laboratory or storage facilities.

Figure 1. Level of interest in different types of facilities (based on 77 responses)

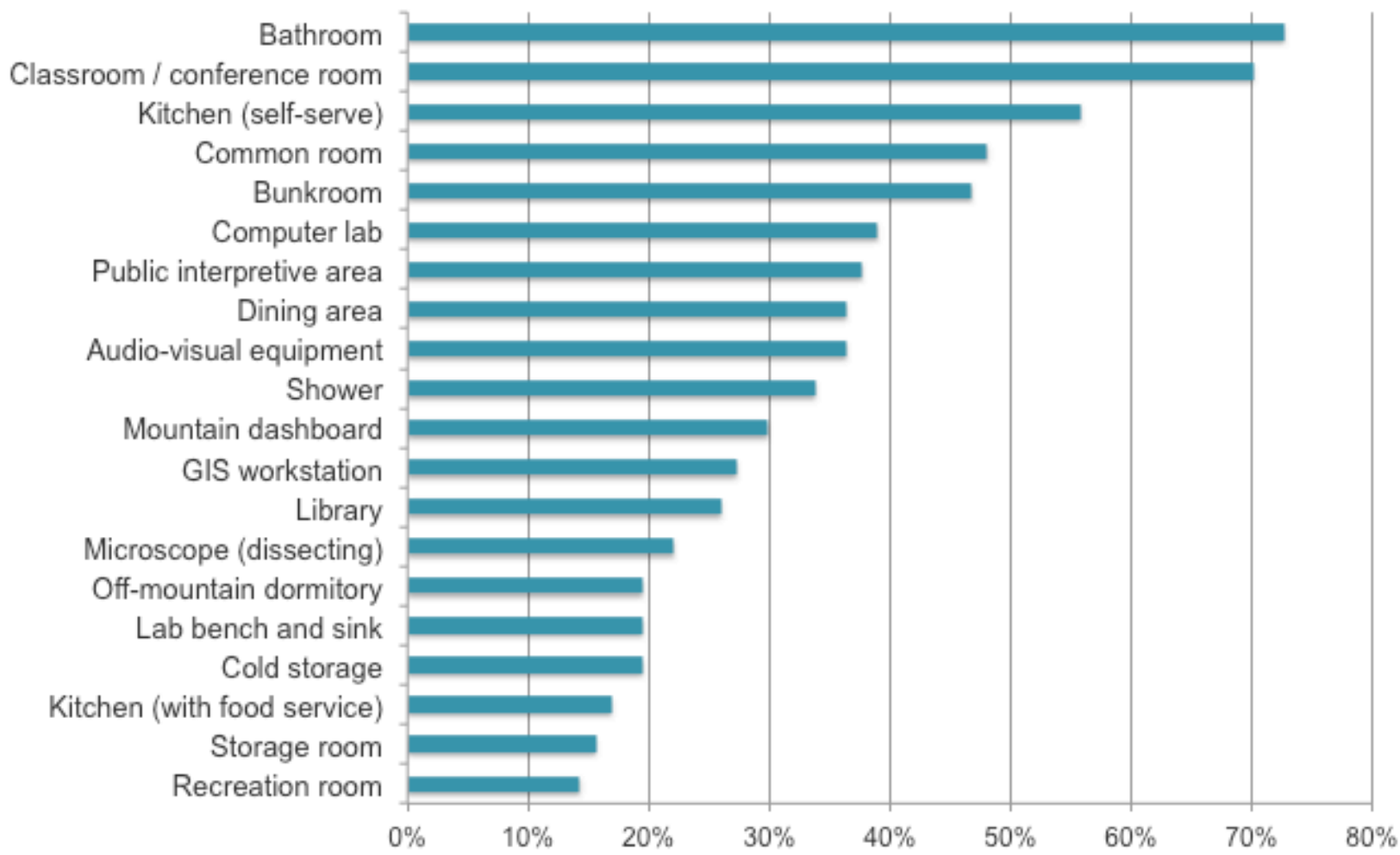

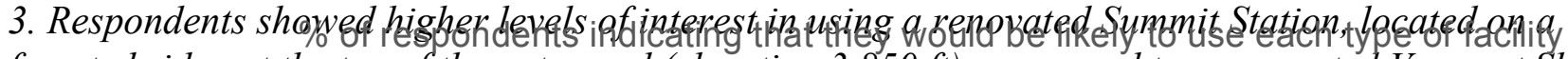
forested ridge at the top of the auto road (elevation 3,850 ft), compared to a renovated Vermont Ski Dorm, located at the base of the mountain on Vermont State Route 108.

Figure 2. Percentage of respondents $(n=89)$ reporting high or very high interest in using the Summit Station compared to the Vermont Ski Dorm for education, science, and/or stewardship activities. 


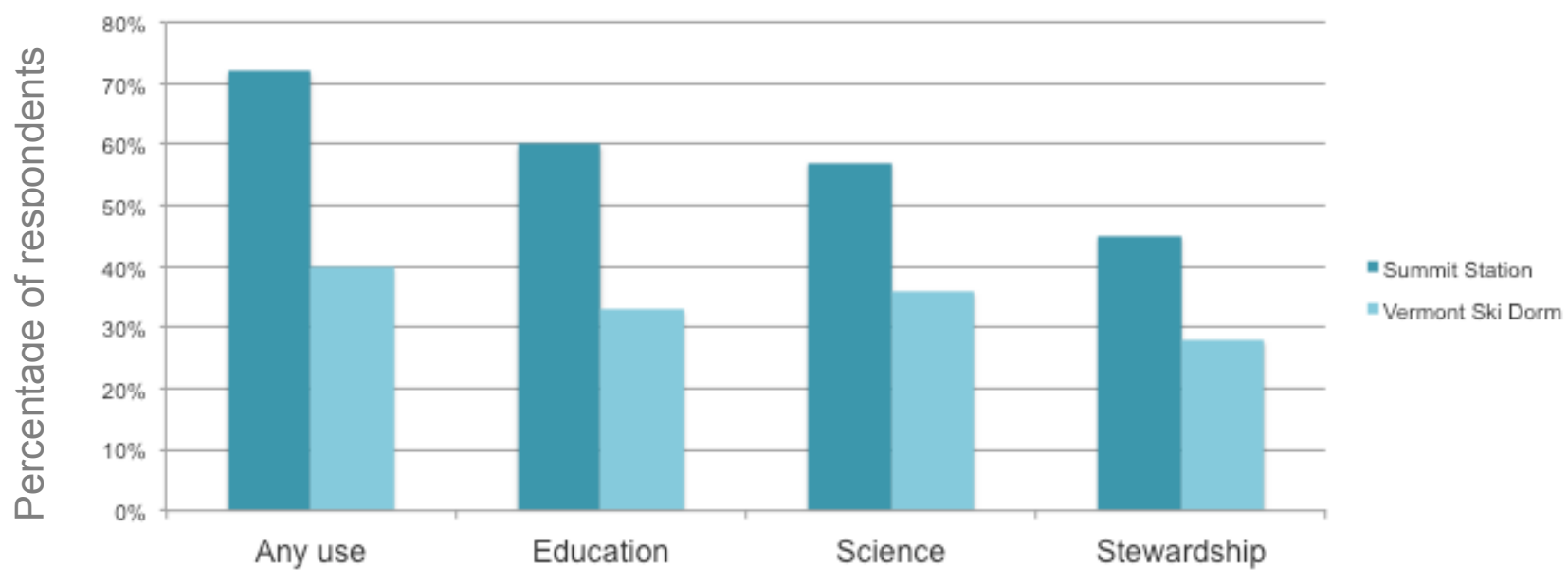

4. Thirty-five percent of respondents are interested in using the Mansfield Center for overnight lodging, while another 35\% may be interested in overnight accommodations. The remaining 30\% expressed interest in daytime use only.

Figure 3. Level of interest in overnight lodging (based on 83 responses)

\section{Are you interested in overnight lodging at the Mansfield Center for yourself, students, colleagues, and/or assistants?}

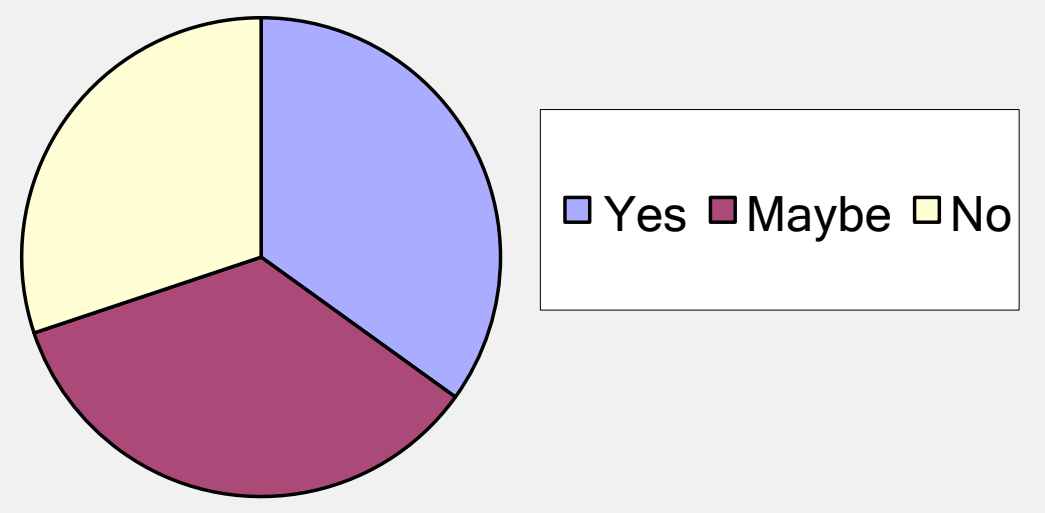


5. Respondents indicated a high demand for overnight use in May, June, July, and September with monthly guest-night projections ranging between 290 and 445 during these months.

Figure 4. Projections of overnight use by month

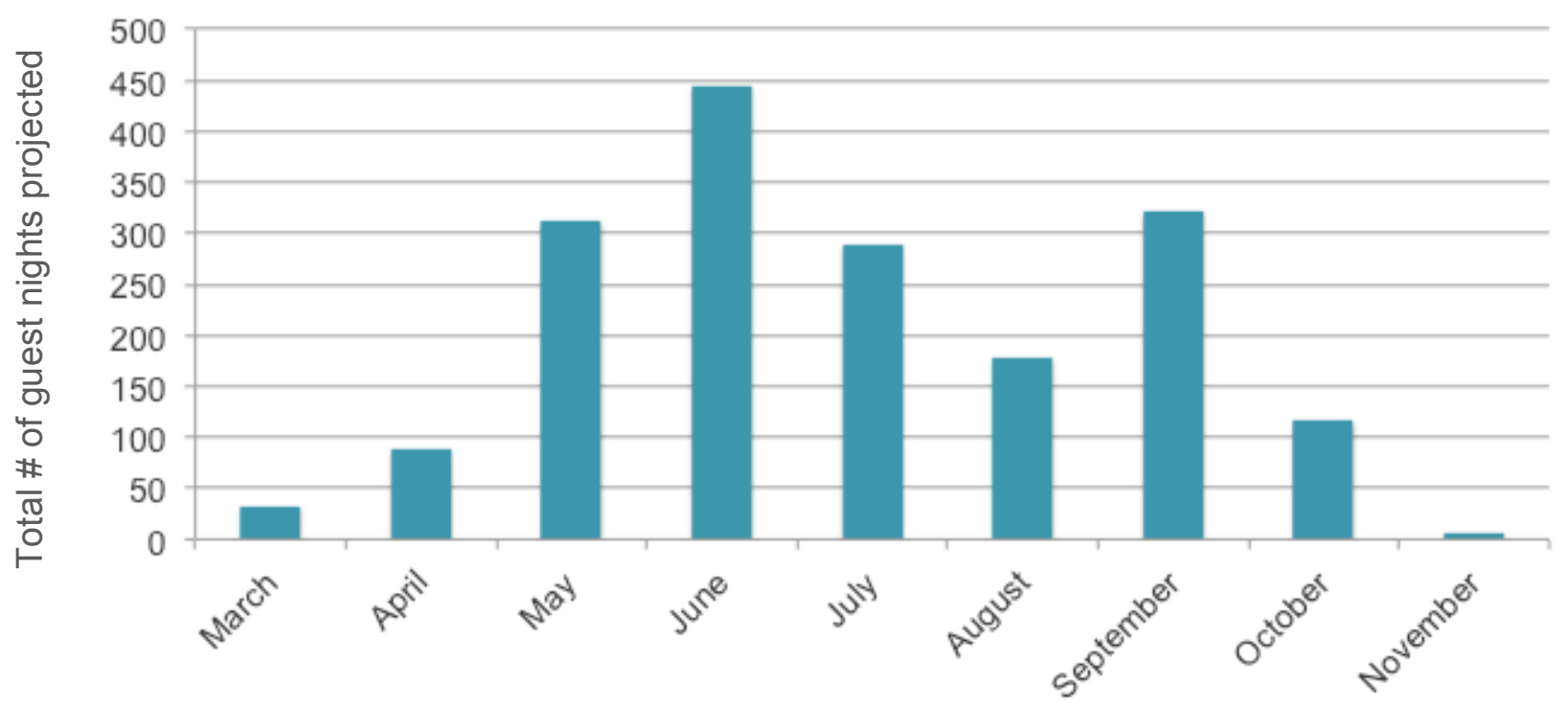

6. Half of those who anticipate using the Mansfield Center as an overnight facility project maximum group sizes of 10 people or fewer. The other half projected maximum group sizes of 15-25 people.

Figure 5. Maximum group sizes projected by likely overnight users

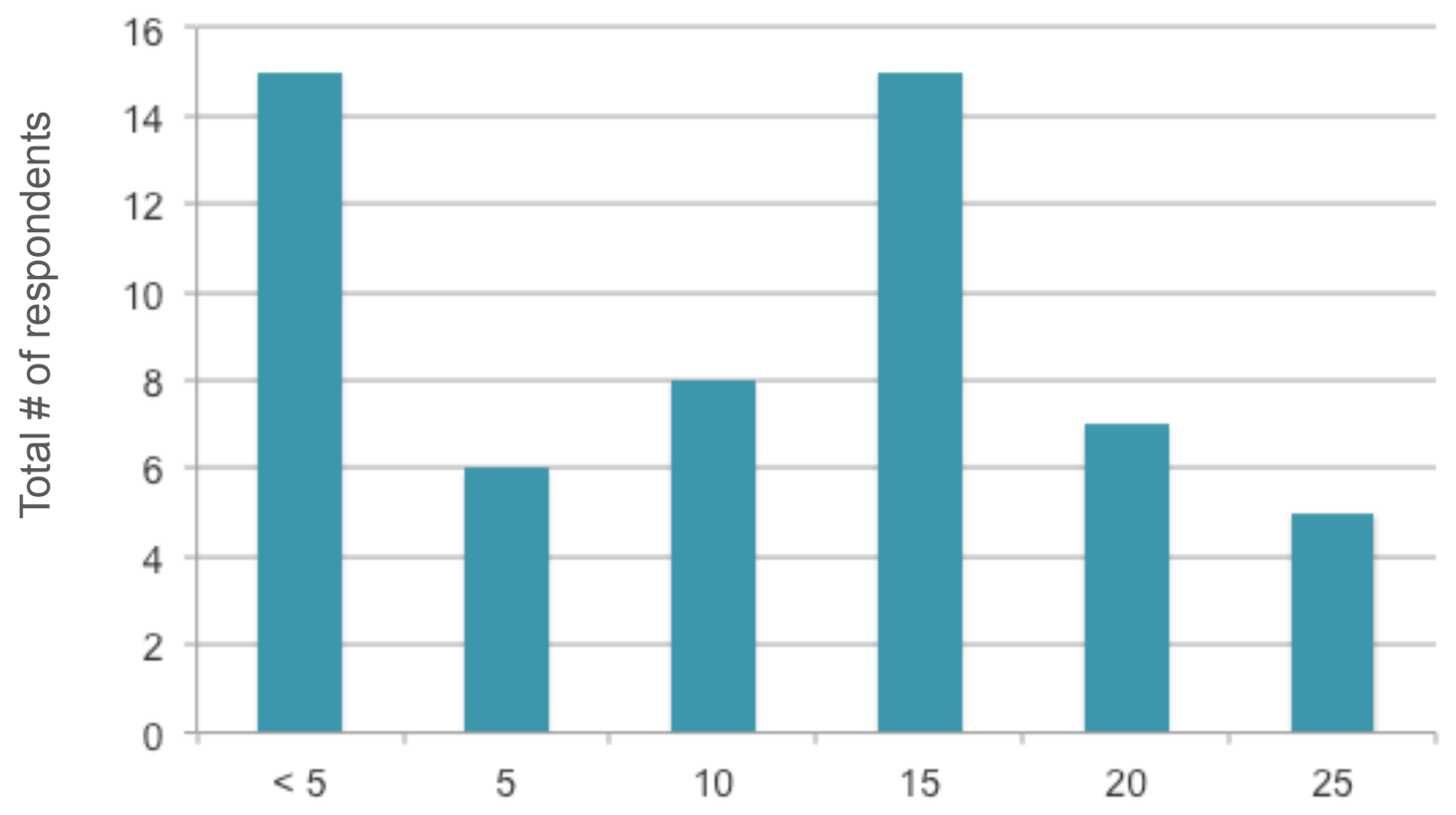

Maximum overnight group size 
7. The maximum amount that prospective users are willing or able to pay for overnight lodging ranges from $\$ 10$ to $\$ 100$. Sixty-nine percent of the responses fell between $\$ 10$ and $\$ 30$ per night.

Figure 6. Nightly fees that users would be willing to pay for lodging at the Mansfield Center

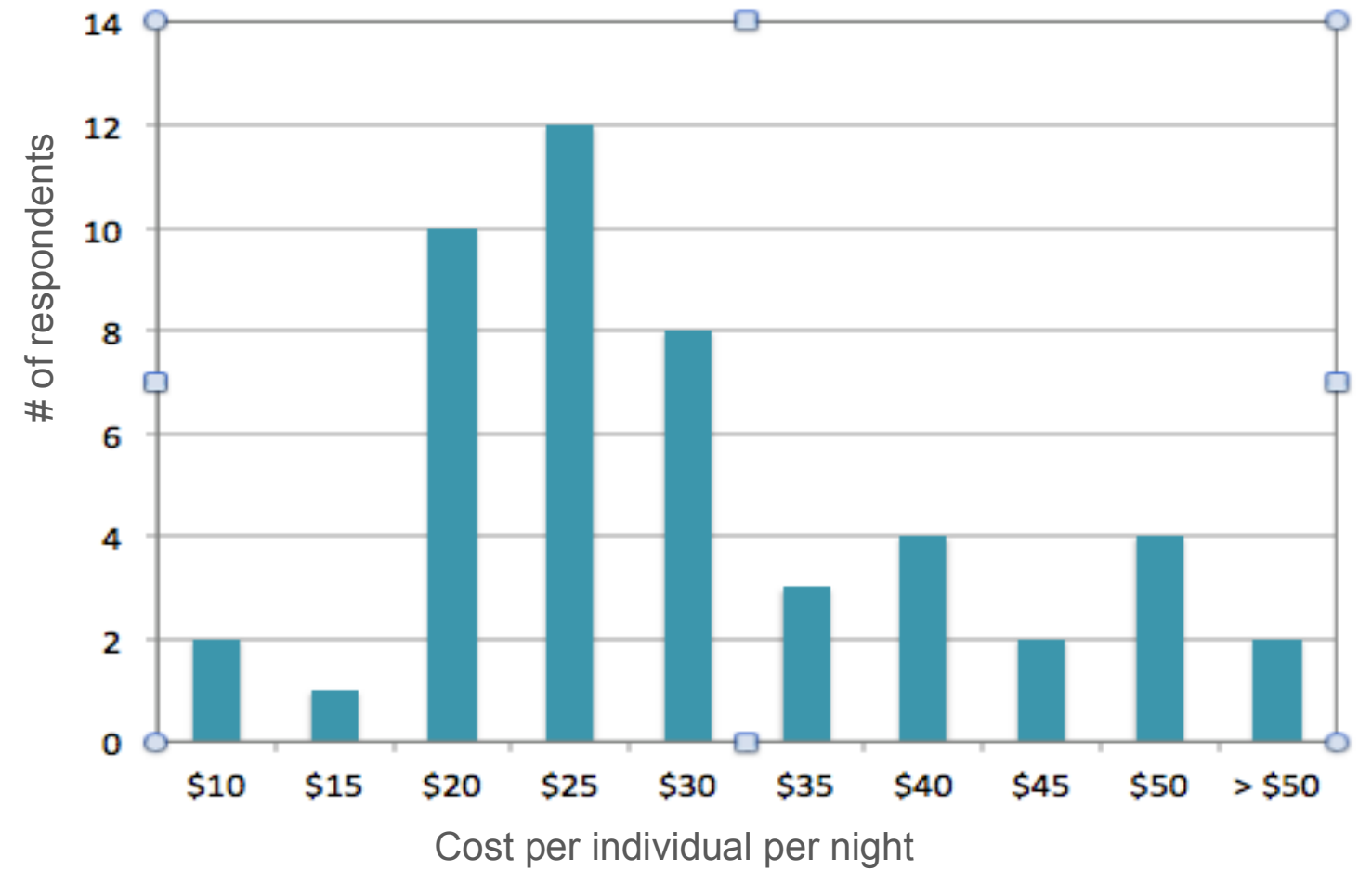

8. There is a high level of interest in use of field instruments on the mountain, especially those designed to monitor meteorological and climatic variables.

Figure 7. Level of interest in different field instruments (based on 68 responses)

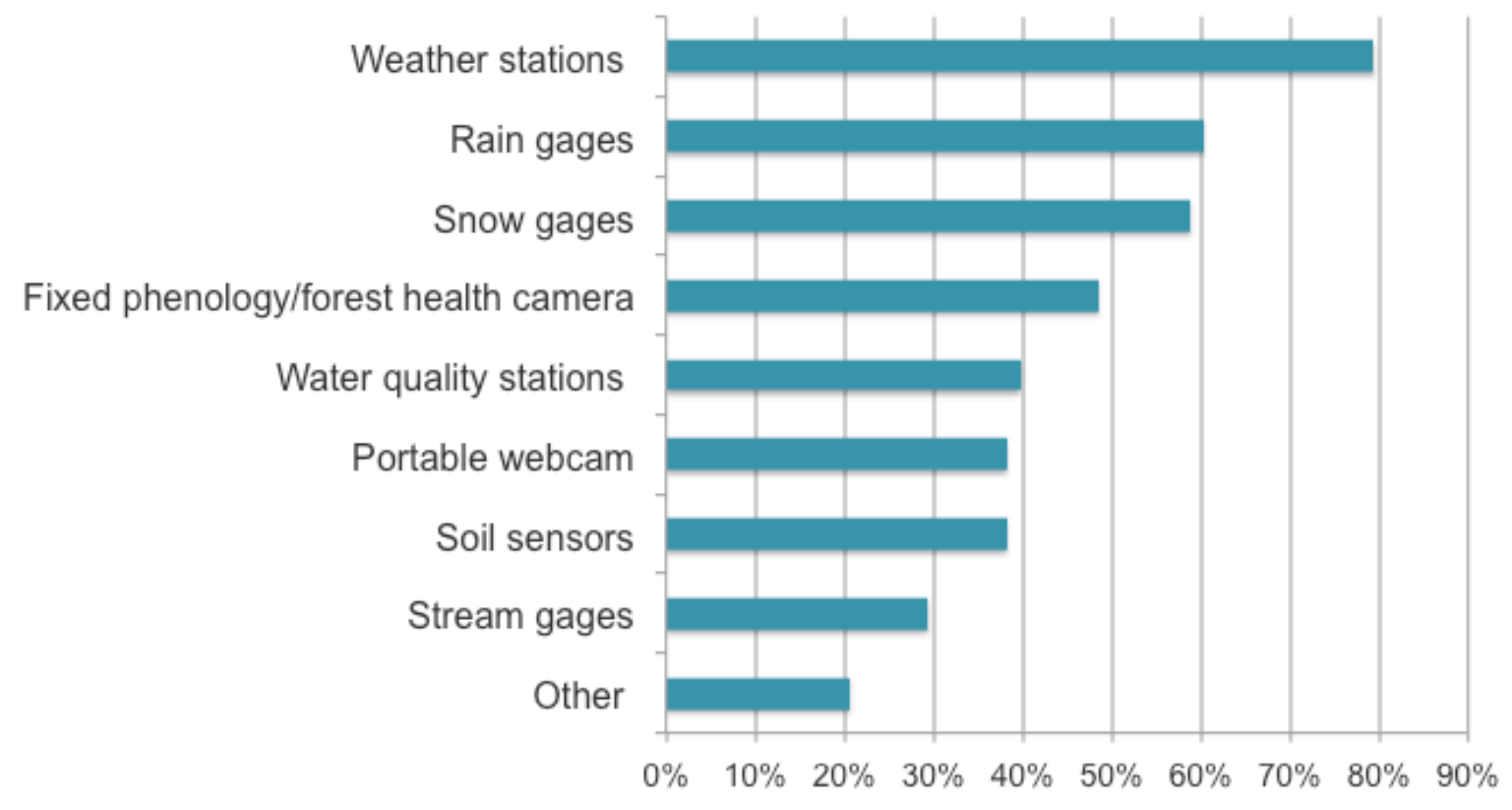

$\%$ of respondents indicating that they would be likely to use each type of instrument 
9. Prospective users are interested in a variety of services that could be provided by the Mansfield Center, especially data management, educational programs and displays, research coordination, and lodging.

Figure 8. Level of interest in different field station services (based on 84 responses)

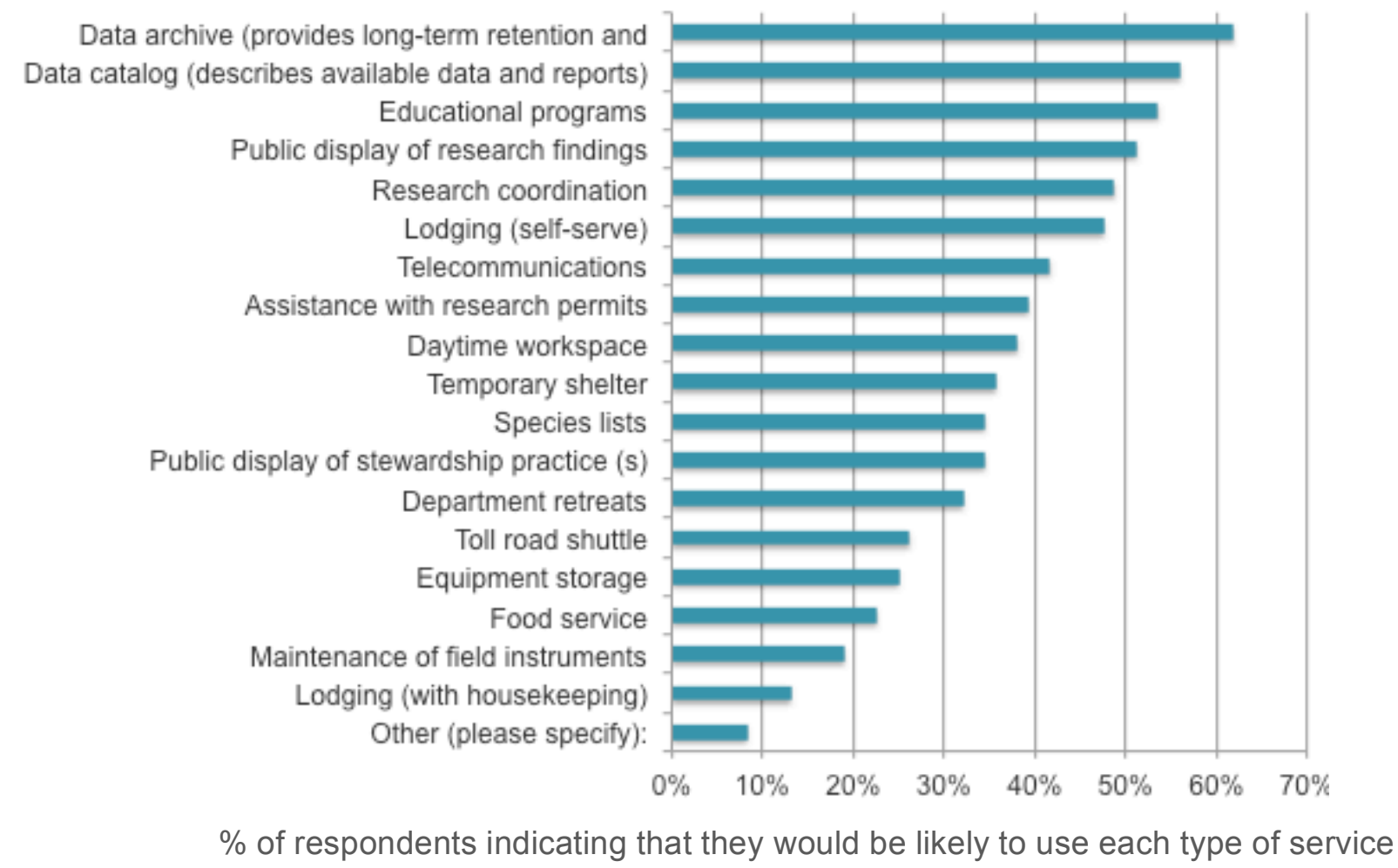

\section{Conclusion}

These data provide a basis for designing programs and facilities that support scientists, educators, and natural resource professionals currently working on Mount Mansfield and in other mountain environments. Mansfield Center planners can use this information to craft a strategic plan that addresses the expressed interests of prospective users. While these interests encompass a wide range of topics and use levels, they largely align behind the establishment of residential and educational space within the Summit Station. Monthly projections of user demand and information on user capacity to pay can be applied to on-site program development and financial planning. By allocating funding and effort according to user interests, Mansfield Center cooperators have the opportunity to realize the shared vision of a vibrant community collaborating to sustain the health of mountain ecosystems.

\section{Acknowledgments}

Several members of the Mansfield Center Leadership Team participated in the development of the planning survey, including Nancy Mathews, Allan Strong, and Rick Paradis (UVM Rubenstein School of Environment and Natural Resources), Jennifer Pontius and Carl Waite (Vermont Monitoring Cooperative), Chris Rimmer (Vermont Center for Ecostudies), and Sandy Wilmot (Vermont Department of Forests Parks and Recreation). Sandy Wilmot created the online questionnaire and April Berteau provided valuable assistance with its administration. 
Facilities Appendix 4. Mount Mansfield Science and Stewardship Center Use Guidelines and Stewardship Opportunities

\section{Protocols for Use of the Facility and Surroundings}

Over the years, we have visited many field research stations and conservation program centers around the country and beyond. Most of these have well-defined rules and protocols regarding expected behavior when using facilities (residence rooms, laboratories, common spaces, kitchens, etc.) and equipment (traps, weirs, nets, etc.), and while on the grounds. These procedures reduce conflict among users, avoid undue wear and tear to facilities and equipment, and protect the often spectacular and fragile settings where many of these stations are located. First-time users of these stations meet the site manager, tour the facilities and premises, and are explicitly oriented on rules and protocols.

We envision similar procedures for the Mount Mansfield Science and Stewardship Center. All new users would be provided with an orientation that includes rules and protocols for use of both the facility and the fragile ridgeline environment. The Mansfield Center steering committee will develop explicit policies during the Center's planning phase, with input from others who have expertise in mountain stewardship, including representatives of the Green Mountain Club, the Vermont Fish and Wildlife Department, and the Vermont Department of Forests, Parks and Recreation. When completed, the rules and protocols are expected to conform with the following guidelines.

1. Activities related to either daytime or overnight use of the facility (including sleeping, meal prep and cooking, washing, etc.) will be restricted to indoors and must not spill out to the surrounding grounds.

2. Science or stewardship work occurring off designated trails will only be authorized by special permits. Specific measures will be taken to ensure that visitors avoid all such sites, as well as any specially designated areas.

3. Except when work off trails has been permitted, users must remain on designated paths or on exposed bedrock to avoid trampling sensitive sub-alpine or alpine vegetation. An area to the immediate south, west and northwest of the building will be off limits and clearly marked as such.

4. Projects taking place on University of Vermont lands or on State of Vermont lands must be permitted by the appropriate landowner.

5. Researchers and stewardship specialists who encounter visitors in the field and at the center will be strongly encouraged to explain the nature of their work. Measures will be taken to ensure that Mansfield Center activities do not unduly inconvenience visitors, such as interfering with hiking along trails or otherwise detracting from the mountain experience.

6. All proposed field research and monitoring will be reviewed to determine its appropriateness, scientific and conservation value, and to ensure minimal impacts on local habitats. This review process will include measures to avoid conflict among science and stewardship activities.

7. Any proposed activity that might result in allowable impacts will be required to include a detailed mitigation plan, including measures to document and assess impacts.

8. Overnight use will be restricted to scientists, conservation professionals, educators, and students involved in Mansfield Center programs.

9. Overnight use for educational purposes will be limited to college-preparatory, undergraduate, graduate, or professional training programs. 
10. Overnight use by recreationists (e.g., hikers, skiers, mountain bikers) will not be allowed.

11. Restrictions on the level of overnight occupancy will incorporate: a limit on the number of nighttime users; a limit on the number of days this cap is reached; restrictions on the frequency of use by individuals and groups; and faculty:student ratios that ensure proper supervision of young adults.

12. Overnight users of the facility will be required to sign code of conduct agreements; violations of the terms of the agreement will be grounds for suspension of privileges for continued use of the facility.

\section{Stewardship Opportunities}

The Summit Station building is located in an area that has experienced a long history of human disturbance and landscape alteration. A large rambling hotel stood on the site for about 100 years. A 300 -foot guyed telecommunications tower was erected in the 1950s and removed in 2010. Horses, carriages, and now automobiles frequent the site via the Toll Road. Annually, tens of thousands of visitors ascend the toll road by vehicle, and another 10-20,000 people hike to the ridgeline, many passing by the Summit Station. Until very recently, controlled vehicle access was available right up to the edge of the building. Prior to these human intrusions, the area around the Summit Station likely consisted of high-elevation spruce-fir forest, rather than alpine tundra. This can be surmised by observing the type of undisturbed vegetation now found nearby, and on most of the ridgeline. Although some alpine plants are currently found growing in front of the building above the parking lot, these were experimentally translocated from tower construction sites at higher elevations on the ridgeline's Nose.

The disturbed landscape around the Summit Station offers an excellent opportunity to showcase montane forest habitat restoration, and to create a demonstration garden for alpine plants. This could provide researchers with an accessible location to study montane forest recovery, and it could educate visitors about common alpine plant species and their ecology, before they venture out onto the ridgeline. 


\section{Facilities Appendix 5. Assessment of Off-Site Lodging Options}

Discussions of alternative or supplementary lodging options have focused on two existing buildings: the Octagon Café and Gallery and the Vermont State Ski Dorm. New construction and use of commercial establishments have also been suggested. Inquiries into each alternative yielded the information summarized below. Findings are based primarily on discussions with Rob Apple (Director of Planning, Stowe Mountain Resort), Ginger Anderson (Forestry District Manager, Vermont Department of Forests Parks and Recreation, hereafter FPR), Diana Frederick (State Lands Stewardship Forester, FPR), and members of the Mansfield Center Leadership Team (see Acknowledgments), as well as on information contained in the Mount Mansfield State Forest Long-range Management Plan.

\section{The Octagon Café and Gallery}

- Located at the top of the Four-Runner Quad chairlift, the Octagon is owned and operated by the Mount Mansfield Company on land leased from the State of Vermont.

- The Octagon was built in 1940 as a warming hut for skiers. Today the building houses a cafeteria and art gallery, which are normally open during the ski season only.

- The Octagon sometimes opens during the summer and fall months at times when the gondola is not in service and the quad lift is used to provide high-elevation access to resort guests.

- The Mount Mansfield Company will not allow multiple-use or renovation of this facility due to conflicts with existing uses, liability concerns, and logistical challenges associated with coordination, monitoring, and management of non-resort use.

- The Vermont Department of Forests, Parks, and Recreation does not support expansion of the Octagon because the site has reached the limit of acceptable development.

Conclusion: The Octagon is not a viable option for overnight lodging.

The Vermont State Ski Dorm

- Located 1.2 mi from the base of the toll road in Smuggler's Notch State Park, the Vermont State Ski Dorm is owned by the State of Vermont and administered by the Department of Forests, Parks and Recreation.

- The Ski Dorm was built by the Civilian Conservation Corps in 1933 and is listed on the State Register of Historic Places. Its listing on the register does not, in itself, impose any restrictions on future uses.

- The building closed to overnight guests in 1998 because it does not meet fire safety codes for group use.

- The cost for bringing the building up to code was once estimated at over $\$ 500,000$. This figure is outdated and does not include the cost of renovation as a science, education, and stewardship facility.

- Renovation and four-season use of the Vermont Ski Dorm is consistent with the State's long-range goals for the building.

- Participants in the Mansfield Center planning survey reported low levels of interest in the Ski Dorm as a platform for science, education and stewardship, compared to the Summit Station.

- Use of the Vermont Ski Dorm as the primary site for overnight lodging would increase toll road traffic and exacerbate concerns about safety and environmental impacts (e.g., fossil fuel emissions and road noise).

- The Ski Dorm does not offer the isolation or immersive experience that would be afforded by a renovated Summit Station.

- Lack of interest in the Ski Dorm among Mansfield Center supporters and prospective users could hinder efforts to raise capital and sustain operations through lodging fees. 
Conclusion: As a stand-alone field station, the Vermont State Ski Dorm does not offer adequate support for the Mansfield Center mission. However, the building warrants further consideration as a site for overflow lodging in the future.

\section{New Construction}

- New construction in a valley location is not consistent with the Mansfield Center's guiding principles, which emphasize resource conservation and immersive research and learning experiences.

- A valley location would increase toll road traffic and exacerbate concerns about safety and environmental impacts.

- Lack of interest in a valley location is likely to hinder efforts to raise capital and sustain operations through lodging fees.

Conclusion: A new building in a valley location is not a viable option for overnight lodging.

\section{Commercial Establishments}

- $\quad$ There is one dormitory-style lodging establishment in Stowe, the Round Hearth, located 2.5 miles from the base of the toll road.

- The Round Hearth accommodates up to 125 people in bunkrooms and semi-private rooms ranging in price from $\$ 30$ to $\$ 50$ per night.

- Between spring and fall, the Round Hearth primarily serves teenage youth groups and sports camps.

- Motel and hotel lodging is available elsewhere near the mountain for $\$ 85$ per night and up, depending on the day of the week and time of year.

- Only one out of three survey respondents are willing or able to pay $\$ 30$ or more per night for lodging. Less than one in five are willing or able to pay more than $\$ 50$ per night.

- Use of commercial establishments for overnight lodging would increase toll road traffic and exacerbate concerns about safety and environmental impacts.

- Commercial establishments do not offer the isolation, community-building, or immersive experience that would be afforded by a renovated Summit Station.

Conclusion: Motel/hotel lodging may present an attractive option to a small segment of the Mansfield Center user population that can afford the higher rates, particularly senior professionals who are interested in short-term, private accommodations. The Round Hearth could play a secondary role in accommodating Mansfield Center users, especially large groups with the resources to afford the higher rates and a scope of interest that encompasses tourism and development. 
Facilities Appendix 6. Comparable Field Stations and Key Elements of Building Design

\section{Comparable Field Stations}

- Bechtel Environmental Classroom at Smith College's Ada and Archibald MacLeish Field Station (Details regarding Bechtel's Living Building Certification)

- Mount Washington Observatory

- Adirondack Visitor Interpretive Centers (SUNY-ESF's The Center for Nature Interpretation in the Adirondacks and the Paul Smith's College Visitor Interpretive Center)

- Black Rock Forest Lodge

- Rocky Mountain Biological Laboratory Community Center and Gothic Research Center

Key Elements of Building Design

- Multi-functional facility featuring efficient use of interpretive, meeting, laboratory, residential, and storage spaces

- Contained within or nearly within existing footprint

- Meets green building certification standards under Living Building Challenge or Leadership in Energy and Environmental Design programs (pending further discussion)

- Exterior design is visually compatible with natural setting

- Operable year-round

- Preference for overnight quarters on the second floor

- Reflects the expressed needs and priorities of prospective users 


\section{Part 3. Mount Mansfield Science and Stewardship Center Business Plan}

\section{Executive Summary}

\section{The Company}

The Mount Mansfield Science and Stewardship Center is an environmental research and conservation enterprise led by the University of Vermont in partnership with the Vermont Monitoring Cooperative, the Vermont Center for Ecostudies, the Vermont Department of Forests, Parks and Recreation, and Stowe Mountain Resort. These organizations plan to establish a field station in a vacant building located on the forested ridgeline of Mount Mansfield in Stowe, Vermont. Once renovated, this uniquely situated facility will create new opportunities for scientists and natural resource managers to work together and interact with visitors in a vast living laboratory. Multidisciplinary studies conducted in UVM's Mount Mansfield Natural Area (400 acres) and in the surrounding Mount Mansfield State Forest (39,837 acres) will focus on the influence of climate and other environmental variables on the ecological and social components of mountain landscapes. Findings from this work will guide land-use and environmental policy decisions.

Throughout the Northeast, research institutions, natural resource agencies, and conservation organizations are focusing attention on exceptionally vulnerable mountain ecosystems. The Mansfield Center will meet the need for safe and affordable access to high-elevation research, management, and demonstration sites. As a hub for cross-sector collaboration, the Center will spur gains in knowledge and improvements in environmental policy. By meeting a market demand and a social need, this initiative strengthens the Vermont brand of green business practice.

\section{Mission}

The Mansfield Center's mission is to catalyze collaborative science and stewardship for healthy mountains, watersheds, and communities. The foundation for this work consists of: a long-term scientific record that spans air, forest, soil, water, and wildlife; a tradition of information sharing and networking; and a commitment to science-based natural resource policy and management.

\section{Stage of Development}

This business plan has been developed with the expectation that the Summit Station on Mount Mansfield will be remodeled to function as a field station offering dormitory, laboratory, exhibit, and multipurpose meeting spaces. A study completed in 2013 affirmed the technical, legal, operational, and economic feasibility of establishing such services within the existing building (Lambert 2013). The Mansfield Center has already received conceptual support and seed funds from a number of local, state, and regional stakeholders. In addition, the National Science Foundation has awarded a research and strategic planning grant to the project's lead institution, the University of Vermont. The business plan enables project leaders to proceed with planning and partnership-building by establishing an administrative framework and financial basis for developing programs and facilities. 


\section{Services}

As the Northeast's only field station located in a montane spruce-fir forest, the Mansfield Center will offer unique, place-based opportunities for research, monitoring, education, and conservation training. In particular, the Center will provide leadership for collaborative projects, data and communication infrastructure, and shelter for lab work, lodging, meeting, educational exhibits, and equipment storage. The Center's staff and cooperators will also provide scientific information to guide personal choices, environmental policy, and natural resource management.

\section{Target Market}

The principal market consists of universities and colleges, non-governmental organizations, and government agencies that carry out and/or fund environmental research, monitoring, and management. Targets for educational services and scientific outreach include visitors to the field station, university-based field courses, and natural resource managers and environmental policy makers working in the following areas: forestry, recreation, wildlife, air and water quality, energy development, and natural areas stewardship.

\section{Marketing Strategy}

The Mansfield Center's primary marketing strategy is to build and maintain close professional relationships with research institutions, conservation organizations, and natural resource agencies in Vermont and throughout the region. In particular, the Center will initiate and support collaborative science and stewardship projects that will generate revenue from user fees and grants. The qualities that define our market position are: scientific credibility, social responsibility, and sustainable environmental practice.

\section{Competition}

The Mansfield Center will be one of just a few mountain research stations in eastern North America, and the only one with lodging and laboratory facilities located in a montane spruce-fir forest. For several decades, summit observatories in the Adirondacks (the Atmospheric Sciences Research Center) and the White Mountains (Mount Washington Observatory) have supported focused study of the atmosphere. Similarly, valley-based field stations such as the Adirondack Ecological Center and Hubbard Brook Experimental Forest have enabled rich investigations of forested mountain watersheds. But as the region's only montane-forest field station, the Mansfield Center will fill a gap in the region's mountain research infrastructure by offering ready access to high-elevation forests, wetlands, and streams, in addition to subalpine and alpine zones. Mount Mansfield's long scientific legacy, forged by UVM scholars and their partners over 170 years, further distinguishes the site from all but the most elite research platforms in the region.

\section{Management}

The Mansfield Center will operate as a program of the UVM Rubenstein School of Environment and Natural Resources, with guidance from a board of advisors. It will be administered with policies and procedures developed by program, facilities, and finance committees. A faculty director, appointed from the Rubenstein School faculty, will provide intellectual leadership and assume responsibility for planning, budgeting, fundraising, personnel management, and partner 
communications from an office on campus. A full-time assistant director will support the director in these capacities and oversee program development and delivery, daily operations, scheduling, and facilities management. The assistant director will also act as an on-site caretaker during the first full year of operation and then train a caretaker to assume this responsibility in subsequent years. A part-time data manager will also be retained to maintain an accessible data archive and facilitate information networking, in concert with the Vermont Monitoring Cooperative.

\section{Operations}

The University of Vermont will lease the existing building from the Mount Mansfield Company for a nominal fee in exchange for designing and carrying out a renovation of the structure. The remodeled facility will be open continuously from late May until the end of September. During this time, the Mansfield Center will host researchers either daily or for extended periods of time. The facility will operate on a limited, self-serve basis at other times of year, with strictly regulated access during the winter months.

\section{Financial Outlook}

The Mansfield Center will be a dynamic enterprise that generates research, stewardship, and learning opportunities. Reasonable rates will allow a broad community of scientists and conservation professionals to utilize the facility. Although user fees will not be sufficient to recover all costs, financial sustainability can be achieved by developing supplementary sources of revenue, including: grants, gifts, and lease royalties that accrue to the university from commercial broadcasters for their use of telecommunication towers located within the Mount Mansfield Natural Area (pending approval of UVM's senior leadership).

Remodeling costs, estimated at $\$ 3.7-5.1 \mathrm{M}$, will be raised from a combination of federal grants and private sources. Annual operating costs are expected to average $\$ 311 \mathrm{~K}$ during the first two years. Besides lease royalties, operating income could be provided by: a share of toll road revenue $(\$ 8.5 \mathrm{~K} / \mathrm{yr})$, institutional memberships $(\$ 15-20 \mathrm{~K} / \mathrm{yr})$, field course and user fees $(\$ 28.5-$ $53 \mathrm{~K} / \mathrm{yr})$, special event income $(\$ 30-35 \mathrm{~K} / \mathrm{yr})$, endowment income $(11-22 \mathrm{~K} / \mathrm{yr})$, and grants and gifts $(\$ 25-100 \mathrm{~K} / \mathrm{yr})$. Enthusiasm for the Mansfield Center concept is growing rapidly among prospective users, granting agencies, and donors. This excitement is expected to translate into a strong capital campaign and a smooth transition to financially secure operations.

\section{Long-Term Goals}

The Mansfield Center intends to maintain steady growth in programs, services, and usage rates and to become a leader in the emerging, international network of mountain research stations. We do not foresee expansion to any other location, although several valley venues present opportunities to serve higher-volume audiences off-site.

\section{Company Description}

The Mount Mansfield Science and Stewardship Center will be an environmental research and conservation facility located on the forested ridgeline of Mount Mansfield, Vermont. The Mansfield Center's scientific program will include multidisciplinary investigations of the treeless alpine zone, subalpine and montane forests, and surrounding areas. Findings from this work will guide efforts to sustain the state's most valued resource, the natural environment. Benefits will extend to the Vermont community and beyond. 


\section{Background}

The Mansfield Center will occupy the Summit Station, a mostly vacant, 1.5-story building situated approximately $1 \mathrm{mi}$ south of the highest summit in Vermont at the terminus of the Mount Mansfield Toll Road (elevation 3,850 feet). Approximately 40,000 people visit the ridgeline each year, on foot and in vehicles. The building is 2,560 square feet, providing space to accommodate users with bathrooms, a kitchen, bunkrooms, wet and dry laboratories, a multipurpose field lab/meeting space, and interpretive exhibits. The facility will primarily serve scientists and natural resource professionals by providing workspace, safe lodging, and proximity to high-elevation study and stewardship sites. The exhibits and multipurpose room will also serve public outreach and educational functions. The bulk of the facility's use will occur from mid-spring until mid-fall, with peak usage in the summer.

This business plan is contingent on the complete renovation and fit-up of the existing structure on the site, which was a former telecommunications and electronics facility supporting media broadcasting in Vermont. The building is owned by the Mount Mansfield Company, which operates Stowe Mountain Resort. The Mount Mansfield Company has agreed to lease the building to the Mansfield Center for the purpose of renovating and operating the building as a field station.

\section{Founding Partners}

The Mansfield Center represents a collaboration of multiple partners, including:

- The University of Vermont

- The Vermont Monitoring Cooperative

- The Vermont Center for Ecostudies

- The Mount Mansfield Company

- The Vermont Department of Forests, Parks and Recreation

\section{Mission}

The Mansfield Center's mission is to catalyze collaborative science and stewardship for healthy mountains, watersheds, and communities. The foundation for this work consists of: a long-term scientific record that spans air, forest, soil, water, and wildlife; a tradition of information sharing and networking; and a commitment to science-based natural resource policy and management.

\section{Vision}

The Mansfield Center will be:

- A community of scholars, educators, and natural resource managers engaged in transformational science and stewardship from a state-of-the-art facility in the heart of the Green Mountains.

- A dynamic hub of inquiry and education, where the Center's cooperators and visitors interact and learn from one another in a living laboratory.

- A home for programs that foster a deeper understanding of high-elevation ecology and sustain the vitality of ecosystems on Mount Mansfield and throughout the bioregion. 
Goals

- Build knowledge of mountain ecosystems and changes affecting mountain flora and fauna.

- Advance understanding of relationships among mountains, streams, and lakes.

- Provide place-based education and outreach on mountain ecology, conservation issues, and stewardship.

- Develop, implement, and demonstrate management actions that lead to improved conservation of mountain environments.

- Provide a platform for scholarship and instruction in fields that address social dimensions of mountain environments, such as engineering, human health, economics, education, and the humanities.

- Foster connections among UVM schools and programs and between the University and the Vermont State College system.

\section{Services: A Platform for Research and Monitoring}

The Mansfield Center will serve as a headquarters for high-elevation research in Vermont. The Center will house wet and dry labs, allowing scientists to conduct on-site analysis of the mountain environment. In addition, the Center will maintain meteorological instruments and other environmental sensors to enhance ecosystem monitoring and research, which began in 1955 with a continuous record of weather conditions at the nearby commercial broadcast facility. In addition, bunkrooms will contain up to 20 beds to accommodate researchers, students, and stewards of the forest and trails. This will allow them to conduct fieldwork early in the morning, late in the evening, overnight, and for several days at a time while avoiding the safety risk, environmental impact, and cost (in time and funds) associated with repeated travel to the mountain and up and down the toll road. The projected number of beds may be subject to change, pending negotiation among stakeholders who hold different views on the appropriate level of overnight use.

\section{Services: Place-based Education and Outreach}

The Mansfield Center will enable hands-on educational and training experiences for a variety of groups, providing efficient and affordable access to a vast outdoor classroom. The building will include a multipurpose space to serve undergraduate or graduate-level field courses, training of field crews, and seminars and meetings among partnering organizations. Inside the main entrance, exhibits will present information about the high-elevation flora, fauna, weather, and research and management activities.

Field demonstrations will showcase science and stewardship activities on the mountain, including VMC's long-term monitoring projects. The indoor and outdoor venues will be open to visitors, including school and camp groups. The Mansfield Center will advise all visitors on group-size limits to avoid adverse environmental impacts. The scientists and stewards who are most active with The Mansfield Center will be encouraged to promote its educational objectives by offering information about their work in the form of materials, demonstrations, and casual interaction with visitors. Eventually, outreach programs may be made available to schools, camps, and/or community groups. 


\section{Daytime Visitors}

Because it is located on property of the Stowe Mountain Resort and on the path of the Long Trail, the Mansfield Center will attract a diverse group of daytime visitors.

- Resort visitors via the toll road or gondola

- Hikers via the Long Trail or other foot paths

- Field trips from school, camp, or other youth groups

- Visitors to nearby state parks and forests

- Local residents

- College classes and clubs (undergraduate and graduate)

\section{Overnight Users}

The Mansfield Center is expected to attract overnight use by the following groups.

- State and federal natural resource agencies

- Non-governmental research institutions

- University students, staff, faculty, and researchers

- Mountain stewards (including staff of the Vermont Agency of Natural Resources, UVM Natural Areas Center, etc.)

- Independent scientists

\section{Technical Feasibility}

A study completed in 2013 assessed the feasibility of remodeling the vacant structure to function as a field station. It determined that the building's electrical power and water supply systems are adequate to meet the operational requirements of a field station. The report also included a schematic plan to pipe wastewater through sewer lines that would be buried beneath the roadway and connected to the municipal sewer line at the Octagon Café and Gallery, a Stowe Mountain Resort facility located about one-half mile from the proposed field station.

\section{Ownership and Revenue}

The Summit Station and its immediate surroundings are owned by the Mount Mansfield Company, which operates Stowe Mountain Resort. The Mount Mansfield Company has agreed to make a long-term lease available to the Mansfield Center. An overnight fee will be charged to researchers that spend the night in the field station. Visiting field courses will also be charged a fee for services provided by the Mansfield Center. These forms of income will offset operational costs, however much of the funding for work conducted at the Center will originate from grants, gifts, and natural area lease royalties.

\section{Industry Analysis}

\section{Industry Description}

Although it is envisioned as a dynamic business combining research, stewardship and education, the Mansfield Center falls primarily within the field station industry. This service-based industry includes field stations, research stations, visitor centers, and marine laboratories. The focus of the industry is on place-based fieldwork. Often, a service-learning component is offered as part of the research experience. Along with professional research (public or private), field stations host academic leaders and students from both undergraduate and graduate programs. Models of 
success in this industry provide access to remote and/or representative locations with welcoming infrastructure and cutting-edge technology that foster innovative, multi-disciplinary research. Field stations cultivate a learning community that contributes new ideas and concepts to the world, particularly when they afford varied opportunities for observational and experimental study.

Many scientists and lead researchers have documented the importance of growth in the field station industry. In particular, The National Science Foundation Committee of Visitors for the Division of Biological Infrastructure has championed funding for infrastructure upgrades and long-term maintenance. Field stations are valuable to research institutions because they "are flexible, cost effective, and allow scientists to observe environmental processes that occur on a staggering range of spatial and temporal scales" (OBFS 2007). Field stations provide organizations with valuable facilities to conduct a wide variety of science and stewardship activities at reasonable expense.

As universities and government institutions expand into the field of climate science, field stations will be "a critical part of the infrastructure the nation needs to address a wide range of environmental issues" (OBFS 2007). Field stations provide research and service opportunities to undergraduates, which enable universities to attract prospective students (Table 1). While undergraduate research is widely implemented at universities around the United States, there is room still for expansion, as rates of enrollment and focus on service and place-based learning in higher education has increased.

Table 1. Opportunities for undergraduates at field stations and marine laboratories (FSMLs), based on a survey of 88 different facilities located throughout the United States (OBFS 2007).

\begin{tabular}{|lc|}
\hline $\begin{array}{l}\text { Undergraduate } \\
\text { opportunity }\end{array}$ & $\begin{array}{c}\text { Percentage of } \\
\text { FSMLs ( } \boldsymbol{n}=\mathbf{8 8})\end{array}$ \\
\hline Formal courses for freshman/sophomores & 41 \\
Formal courses for Junlors/senlors & 65 \\
National Sclence Foundation Research & 21 \\
Experlences for Undergraduates (REU) & \\
site program & 33 \\
REU experlence with Indlividual Investigators & 72 \\
Other research experience opportunitles & 61 \\
Jolnt research and service Internships & 22 \\
Service-only Internshlps & \\
\hline
\end{tabular}

\section{Strategic Opportunity}

Mount Mansfield has a long history of research, monitoring, and stewardship, which has resulted in an extensive body of knowledge and a tradition of cooperative enterprise. The Vermont Monitoring Cooperative, which has facilitated collaborative science on Mount Mansfield since 1990, has built a solid foundation for continuing research and stewardship at the Mansfield Center. Because it is the highest peak in Vermont with relatively large areas of sensitive alpine tundra and montane forest, Mount Mansfield presents an excellent location for research into the 
effects of climate change, acidification, mercury contamination, recreation, and other environmental stressors. Its value as a field site is enhanced by: an extensive road/trail network; pronounced topographic and climatic gradients; and a combination of stewardship practices that include forestry, various forms of commercial recreation, and the preservation of natural areas.

The most apparent and widely accepted strategic opportunity for field stations is to provide facilities and services for a variety of institutional uses. Since the Mansfield Center will be equipped to serve climate change research, it will also be a resource for scientists and educators working in a number of related concentrations, such as "earth and atmospheric sciences, botany, zoology, chemistry, and interdisciplinary fields such as ecology and biogeochemistry" (OBFS 2007). By emphasizing human dimensions and stewardship applications of science, the Mansfield Center will capitalize on the growing investment in socio-ecological research. This approach will accommodate all of the traditional field station offerings (Table 2), as well as new and upcoming forms of social, biological, and climate science.

Table 2. Availability of traditional course offerings at 88 field stations and marine laboratories and a comparison with their availability on main campuses (OBFS 2007).

\begin{tabular}{|lcc|}
\hline Course & $\begin{array}{c}\text { Number of FSMLs } \\
\text { offering the course }\end{array}$ & $\begin{array}{c}\text { Number of courses } \\
\text { taught at the main campus } \\
\text { associated with the FSML }\end{array}$ \\
\hline Botany & 15 & 12 \\
Herptology & 6 & 5 \\
Ichtryology & 18 & 12 \\
Insect blology & 9 & 4 \\
Invertebrate zoology & 23 & 12 \\
Mammalogy & 14 & 6 \\
Omithology & 14 & 8 \\
\hline
\end{tabular}

The Summit Station occupies a prime location for public exposure at the intersection of the Long Trail and Mount Mansfield Toll Road, popular attractions that see a high volume of traffic each year. Its renovation presents financial and permitting advantages over the construction of a new building. Because current environmental regulations make it difficult to construct at high elevation in Vermont and elsewhere in the region, competitors are unlikely to enter the market in the foreseeable future. This gives The Mansfield Center the opportunity to compete in a market that is difficult to enter and where nothing comparable exists. 


\section{Target Market}

\section{Market Description}

The Mount Mansfield Science and Stewardship Center primarily targets universities and colleges, non-governmental organizations (NGOs), and state agencies that have funding for major research endeavors or classes. In allocating these funds, they seek places with the facilities and location that will advance their work. The Mansfield Center will provide the infrastructure and tools necessary to attract individuals and institutions focused on filling gaps in knowledge of mountain ecosystems. Visitors and residents of the surrounding Chittenden and Lamoille counties represent a secondary market, particularly those interested in learning more about the dynamics and management of mountain ecosystems.

\section{Market Size and Trends}

In recent years, research and development (R\&D) has been increasing in the United States. The National Science Foundation (NSF) estimated the country's total 2012 expenditure on R\&D at $\$ 452.6$ billion, up over $\$ 50$ billion since 2007 . The NSF also stated that after accounting for inflation, R\&D grew at a faster rate than the gross domestic product (GDP) in 2011. While universities, government agencies, and NGOs account for $30 \%$ of the total performing sector of US research and development, the majority of research and development is funded by businesses. Still, in 2012, the federal government conducted $\$ 53.5$ billion of R\&D; universities and colleges performed $\$ 62.5$ billion of $R \& D$; and non-profit organizations are estimated to have performed \$18.1 billion of R\&D (Bororush 2013).

The establishment of new universities has grown at a steady rate over the past 14 years. In 2000, there were 2,363 four-year colleges, and in 2009 the number grew to 2,774 (US Department of Education as cited in Gonzales et al. 2013). Research is fundamental to colleges and universities, which are experiencing growth in graduate student enrollment. In the fall term in 2012, more than 461,000 students enrolled for the first time in graduate certificate, education specialist, master's, or doctoral programs at the institutions responding to the CGS/GRE Survey of Graduate Enrollment and Degrees. Between fall 2011 and fall 2012, first-time enrollment to graduate programs grew $1.8 \%$, extending the steady growth rate of first-time graduate enrollment that has been observed since the fall of 2002 (Gonzales et al. 2013). This suggests that there is a large potential market for facilities that serve graduate programs.

Vermont welcomes 13.7 million visitors to the state each year, with summer being the most popular season at 5.1 million visitors. Vermont's visitors primarily come from areas within 300 miles of Vermont, including the northeastern United States and the Canadian provinces of Quebec and Ontario (Cook 2012). An estimated 40,000 visitors reach the upper elevations of Mount Mansfield each year. The Mansfield Center will feature exhibit space to educate these visitors.

\section{Target Customers}

The Mansfield Center will serve two distinct markets: one that will utilize the research facilities and a second that will utilize the interpretive exhibits. Initially, the principal target market for the laboratory, meeting, and lodging services will be comprised of Vermont-based scientists and 
stewards representing educational institutions, government agencies, and NGOs. Some examples are provided below.

\section{Vermont Universities and Colleges}

1. University of Vermont Rubenstein School for the Environment and Natural Resources (Environmental Science, Forestry, Natural Resources, Parks, Recreation and Tourism, and Wildlife and Fisheries Biology majors)

2. Saint Michael's College (Biology, Biochemistry, and Geology majors)

3. Vermont State Colleges

a. Johnson State College (Field Naturalist Biology, Natural Resources, Integrated Environmental Science, and Outdoor Education majors)

b. Lyndon State College (Meteorology, Mountain Recreation Management, and Natural Sciences majors)

c. Castleton State College (Biology, Environmental Science, and Natural Sciences majors)

4. Norwich University (Biology, Environmental Science, and Geology majors)

5. Middlebury College (Biology, Biochemistry, and Geology majors)

6. Green Mountain College (Adventure Education, Biology, and Natural Resource Management majors)

Vermont State Government

- Vermont Fish and Wildlife Department

- Vermont Department of Forests, Parks and Recreation

- Vermont Department of Environmental Conservation

Non-governmental Organizations

- Vermont Center for Ecostudies

- Green Mountain Club

- Audubon Vermont

As the Mansfield Center becomes more established, there is room for expansion of the target market to other New England states, New York, and Canada. For example, in the surrounding New England states there are many large universities and colleges such as, University of New Hampshire, University of Massachusetts, Boston University, Yale, Brown, and Dartmouth College. McGill University is located in Montreal, only about a 2.5 hour drive away from Mount Mansfield. Finally, New York is home to many large research institutions, including Cornell University, Syracuse University, and the State Universities of New York.

An expanded target market could also include regional, national, and international organizations and agencies such as:

- The School for Field Studies

- The Center for Biological Diversity

- The Wildlife Conservation Society

- National Audubon Society

- The US Forest Service 
- The US Fish and Wildlife Service

- The National Oceanographic and Atmospheric Administration

- The Environmental Protection Agency

The Mansfield Center's educational displays and interactive exhibits will serve a second distinct market, comprised of day visitors, including families with children, who are looking to learn more about the Mount Mansfield ecosystem. Although the exhibit area will be open at no charge to all visitors to the ridgeline, it will not be marketed as a destination for Vermont tourists.

\section{Analysis of Competition}

\section{Competitive Environment}

The Mount Mansfield Science and Stewardship Center will be one of the few mountain research stations located in eastern North America, and the only one with lodging and laboratory facilities situated in a montane spruce-fir forest. The closest mountain science facility is the Mount Washington Observatory, located in New Hampshire. Perched high above treeline, this observatory functions primarily as a meteorological and educational center. The State University of New York at Albany operates the Atmospheric Sciences Research Center (ASRC) on Whiteface Mountain, another mountaintop facility focused primarily on the chemical and physical properties of the atmosphere. Although the ASRC does not offer overnight accommodations or laboratory space to visitors, these are available at the Marble Mountain Lodge, a companion facility located six miles away, near the base of the mountain at an elevation of $1,980 \mathrm{ft}$.

In the northern Adirondacks, the State University of New York College of Environmental Science and Forestry (ESF) operates the Adirondack Ecological Center on ESF's Huntington Wildlife Forest, which ranges between 1,500 ft and 2,700 ft in elevation. This full-service field station supports dozens of monitoring and research programs with housing, dining, and instructional facilities. A similar set of services is available at the Hubbard Brook Experimental Forest, located in New Hampshire's White Mountain National Forest. Like the Huntington Wildlife Forest, Hubbard Brook is an active hub of place-based science and education with infrastructure concentrated at the lower reaches of a mountain watershed.

These stations offer excellent models and collaborative opportunities for the Mansfield Center. However, no other facility in the Northeast offers visiting scientists and students ready access to high-elevation forest and alpine communities. Region-wide restrictions on building at high elevations ensure that the Mansfield Center will remain unique among mountain research and monitoring facilities in eastern North America.

Many northern Vermont sites offer educational exhibits that focus on the environment, including the Barnes Camp Visitor Center (Stowe), the Green Mountain Club Visitor Center (Waterbury Center), and the ECHO Center (Burlington). At the base of Mount Mansfield, UVM operates the Proctor Maple Research Center (Underhill) and the Forest E. Orr Conservation Center, a small classroom building located in the Jericho Research Forest. The proximity of these facilities presents additional collaborative possibilities, as their missions are complementary to that of The Mansfield Center. 


\section{Strengths}

The Mansfield Center will provide an exceptional opportunity for scientists and students to conduct onsite observation and analysis from state-of-the-art facilities located at an elevation of 3,850 feet. As a hub for investigators and natural resource managers, the Mansfield Center program and facility will promote exchanges between science and stewardship that are needed to address contemporary environmental challenges. The location at the top of a popular mountain toll road ensures a steady flow of visitors throughout the summer and early fall. The Mansfield Center is conveniently located an hour from the Montpelier headquarters of the Vermont Agency of Natural Resources and about the same distance from Burlington, home to the University of Vermont, Champlain College, and Saint Michael's College. It is less than an hour from Johnson State College (Johnson) and the central office of the Green Mountain Club (Waterbury Center). The Mansfield Center is only 3.5 hours from Boston and 5.5 hours from New York City. This coupled with its close proximity to both the Burlington International Airport and Essex Junction Train Station make it an easy destination for visiting scientists, natural resource professionals, and recreational visitors.

\section{Marketing Plan}

\section{Market Position and Branding}

The Mansfield Center will be known as a unique mountain research, monitoring, and conservation facility. Through mission-driven work, we will build an identity that combines scientific credibility with service to the environment and society.

\section{Public Relations}

The primary target for marketing the Mansfield Center will be colleges and universities in New England. The director and assistant director will be charged with recruiting faculty and graduate students who are engaged in the study of mountain environments through personal outreach, mailings, posters, and promotion of the Mansfield Center at professional meetings and workshops. We also plan to attract government and non-government researchers to the facility through the same avenues. The Mansfield Center aims to create a strong network of institutions that will operate within a unifying science and stewardship framework. Building a community of collaborators will help ensure that scientists and stewards make use of the field station's services season after season.

\section{Strategic Partnerships}

Active participation in regional research and data networks and the Organization of Biological Field Stations will allow potential users from around the region and around the world to discover and learn about the Mansfield Center through online portals such as the OBFS "field station finder".

\section{Online Marketing}

The Mansfield Center will maintain and regularly update an appealing and informative website to support the operation's mission. The website will be updated regularly with reports on the research, monitoring, and stewardship activities that are underway. 


\section{Internal Strengths and Limitations}

The following summaries of internal and external factors is excerpted from "The Mount Mansfield Science and Stewardship Center Feasibility Study" (Lambert 2013).

\begin{tabular}{|c|c|c|}
\hline 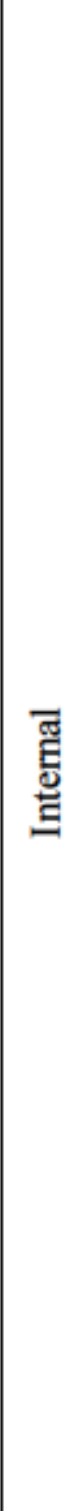 & $\begin{array}{l}\text { Strengths / Assets } \\
\text { - Collaborating institutions have united } \\
\text { behind a compelling vision, goals, and } \\
\text { guiding principles. } \\
\text { - Cooperators have already helped build a } \\
\text { legacy of science and stewardship on } \\
\text { Mount Mansfield (e.g., Vermont } \\
\text { Monitoring Cooperative, Summit } \\
\text { Caretakers program, etc.). } \\
\text { - The tradition of joint enterprise and the } \\
\text { resulting data sets position cooperators to } \\
\text { address the major science questions of } \\
\text { today and the future. } \\
\text { - Partnering organizations have statewide } \\
\text { and regional stature among broad and } \\
\text { complementary constituencies. } \\
\text { - The Summit Station affords spacious } \\
\text { shelter while the mountain's roads and } \\
\text { trails facilitate access to a vast living } \\
\text { laboratory. } \\
\text { - The prominent and majestic location } \\
\text { opresents an attractive sponsorship } \\
\text { donors. }\end{array}$ & $\begin{array}{l}\text { Limitations / Needs } \\
\text { - Cooperators currently lack the excess } \\
\text { staffing to implement the proposal, } \\
\text { requiring reallocation of duties and/or new } \\
\text { personnel. } \\
\text { - Involvement of multiple institutions, each } \\
\text { with unique administrative systems and } \\
\text { practices, presents communication and } \\
\text { execution challenges that call for effective } \\
\text { and coordinated governance. } \\
\text { - Although the broadly representative } \\
\text { steering committee satisfies administrative } \\
\text { needs during the planning phase, } \\
\text { implementation will require a refined or } \\
\text { modified approach to governance. } \\
\text { - Cooperators hold somewhat differing } \\
\text { perspectives on the desirable level of } \\
\text { overnight use of the proposed Mansfield } \\
\text { Center. }\end{array}$ \\
\hline
\end{tabular}




\section{External Opportunities and Challenges}

\begin{tabular}{|c|c|c|}
\hline 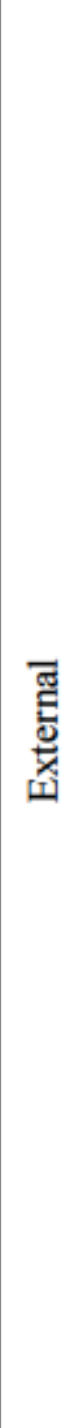 & $\begin{array}{l}\text { Opportunities } \\
\text { - The National Science Foundation and } \\
\text { other public agencies support basic, } \\
\text { applied, and interdisciplinary research in } \\
\text { the many scientific fields that pertain to } \\
\text { mountain ecosystems. } \\
\text { - The proposed facility meets scientific } \\
\text { and societal needs identified in studies } \\
\text { sponsored by the National Science } \\
\text { Foundation. } \\
\text { - Economic and philanthropic trends } \\
\text { create favorable and improving } \\
\text { conditions for soliciting private support, } \\
\text { especially from the corporate sector. } \\
\text { - Several academic institutions and } \\
\text { conservation organizations wish to } \\
\text { participate in a northeastern network of } \\
\text { mountain field stations, presenting a } \\
\text { range of partnership opportunities. } \\
\text { - Cooperators can learn from a variety of } \\
\text { existing models demonstrating } \\
\text { collaborative, site-based science and } \\
\text { stewardship. }\end{array}$ & $\begin{array}{l}\text { Challenges / Needs } \\
\text { - The Summit Station is in need of major } \\
\text { renovation and system upgrades. } \\
\text { - Its location presents a set of unique but } \\
\text { manageable engineering and regulatory } \\
\text { challenges. } \\
\text { - Cooperators need to choose a focused line } \\
\text { of inquiry that will guide the development } \\
\text { of the Mansfield Center's founding science } \\
\text { and stewardship programs. } \\
\text { - Business and capital campaign plans are } \\
\text { needed to complete the assessment of } \\
\text { economic feasibility. } \\
\text { - Realizing programmatic and capital } \\
\text { objectives will require significant financial } \\
\text { support and a plan to sustain operations. }\end{array}$ \\
\hline
\end{tabular}

\section{Management and Sustainability}

\section{Management and Personnel}

The Mansfield Center will operate as a program of the Rubenstein School of Environment and Natural Resources, with guidance provided by a board of advisors. It will be administered with policies and procedures developed by program, facilities, and finance committees. The following organizations will be offered permanent positions on one or more of these committees: the UVM Colleges of Agriculture and Life Sciences, Arts and Sciences, Engineering and Mathematical Sciences, the Vermont State College System, the Vermont Monitoring Cooperative, the Vermont Department of Forests, Parks and Recreation, the Vermont Department of Fish and Wildlife, the Vermont Center for Ecostudies, and the Green Mountain Club. 
A faculty director, appointed from the Rubenstein School faculty, will provide intellectual leadership and assume responsibility for planning, budgeting, fundraising, personnel management, and partner communications from an office on campus. A full-time assistant director will support the director in these capacities and oversee program development and delivery, daily operations, scheduling, and facilities management. The assistant director will also act as an on-site caretaker during the first full year of operation and then train a caretaker to assume this responsibility in future years. A part-time data manager will also be retained to maintain an accessible data archive and facilitate information networking, in concert with the Vermont Monitoring Cooperative. The Mansfield Center will also recruit and engage interns and volunteers to help with environmental interpretation, facility maintenance, and research, monitoring, and stewardship assistance. The director will evaluate staffing levels and performance each year in order to maintain efficient and cost-effective operation. The Mansfield Center will provide professional development and mentoring support, as needed, to its yearround and seasonal staff.

\section{Environmental Sustainability}

Opposition to this project may arise from the perception that an increased human presence on the ridgeline will negatively affect the environment or the experience of "wildness". However, operating a field station with best environmental practices poses no threat to the setting, which has already been significantly modified by buildings, towers, trails, portable toilets, a parking area, a road, ditches, etc. In fact, a fundamental objective of the Mansfield Center is to develop and demonstrate protective and restorative stewardship practices on site. Therefore, the current effects of tourism on the mountain ecosystem will be managed responsibly and mitigated as opportunities arise. The Mansfield Center will help to reduce impacts of tourism by: a) enabling scientists to assess the status, vulnerability, and resilience of ecosystem elements and processes;

b) delivering science-based conservation messages in educational exhibits; and c) integrating new knowledge into decisions related to mountain resource management and policy.

\section{Financial Sustainability}

The Mansfield Center will use a variety of approaches to ensure financial viability over the long term. Examples include:

- offering customizable scheduling and fee packages;

- including infrastructure costs explicitly in all grants and contracts;

- engaging the user community at all levels to maintain an understanding of and responsiveness to user needs;

- building relationships with partner institutions and state governments to ensure that service offerings stay relevant;

- reaching out to government agencies and other consumers of science and stewardship services for help justifying the importance of Mansfield Center programs; and

- initiating capital and endowment campaigns to meet infrastructure and long-term operational funding requirements, respectively. 


\section{Operations}

\section{Building Location and Lease}

The Summit Station is a concrete block structure that measures $64 \mathrm{ft}$ by $40 \mathrm{ft}$. The Mount Mansfield Company owns the vacant building and has agreed, in principle, to make a long-term, low-cost lease available to UVM if the university finances its renovation.

\section{Improvements and Upkeep}

The building will be remodeled and fully functional for year-round use, with the bulk of activities expected to take place between May and October. Terms of maintenance will be established by the lease agreement. Users of the facility will participate in day-to-day upkeep and cleaning. The seasonal caretaker will provide supplemental maintenance and custodial services, as needed.

\section{Utilities}

Electricity will be provided by Green Mountain Power. Water will come from a storage tank fed by an existing well, whose yield may not be sufficient to meet peak demand or fire safety standards without storage. Alternatively, water will be supplied by hook-up to a municipal water supply located 0.4 mi down the toll road at Stowe Mountain Resort's Octagon Café and Gallery. Plans for disposing of wastewater through a municipal sewer link at this same site are described in the facilities and infrastructure plan. Renovation of the building will take measures to improve energy efficiency and provide high-speed Internet capability.

\section{Inventory Control}

All lab equipment, field equipment, tools, and appliances will be secured, catalogued, and inventoried at regular intervals. No excess inventory will be kept on the premises.

\section{Purchasing and Customer Service}

The Mansfield Center director will be responsible for major purchasing decisions and will adhere to an annual financial plan and UVM policies and procedures. Minor purchases and researcher requests will be managed by the assistant director and seasonal caretaker. Supplies will be purchased from a reputable source or accepted by donation from third parties. The assistant director will oversee reservations and customer service during the off-season. These responsibilities will be shared by the seasonal caretaker while s/he is in residence at the station.

\section{Theft and Damage}

To minimize the risk of theft and damage to the facility or its equipment, overnight or regular users of the building may be required to submit a refundable security deposit.

\section{Health and Safety}

The Mansfield Center will place a strong emphasis on safety in its lab space, living quarters, and field operations. The facility will be outfitted with first aid, lab safety, and mountain rescue equipment that could be needed to respond to emergencies. The seasonal caretaker will receive 
health and safety training on an annual basis and meet minimum certification requirements in first aid.

\section{Operational Contingency}

A backup generator will be stored onsite in the event of an emergency. Emergency procedures will be documented and available throughout the facility. First-time users of the facility will be asked to view an orientation video, either prior to arrival or after arriving on site.

\section{Development and Milestones}

\section{Stage of Development}

The Mount Mansfield Science and Stewardship Center has been the subject of extensive deliberation and planning since 2012. The partnering institutions have produced a vision and prospectus (Paradis et al. 2012), conducted a feasibility study (Lambert 2013), and organized two planning workshops (Pontius et al. 2015). A survey of prospective users that was completed at the end of 2015 has recently informed the development of program and facilities plans, each currently under review. Vetting and further development of the business plan will position the Mansfield Center cooperators to engage new partners and initiate a capital campaign.

The Northeast Mountain Science Conference, to be held in April 2016, will bring collaborators together from throughout the region to identify priority information needs, develop the station's research plan, and initiate work on one or more multi-disciplinary project proposals. In conjunction with this meeting, the UVM will host a review of the Mansfield Center initiative by the Organization of Biological Field Stations. Recommendations from the review team will be incorporated into a five-year strategic plan and into a formal proposal to the UVM provost and president.

\section{Rate Changes and Expansion}

The Mansfield Center will seek to achieve seasonal occupancy rates of $85-90 \%$ before adjusting user fees. Though we would prefer to attract researchers with rates below the industry average, it would be difficult to raise prices if they were discounted at the outset. Rates will be set at levels consistent with other northeastern field stations that provide similar field access and amenities.

We do not foresee physical expansion beyond the building's remodeled footprint or expansion to any other location. However, we may take advantage of low-elevation venues in order to serve large groups off-site. Examples include the Smuggler's Notch Visitor Center, located $0.5 \mathrm{mi}$ from the Mount Mansfield toll road, and the privately operated Round Hearth at Stowe, which offers dormitory-style accommodations 2.6 miles from the mountain. If the Vermont Department of Forests, Parks and Recreation achieves its goal of renovating the Vermont State Ski Dorm, this could provide additional lodging capacity just 0.2 miles from the toll road.

\section{Long-Term Goals}

The Mansfield Center intends to maintain steady growth in programs and services in order to build the station's market position and usage rates over the first five years. Once close user relationships have been established in the regional market, the Mansfield Center will be able to expand the geographic scope of its target market to include research institutions outside of the 
region. However, The Mansfield Center will continuously serve educational institutions based in Vermont by offering a living laboratory for science, recreation, and natural resource management courses that include a field component.

Within the next decade, the Mansfield Center aims to become a nationally recognized hub for mountain science and stewardship and a leader in the emerging, international network of mountain observatories. Another goal is to bring new work conducted on Mount Mansfield to the forefront of climate studies and environmental decision-making.

\section{Financial Analysis}

The income and expense projections summarized in Table 3 account for planning and fundraising in year one, program development and renovation in year two, and full operation in years three through five. Itemized financials for each year are included in Business Appendix 1.

\section{Assumptions}

1. A capital campaign will raise funds sufficient to complete renovation of the building.

2. The Mount Mansfield Company will charge a nominal fee to lease the remodeled building.

3. The renovated facility will accommodate at least 12 and no more than 20 overnight guests at one time.

4. Overnight use in the first season will average 156 user nights per month between May and September and rise to an average of 280 user nights per month during the same period by the third year of operation.

5. The per-person user fee will depend on the individual's affiliation and length of stay, but will average \$25/night.

Table 3. A five-year summary of projected revenue and expenditures

\begin{tabular}{|c|c|c|c|c|c|}
\hline & \multicolumn{3}{|c|}{ Development and Construction } & \multicolumn{2}{|c|}{ Operation } \\
\hline Revenues & Year 1 & Year 2 & Year 3 & Year 4 & Year 5 \\
\hline Institutional Memberships & $\$ 0$ & \$o & SO & $\$ 15,000$ & $\$ 20,000$ \\
\hline Special Events & $\$ 0$ & So & $\$ 30,000$ & $\$ 30,000$ & $\$ 35,000$ \\
\hline Toll Road Surcharge & $\$ 0$ & \$o & So & $\$ 8,500$ & $\$ 8,500$ \\
\hline Field Course Fees & $\$ 0$ & So & So & $\$ 7,500$ & $\$ 15,000$ \\
\hline User Fees & $\$ 0$ & \$0 & So & $\$ 21,000$ & $\$ 38,000$ \\
\hline Grants and Gifts & $\$ 25,000$ & $\$ 25,000$ & $\$ 85,000$ & $\$ 85,000$ & $\$ 100,000$ \\
\hline Lease Royalties & $\$ 27,500$ & $\$ 27,500$ & $\$ 90,000$ & $\$ 95,000$ & $\$ 100,000$ \\
\hline Endowment & $\$ 0$ & So & $\$ 11,000$ & $\$ 22,000$ & $\$ 22,000$ \\
\hline Total & $\$ 52,500$ & $\$ 52,500$ & $\$ 216,000$ & $\$ 284,000$ & $\$ 338,500$ \\
\hline \multicolumn{6}{|l|}{ Expenses } \\
\hline Salaries and Benefits & $\$ 46,475$ & $\$ 46,475$ & $\$ 194,444$ & $\$ 206,513$ & $\$ 250,127$ \\
\hline Utilities and Maintenance & $\$ 0$ & \$0 & SO & $\$ 35,637$ & $\$ 43,932$ \\
\hline Other & $\$ 4,595$ & $\$ 4,595$ & $\$ 10,215$ & $\$ 31,070$ & $\$ 42,750$ \\
\hline Total & $\$ 51,070$ & $\$ 51,070$ & $\$ 204,659$ & $\$ 273,220$ & $\$ 336,808$ \\
\hline Balance & $\$ 1,430$ & $\$ 1,430$ & $\$ 11,341$ & $\$ 10,780$ & $\$ 1,691$ \\
\hline
\end{tabular}




\section{Outlook}

The Mansfield Center will offer reasonable rates to allow a broad community of scientists and conservation professionals to utilize the facility. Although user fees will not be sufficient to recover all costs, financial sustainability can be achieved by developing supplementary sources of revenue, including: grants, gifts, and lease royalties that accrue to the university from commercial broadcasters for their use of telecommunication towers located within the Mount Mansfield Natural Area (pending approval of UVM's senior leadership).

Remodeling costs, estimated at $\$ 3.7-5.1 \mathrm{M}$, will be raised from a combination of federal grants and private sources. Annual operating costs are expected to average $\$ 311 \mathrm{~K}$ during the first two years. Besides lease royalties, operating income could be provided by: a share of toll road revenue $(\$ 8.5 \mathrm{~K} / \mathrm{yr})$, institutional memberships $(\$ 15-20 \mathrm{~K} / \mathrm{yr})$, field course and user fees $(\$ 28.5-$ $53 \mathrm{~K} / \mathrm{yr})$, special event income $(\$ 30-35 \mathrm{~K} / \mathrm{yr})$, endowment income $(11-22 \mathrm{~K} / \mathrm{yr})$, and grants and gifts $(\$ 25-100 \mathrm{~K} / \mathrm{yr})$. Enthusiasm for the Mansfield Center concept is growing rapidly among prospective users, granting agencies, and donors. This excitement is expected to translate into a strong capital campaign and a smooth transition to financially secure operations.

\section{Measuring Performance and Impact}

Mansfield Center staff and committee members will use a variety of metrics to measure the enterprise's performance and impact at intervals of one to five years.

Table 4. Metrics for measuring program performance and impact.

\begin{tabular}{|l|l|}
\hline Program & Metric \\
\hline \multirow{4}{*}{ Science and Stewardship } & Number of publications and their citation impact factors \\
\cline { 2 - 2 } & Number of laws, regulations, and policies influenced \\
\cline { 2 - 2 } & Participation in collaborative networks \\
\hline \multirow{5}{*}{ Education } & Number of students conducting independent research \\
\cline { 2 - 2 } & Learning-outcomes assessments \\
\cline { 2 - 2 } & Number of organizations that visit the field station \\
\cline { 2 - 2 } & Number of content-rich media impressions \\
\cline { 2 - 2 } & Number of contact hours \\
\hline Data Management & Number of digital datasets archived, downloaded, and cited \\
\hline Facilities and & Number of user days supported \\
\hline \multirow{3}{*}{$\begin{array}{l}\text { Infrastructure } \\
\text { Finance }\end{array}$} & Number and size of grants enabled by the field station \\
\cline { 2 - 2 } & Operating and maintenance expenses \\
\cline { 2 - 2 } & Level of Support from the National Science Foundation \\
\hline
\end{tabular}




\section{Business Planning Objectives and Timeline}

\section{Year 1}

1. Refine the revenue model with more information regarding availability of natural area lease royalties.

2. Retain the services of an architect and exhibit designer.

3. Engage cooperators in the review and customization of architectural and exhibit design plans.

4. Conduct a capital campaign to support renovation of the building.

5. Secure the municipal and state permits needed to carry out the renovation.

6. Define the charge and authority of the board of advisors; specify the roles, responsibilities, and membership structure of program, finance, and facilities committees.

7. Recruit members for each committee.

6. Develop an organizational chart and job descriptions for the director, assistant director, database manager, and caretaker.

Years 2 and 3

1. Appoint a director from the Rubenstein School faculty.

2. Hire an assistant director and database manager (possible joint position with Vermont Monitoring Cooperative).

3. Renovate and fit up the Summit Station.

4. Formalize policies, procedures, and systems for registering and orienting guests, safeguarding individuals and the environment, and securing the building and its contents.

5. Initiate marketing.

Years 4 and 5

1. Open and operate the facility.

2. Offer educational and training programs.

3. Develop a facility/program evaluation scheme to collect user feedback.

4. Incorporate feedback from users into updates of policies, systems, and programs.

5. Expand marketing.

6. Hire a seasonal caretaker.

7. Convene a regional research-planning workshop to support the maintenance and development of multi-disciplinary science and stewardship projects. 


\section{References}

Bororush, M. 2013. U.S. R\&D Resumes Growth in 2011 and 2012, Ahead of the Pace of the Gross Domestic Product. National Science Foundation. Retrieved February 27, 2014, from http://www.nsf.gov/statistics/infbrief/nsf14307/

Cook, S. 2012. Tourism in Vermont. Department of Tourism and Marketing. Retrieved February 27, 2014, from http://accd.vermont.gov/tourism_and_marketing/tourism

Organization of Biological Field Stations and National Association of Marine Labs. 2007. Field Stations and Marine Laboratories of the Future: A Strategic Vision. Retrieved April 4, 2014, from http://www.obfs.org/assets/docs/fsml_final_report.pdf

Gonzales, L., Allum, J., \& Sowell, R. 2013. Graduate Enrollment and Degrees: 1999 to 2009. Council of Graduate Schools. Retrieved February 27, 2014, from http://www.cgsnet.org/ckfinder/userfiles/files/GEDReport_2012.pdf

Lambert, D. 2013. Mount Mansfield Science and Stewardship Center Feasibility Study. Unpublished report.

Paradis, R., C. Rimmer, and K. McFarland. 2012. The Mount Mansfield Research and Stewardship Center: A Prospectus (draft). Unpublished report by University of Vermont Natural Areas Center and Vermont Center for Ecostudies.

Pontius, J., J. Duncan, M. Pendleton, J. Rosovsky, and C. Waite (Eds.) 2015. Science to Policy: Benefitting from Actionable Science. Proceedings of the December 11, 2014 Vermont Monitoring Cooperative and Mt. Mansfield Science and Stewardship Conference: Burlington, VT, Vermont Monitoring Cooperative. Available online at http://www.uvm.edu/vmc/annualMeeting/2014/proceeding 


\section{Business Appendix 1. Mount Mansfield Science and Stewardship Center Income and Expense Projections}

1st Year of Planning and Development

Revenue \& Expense Projection

\begin{tabular}{|c|c|c|c|c|c|c|c|c|c|c|c|c|c|}
\hline Revenues & Jan & Feb & March & April & May & June & July & Aug & Sep & Oct & Nov & $\mathrm{Dec}$ & Total \\
\hline Grants and Gifts & $\$ 2,083$ & $\$ 2,083$ & $\$ 2,083$ & $\$ 2,083$ & $\$ 2,083$ & $\$ 2,083$ & $\$ 2,083$ & $\$ 2,083$ & $\$ 2,083$ & $\$ 2,083$ & $\$ 2,083$ & $\$ 2,083$ & $\$ 25,000$ \\
\hline Natural Area Lease Royalties & $\$ 2,292$ & $\$ 2,292$ & $\$ 2,292$ & $\$ 2,292$ & $\$ 2,292$ & $\$ 2,292$ & $\$ 2,292$ & $\$ 2,292$ & $\$ 2,292$ & $\$ 2,292$ & $\$ 2,292$ & $\$ 2,292$ & $\$ 27,500$ \\
\hline Total Revenues & $\$ 4,375$ & $\$ 4,375$ & $\$ 4,375$ & $\$ 4,375$ & $\$ 4,375$ & $\$ 4,375$ & $\$ 4,375$ & $\$ 4,375$ & $\$ 4,375$ & $\$ 4,375$ & $\$ 4,375$ & $\$ 4,375$ & $\$ 52,500$ \\
\hline \multicolumn{14}{|l|}{ Expenses } \\
\hline \multicolumn{14}{|l|}{ Salary } \\
\hline Project Coordinator (0.5 FTE) & $\$ 2,708$ & $\$ 2,708$ & $\$ 2,708$ & $\$ 2,708$ & $\$ 2,708$ & $\$ 2,708$ & $\$ 2,708$ & $\$ 2,708$ & $\$ 2,708$ & $\$ 2,708$ & $\$ 2,708$ & $\$ 2,708$ & $\$ 32,500$ \\
\hline Fringe Benefits & $\$ 1,165$ & $\$ 1,165$ & $\$ 1,165$ & $\$ 1,165$ & $\$ 1,165$ & $\$ 1,165$ & $\$ 1,165$ & $\$ 1,165$ & $\$ 1,165$ & $\$ 1,165$ & $\$ 1,165$ & $\$ 1,165$ & $\$ 13,975$ \\
\hline Telephone & $\$ 50$ & $\$ 50$ & $\$ 50$ & $\$ 50$ & $\$ 50$ & $\$ 50$ & $\$ 50$ & $\$ 50$ & $\$ 50$ & $\$ 50$ & $\$ 50$ & $\$ 50$ & $\$ 600$ \\
\hline Supplies & $\$ 23$ & $\$ 23$ & $\$ 23$ & $\$ 23$ & $\$ 23$ & $\$ 23$ & $\$ 23$ & $\$ 23$ & $\$ 23$ & $\$ 23$ & $\$ 23$ & $\$ 23$ & $\$ 280$ \\
\hline Printing and Copying & $\$ 23$ & $\$ 23$ & $\$ 23$ & $\$ 23$ & $\$ 23$ & $\$ 23$ & $\$ 23$ & $\$ 23$ & $\$ 23$ & $\$ 23$ & $\$ 23$ & $\$ 23$ & $\$ 275$ \\
\hline Marketing and Communications & $\$ 83$ & $\$ 83$ & $\$ 83$ & $\$ 83$ & $\$ 83$ & $\$ 83$ & $\$ 83$ & $\$ 83$ & $\$ 83$ & $\$ 83$ & $\$ 83$ & $\$ 83$ & $\$ 1,000$ \\
\hline Conferences and Programs & $\$ 120$ & $\$ 120$ & $\$ 120$ & $\$ 120$ & $\$ 120$ & $\$ 120$ & $\$ 120$ & $\$ 120$ & $\$ 120$ & $\$ 120$ & $\$ 120$ & $\$ 120$ & $\$ 1,440$ \\
\hline Travel and Lodging & $\$ 83$ & $\$ 83$ & $\$ 83$ & $\$ 83$ & $\$ 83$ & $\$ 83$ & $\$ 83$ & $\$ 83$ & $\$ 83$ & $\$ 83$ & $\$ 83$ & $\$ 83$ & $\$ 1,000$ \\
\hline
\end{tabular}

Excess of Revenues Over Expenses

$\$ 1,430$ 


\section{Business Appendix 1. Mount Mansfield Science and Stewardship Center Income and Expense Projections (continued)}

2nd Year of Planning and Development

Revenue \& Expense Projection

\begin{tabular}{|c|c|c|c|c|c|c|c|c|c|c|c|c|c|}
\hline Revenues & Jan & Feb & March & April & May & June & July & Aug & Sep & Oct & Nov & $\mathrm{Dec}$ & Total \\
\hline Grants and Gifts & $\$ 2,083$ & $\$ 2,083$ & $\$ 2,083$ & $\$ 2,083$ & $\$ 2,083$ & $\$ 2,083$ & $\$ 2,083$ & $\$ 2,083$ & $\$ 2,083$ & $\$ 2,083$ & $\$ 2,083$ & $\$ 2,083$ & $\$ 25,000$ \\
\hline Natural Area Lease Royalties & $\$ 2,292$ & $\$ 2,292$ & $\$ 2,292$ & $\$ 2,292$ & $\$ 2,292$ & $\$ 2,292$ & $\$ 2,292$ & $\$ 2,292$ & $\$ 2,292$ & $\$ 2,292$ & $\$ 2,292$ & $\$ 2,292$ & $\$ 27,500$ \\
\hline Total Revenues & $\$ 4,375$ & $\$ 4,375$ & $\$ 4,375$ & $\$ 4,375$ & $\$ 4,375$ & $\$ 4,375$ & $\$ 4,375$ & $\$ 4,375$ & $\$ 4,375$ & $\$ 4,375$ & $\$ 4,375$ & $\$ 4,375$ & $\$ 52,500$ \\
\hline \multicolumn{14}{|l|}{ Expenses } \\
\hline \multicolumn{14}{|l|}{ Salary } \\
\hline Project Coordinator (0.5 FTE) & $\$ 2,708$ & $\$ 2,708$ & $\$ 2,708$ & $\$ 2,708$ & $\$ 2,708$ & $\$ 2,708$ & $\$ 2,708$ & $\$ 2,708$ & $\$ 2,708$ & $\$ 2,708$ & $\$ 2,708$ & $\$ 2,708$ & $\$ 32,500$ \\
\hline Fringe Benefits & $\$ 1,165$ & $\$ 1,165$ & $\$ 1,165$ & $\$ 1,165$ & $\$ 1,165$ & $\$ 1,165$ & $\$ 1,165$ & $\$ 1,165$ & $\$ 1,165$ & $\$ 1,165$ & $\$ 1,165$ & $\$ 1,165$ & $\$ 13,975$ \\
\hline Telephone & $\$ 50$ & $\$ 50$ & $\$ 50$ & $\$ 50$ & $\$ 50$ & $\$ 50$ & $\$ 50$ & $\$ 50$ & $\$ 50$ & $\$ 50$ & $\$ 50$ & $\$ 50$ & $\$ 600$ \\
\hline Supplies & $\$ 23$ & $\$ 23$ & $\$ 23$ & $\$ 23$ & $\$ 23$ & $\$ 23$ & $\$ 23$ & $\$ 23$ & $\$ 23$ & $\$ 23$ & $\$ 23$ & $\$ 23$ & $\$ 280$ \\
\hline Printing and Copying & $\$ 23$ & $\$ 23$ & $\$ 23$ & $\$ 23$ & $\$ 23$ & $\$ 23$ & $\$ 23$ & $\$ 23$ & $\$ 23$ & $\$ 23$ & $\$ 23$ & $\$ 23$ & $\$ 275$ \\
\hline Marketing and Communications & $\$ 83$ & $\$ 83$ & $\$ 83$ & $\$ 83$ & $\$ 83$ & $\$ 83$ & $\$ 83$ & $\$ 83$ & $\$ 83$ & $\$ 83$ & $\$ 83$ & $\$ 83$ & $\$ 1,000$ \\
\hline Conferences and Programs & $\$ 120$ & $\$ 120$ & $\$ 120$ & $\$ 120$ & $\$ 120$ & $\$ 120$ & $\$ 120$ & $\$ 120$ & $\$ 120$ & $\$ 120$ & $\$ 120$ & $\$ 120$ & $\$ 1,440$ \\
\hline Travel and Lodging & $\$ 83$ & $\$ 83$ & $\$ 83$ & $\$ 83$ & $\$ 83$ & $\$ 83$ & $\$ 83$ & $\$ 83$ & $\$ 83$ & $\$ 83$ & $\$ 83$ & $\$ 83$ & $\$ 1,000$ \\
\hline
\end{tabular}

Excess of Revenues Over Expenses

$\$ 1,430$ 


\section{Business Appendix 1. Mount Mansfield Science and Stewardship Center Income and Expense Projections (continued)}

3rd Year of Planning and

Development

Revenue \& Expense Projection

\begin{tabular}{|c|c|c|c|c|c|c|c|c|c|c|c|c|c|}
\hline Revenues & Jan & Feb & March & April & May & June & July & Aug & Sep & Oct & Nov & Dec & Total \\
\hline Special Events & $\$ 2,500$ & $\$ 2,500$ & $\$ 2,500$ & $\$ 2,500$ & $\$ 2,500$ & $\$ 2,500$ & $\$ 2,500$ & $\$ 2,500$ & $\$ 2,500$ & $\$ 2,500$ & $\$ 2,500$ & $\$ 2,500$ & $\$ 30,000$ \\
\hline Grants and Gifts & $\$ 7,083$ & $\$ 7,083$ & $\$ 7,083$ & $\$ 7,083$ & $\$ 7,083$ & $\$ 7,083$ & $\$ 7,083$ & $\$ 7,083$ & $\$ 7,083$ & $\$ 7,083$ & $\$ 7,083$ & $\$ 7,083$ & $\$ 85,000$ \\
\hline Natural Area Lease Royalties & $\$ 7,500$ & $\$ 7,500$ & $\$ 7,500$ & $\$ 7,500$ & $\$ 7,500$ & $\$ 7,500$ & $\$ 7,500$ & $\$ 7,500$ & $\$ 7,500$ & $\$ 7,500$ & $\$ 7,500$ & $\$ 7,500$ & $\$ 90,000$ \\
\hline Endowment & $\$ 0$ & $\$ 0$ & $\$ 0$ & $\$ 0$ & $\$ 0$ & $\$ 0$ & $\$ 1,833$ & $\$ 1,833$ & $\$ 1,833$ & $\$ 1,833$ & $\$ 1,833$ & $\$ 1,833$ & $\$ 11,000$ \\
\hline Total Revenues & $\$ 17,083$ & $\$ 17,083$ & $\$ 17,083$ & $\$ 17,083$ & $\$ 17,083$ & $\$ 17,083$ & $\$ 17,083$ & $\$ 17,083$ & $\$ 17,083$ & $\$ 17,083$ & $\$ 17,083$ & $\$ 17,083$ & $\$ 216,000$ \\
\hline \multicolumn{14}{|l|}{ Expenses } \\
\hline \multicolumn{14}{|l|}{ Salaries and Fringe } \\
\hline Professor/Director (0.7 FTE) & $\$ 5,833$ & $\$ 5,833$ & $\$ 5,833$ & $\$ 5,833$ & $\$ 5,833$ & $\$ 5,833$ & $\$ 5,833$ & $\$ 5,833$ & $\$ 5,833$ & $\$ 5,833$ & $\$ 5,833$ & $\$ 5,833$ & $\$ 70,000$ \\
\hline Assistant Director (1.0 FTE) & $\$ 5,498$ & $\$ 5,498$ & $\$ 5,498$ & $\$ 5,498$ & $\$ 5,498$ & $\$ 5,498$ & $\$ 5,498$ & $\$ 5,498$ & $\$ 5,498$ & $\$ 5,498$ & $\$ 5,498$ & $\$ 5,498$ & $\$ 65,975$ \\
\hline Fringe Benefits & $\$ 4,872$ & $\$ 4,872$ & $\$ 4,872$ & $\$ 4,872$ & $\$ 4,872$ & $\$ 4,872$ & $\$ 4,872$ & $\$ 4,872$ & $\$ 4,872$ & $\$ 4,872$ & $\$ 4,872$ & $\$ 4,872$ & $\$ 58,469$ \\
\hline Rent/Lease & $\$ 370$ & $\$ 370$ & $\$ 370$ & $\$ 370$ & $\$ 370$ & $\$ 370$ & $\$ 370$ & $\$ 370$ & $\$ 370$ & $\$ 370$ & $\$ 370$ & $\$ 370$ & $\$ 4,440$ \\
\hline Telephone & $\$ 50$ & $\$ 50$ & $\$ 50$ & $\$ 50$ & $\$ 50$ & $\$ 50$ & $\$ 50$ & $\$ 50$ & $\$ 50$ & $\$ 50$ & $\$ 50$ & $\$ 50$ & $\$ 600$ \\
\hline Supplies & $\$ 25$ & $\$ 25$ & $\$ 25$ & $\$ 25$ & $\$ 25$ & $\$ 25$ & $\$ 25$ & $\$ 25$ & $\$ 25$ & $\$ 25$ & $\$ 25$ & $\$ 25$ & $\$ 300$ \\
\hline Conferences and Programs & $\$ 120$ & $\$ 120$ & $\$ 120$ & $\$ 120$ & $\$ 120$ & $\$ 120$ & $\$ 120$ & $\$ 120$ & $\$ 120$ & $\$ 120$ & $\$ 120$ & $\$ 120$ & $\$ 1,440$ \\
\hline Travel and Lodging & $\$ 92$ & $\$ 92$ & $\$ 92$ & $\$ 92$ & $\$ 92$ & $\$ 92$ & $\$ 92$ & $\$ 92$ & $\$ 92$ & $\$ 92$ & $\$ 92$ & $\$ 92$ & $\$ 1,100$ \\
\hline Insurance & $\$ 83$ & $\$ 83$ & $\$ 83$ & $\$ 83$ & $\$ 83$ & $\$ 83$ & $\$ 83$ & $\$ 83$ & $\$ 83$ & $\$ 83$ & $\$ 83$ & $\$ 83$ & $\$ 1,000$ \\
\hline Total Expenditures & $\$ 17,055$ & $\$ 17,055$ & $\$ 17,055$ & $\$ 17,055$ & $\$ 17,055$ & $\$ 17,055$ & $\$ 17,055$ & $\$ 17,055$ & $\$ 17,055$ & $\$ 17,055$ & $\$ 17,055$ & $\$ 17,055$ & $\$ 204,659$ \\
\hline
\end{tabular}

\section{Excess of Revenues Over}

Expenses

$\$ 11,341$ 


\section{Business Appendix 1. Mount Mansfield Science and Stewardship Center Income and Expense Projections (continued)}

1st Year of Operation

Revenue \& Expense

Projection

\begin{tabular}{|c|c|c|c|c|c|c|c|c|c|c|c|c|c|}
\hline Revenues & Jan & Feb & March & April & May & June & July & Aug & Sep & Oct & Nov & Dec & Total \\
\hline Institutional Memberships & $\$ 1,250$ & $\$ 1,250$ & $\$ 1,250$ & $\$ 1,250$ & $\$ 1,250$ & $\$ 1,250$ & $\$ 1,250$ & $\$ 1,250$ & $\$ 1,250$ & $\$ 1,250$ & $\$ 1,250$ & $\$ 1,250$ & $\$ 15,000$ \\
\hline Special Events & $\$ 2,500$ & $\$ 2,500$ & $\$ 2,500$ & $\$ 2,500$ & $\$ 2,500$ & $\$ 2,500$ & $\$ 2,500$ & $\$ 2,500$ & $\$ 2,500$ & $\$ 2,500$ & $\$ 2,500$ & $\$ 2,500$ & $\$ 30,000$ \\
\hline Toll Road Surcharge & $\$ 0$ & $\$ 0$ & $\$ 0$ & $\$ 0$ & $\$ 0$ & $\$ 0$ & $\$ 1,500$ & $\$ 1,500$ & $\$ 1,500$ & $\$ 2,000$ & $\$ 2,000$ & $\$ 0$ & $\$ 8,500$ \\
\hline Field Course Fees & $\$ 0$ & $\$ 0$ & $\$ 0$ & $\$ 0$ & $\$ 1,500$ & $\$ 1,500$ & $\$ 1,500$ & $\$ 1,500$ & $\$ 1,500$ & $\$ 0$ & $\$ 0$ & $\$ 0$ & $\$ 7,500$ \\
\hline User fees & $\$ 0$ & $\$ 0$ & $\$ 0$ & $\$ 500$ & $\$ 4,500$ & $\$ 4,500$ & $\$ 3,000$ & $\$ 3,000$ & $\$ 4,500$ & $\$ 1,000$ & $\$ 0$ & $\$ 0$ & $\$ 21,000$ \\
\hline Grants and Gifts & $\$ 7,083$ & $\$ 7,083$ & $\$ 7,083$ & $\$ 7,083$ & $\$ 7,083$ & $\$ 7,083$ & $\$ 7,083$ & $\$ 7,083$ & $\$ 7,083$ & $\$ 7,083$ & $\$ 7,083$ & $\$ 7,083$ & $\$ 85,000$ \\
\hline Natural Area Lease Royalties & $\$ 7,917$ & $\$ 7,917$ & $\$ 7,917$ & $\$ 7,917$ & $\$ 7,917$ & $\$ 7,917$ & $\$ 7,917$ & $\$ 7,917$ & $\$ 7,917$ & $\$ 7,917$ & $\$ 7,917$ & $\$ 7,917$ & $\$ 95,000$ \\
\hline Endowment & $\$ 1,833$ & $\$ 1,833$ & $\$ 1,833$ & $\$ 1,833$ & $\$ 1,833$ & $\$ 1,833$ & $\$ 1,833$ & $\$ 1,833$ & $\$ 1,833$ & $\$ 1,833$ & $\$ 1,833$ & $\$ 1,833$ & $\$ 22,000$ \\
\hline Total Revenues & $\$ 20,583$ & $\$ 18,750$ & $\$ 18,750$ & $\$ 19,250$ & $\$ 24,750$ & $\$ 24,750$ & $\$ 24,750$ & $\$ 24,750$ & $\$ 26,250$ & $\$ 21,750$ & $\$ 20,750$ & $\$ 18,750$ & $\$ 284,000$ \\
\hline Expenses & & & & & & & & & & & & & Total \\
\hline Salaries & & & & & & & & & & & & & \\
\hline Professor/Director (0.7 FTE) & $\$ 5,921$ & $\$ 5,921$ & $\$ 5,921$ & $\$ 5,921$ & $\$ 5,921$ & $\$ 5,921$ & $\$ 5,921$ & $\$ 5,921$ & $\$ 5,921$ & $\$ 5,921$ & $\$ 5,921$ & $\$ 5,921$ & $\$ 71,050$ \\
\hline Assistant Director (1.0 FTE) & $\$ 5,580$ & $\$ 5,580$ & $\$ 5,580$ & $\$ 5,580$ & $\$ 5,580$ & $\$ 5,580$ & $\$ 5,580$ & $\$ 5,580$ & $\$ 5,580$ & $\$ 5,580$ & $\$ 5,580$ & $\$ 5,580$ & $\$ 66,965$ \\
\hline Data Coordinator (0.1 FTE) & $\$ 533$ & $\$ 533$ & $\$ 533$ & $\$ 533$ & $\$ 533$ & $\$ 533$ & $\$ 533$ & $\$ 533$ & $\$ 533$ & $\$ 533$ & $\$ 533$ & $\$ 533$ & $\$ 6,400$ \\
\hline Fringe Benefits & $\$ 5,175$ & $\$ 5,175$ & $\$ 5,175$ & $\$ 5,175$ & $\$ 5,175$ & $\$ 5,175$ & $\$ 5,175$ & $\$ 5,175$ & $\$ 5,175$ & $\$ 5,175$ & $\$ 5,175$ & $\$ 5,175$ & $\$ 62,098$ \\
\hline Contracted Services & $\$ 0$ & $\$ 0$ & $\$ 0$ & $\$ 0$ & $\$ 1,000$ & $\$ 1,000$ & $\$ 1,000$ & $\$ 1,000$ & $\$ 1,000$ & $\$ 0$ & $\$ 0$ & $\$ 0$ & $\$ 5,000$ \\
\hline Rent/Lease & $\$ 385$ & $\$ 385$ & $\$ 385$ & $\$ 385$ & $\$ 385$ & $\$ 385$ & $\$ 385$ & $\$ 385$ & $\$ 385$ & $\$ 385$ & $\$ 385$ & $\$ 385$ & $\$ 4,620$ \\
\hline Telephone/Internet & $\$ 250$ & $\$ 250$ & $\$ 250$ & $\$ 250$ & $\$ 250$ & $\$ 250$ & $\$ 250$ & $\$ 250$ & $\$ 250$ & $\$ 250$ & $\$ 250$ & $\$ 250$ & $\$ 3,000$ \\
\hline Supplies & $\$ 200$ & $\$ 200$ & $\$ 200$ & $\$ 600$ & $\$ 600$ & $\$ 600$ & $\$ 600$ & $\$ 600$ & $\$ 600$ & $\$ 200$ & $\$ 200$ & $\$ 200$ & $\$ 4,800$ \\
\hline Printing and Copying & $\$ 42$ & $\$ 42$ & $\$ 42$ & $\$ 42$ & $\$ 42$ & $\$ 42$ & $\$ 42$ & $\$ 42$ & $\$ 42$ & $\$ 42$ & $\$ 42$ & $\$ 42$ & $\$ 500$ \\
\hline Equipment Upkeep & $\$ 0$ & $\$ 0$ & $\$ 0$ & $\$ 500$ & $\$ 750$ & $\$ 750$ & $\$ 750$ & $\$ 750$ & $\$ 750$ & $\$ 500$ & $\$ 0$ & $\$ 0$ & $\$ 4,750$ \\
\hline Utilities and Maintenance & $\$ 2,818$ & $\$ 2,818$ & $\$ 2,818$ & $\$ 2,953$ & $\$ 3,140$ & $\$ 3,140$ & $\$ 3,140$ & $\$ 3,140$ & $\$ 3,140$ & $\$ 2,893$ & $\$ 2,818$ & $\$ 2,818$ & $\$ 35,637$ \\
\hline $\begin{array}{l}\text { Marketing and } \\
\text { Communications }\end{array}$ & $\$ 158$ & $\$ 158$ & $\$ 158$ & $\$ 158$ & $\$ 158$ & $\$ 158$ & $\$ 158$ & $\$ 158$ & $\$ 158$ & $\$ 158$ & $\$ 158$ & $\$ 158$ & $\$ 1,900$ \\
\hline Conferences and Programs & $\$ 200$ & $\$ 200$ & $\$ 200$ & $\$ 200$ & $\$ 200$ & $\$ 200$ & $\$ 200$ & $\$ 200$ & $\$ 200$ & $\$ 200$ & $\$ 200$ & $\$ 200$ & $\$ 2,400$ \\
\hline Travel and Lodging & $\$ 158$ & $\$ 158$ & $\$ 158$ & $\$ 158$ & $\$ 158$ & $\$ 158$ & $\$ 158$ & $\$ 158$ & $\$ 158$ & $\$ 158$ & $\$ 158$ & $\$ 158$ & $\$ 1,900$ \\
\hline Professional Development & $\$ 100$ & $\$ 100$ & $\$ 100$ & $\$ 100$ & $\$ 100$ & $\$ 100$ & $\$ 100$ & $\$ 100$ & $\$ 100$ & $\$ 100$ & $\$ 100$ & $\$ 100$ & $\$ 1,200$ \\
\hline Insurance & $\$ 83$ & $\$ 83$ & $\$ 83$ & $\$ 83$ & $\$ 83$ & $\$ 83$ & $\$ 83$ & $\$ 83$ & $\$ 83$ & $\$ 83$ & $\$ 83$ & $\$ 83$ & $\$ 1,000$ \\
\hline Total Expenditures & $\$ 21,604$ & $\$ 21,604$ & $\$ 21,604$ & $\$ 22,639$ & $\$ 24,076$ & $\$ 24,076$ & $\$ 24,076$ & $\$ 24,076$ & $\$ 24,076$ & $\$ 22,179$ & $\$ 21,604$ & $\$ 21,604$ & $\$ 273,220$ \\
\hline
\end{tabular}

Excess of Revenues Over

Expenses

$\$ 10,780$ 


\section{Business Appendix 1. Mount Mansfield Science and Stewardship Center Income and Expense Projections (continued)}

2nd Year of Operation

Revenue \& Expense Projection

\begin{tabular}{|c|c|c|c|c|c|c|c|c|c|c|c|c|c|}
\hline Revenues & Jan & Feb & March & April & May & June & July & Aug & Sep & Oct & Nov & Dec & Total \\
\hline Institutional Memberships & $\$ 1,667$ & $\$ 1,667$ & $\$ 1,667$ & $\$ 1,667$ & $\$ 1,667$ & $\$ 1,667$ & $\$ 1,667$ & $\$ 1,667$ & $\$ 1,667$ & $\$ 1,667$ & $\$ 1,667$ & $\$ 1,667$ & $\$ 20,000$ \\
\hline Special Events & $\$ 2,917$ & $\$ 2,917$ & $\$ 2,917$ & $\$ 2,917$ & $\$ 2,917$ & $\$ 2,917$ & $\$ 2,917$ & $\$ 2,917$ & $\$ 2,917$ & $\$ 2,917$ & $\$ 2,917$ & $\$ 2,917$ & $\$ 35,000$ \\
\hline Toll Road Surcharge & $\$ 0$ & $\$ 0$ & $\$ 0$ & $\$ 0$ & $\$ 0$ & $\$ 0$ & $\$ 1,500$ & $\$ 1,500$ & $\$ 1,500$ & $\$ 2,000$ & $\$ 2,000$ & $\$ 0$ & $\$ 8,500$ \\
\hline Field Course Fees & $\$ 0$ & $\$ 0$ & $\$ 0$ & $\$ 0$ & $\$ 3,000$ & $\$ 3,000$ & $\$ 3,000$ & $\$ 3,000$ & $\$ 3,000$ & $\$ 0$ & $\$ 0$ & $\$ 0$ & $\$ 15,000$ \\
\hline User fees & $\$ 0$ & $\$ 0$ & $\$ 0$ & $\$ 1,000$ & $\$ 7,500$ & $\$ 7,500$ & $\$ 6,000$ & $\$ 6,000$ & $\$ 8,000$ & $\$ 2,000$ & $\$ 0$ & $\$ 0$ & $\$ 38,000$ \\
\hline Grants and Gifts & $\$ 8,333$ & $\$ 8,333$ & $\$ 8,333$ & $\$ 8,333$ & $\$ 8,333$ & $\$ 8,333$ & $\$ 8,333$ & $\$ 8,333$ & $\$ 8,333$ & $\$ 8,333$ & $\$ 8,333$ & $\$ 8,333$ & $\$ 100,000$ \\
\hline Natural Area Lease Royalties & $\$ 8,333$ & $\$ 8,333$ & $\$ 8,333$ & $\$ 8,333$ & $\$ 8,333$ & $\$ 8,333$ & $\$ 8,333$ & $\$ 8,333$ & $\$ 8,333$ & $\$ 8,333$ & $\$ 8,333$ & $\$ 8,333$ & $\$ 100,000$ \\
\hline Endowment & $\$ 1,833$ & $\$ 1,833$ & $\$ 1,833$ & $\$ 1,833$ & $\$ 1,833$ & $\$ 1,833$ & $\$ 1,833$ & $\$ 1,833$ & $\$ 1,833$ & $\$ 1,833$ & $\$ 1,833$ & $\$ 1,833$ & $\$ 22,000$ \\
\hline Total Revenues & $\$ 21,250$ & $\$ 21,250$ & $\$ 21,250$ & $\$ 22,250$ & $\$ 31,750$ & $\$ 31,750$ & $\$ 31,750$ & $\$ 31,750$ & $\$ 33,750$ & $\$ 25,250$ & $\$ 23,250$ & $\$ 21,250$ & $\$ 338,500$ \\
\hline \multicolumn{14}{|l|}{ Expenses } \\
\hline \multicolumn{14}{|l|}{ Salaries } \\
\hline Professor/Director (0.7 FTE) & $\$ 6,100$ & $\$ 6,100$ & $\$ 6,100$ & $\$ 6,100$ & $\$ 6,100$ & $\$ 6,100$ & $\$ 6,100$ & $\$ 6,100$ & $\$ 6,100$ & $\$ 6,100$ & $\$ 6,100$ & $\$ 6,100$ & $\$ 73,198$ \\
\hline Assistant Director (1.0 FTE) & $\$ 5,749$ & $\$ 5,749$ & $\$ 5,749$ & $\$ 5,749$ & $\$ 5,749$ & $\$ 5,749$ & $\$ 5,749$ & $\$ 5,749$ & $\$ 5,749$ & $\$ 5,749$ & $\$ 5,749$ & $\$ 5,749$ & $\$ 68,989$ \\
\hline Data Coordinator (0.15 FTE) & $\$ 824$ & $\$ 824$ & $\$ 824$ & $\$ 824$ & $\$ 824$ & $\$ 824$ & $\$ 824$ & $\$ 824$ & $\$ 824$ & $\$ 824$ & $\$ 824$ & $\$ 824$ & $\$ 9,890$ \\
\hline Caretaker (0.5 FTE) & $\$ 0$ & $\$ 0$ & $\$ 0$ & $\$ 0$ & $\$ 3,806$ & $\$ 3,806$ & $\$ 3,806$ & $\$ 3,806$ & $\$ 3,806$ & $\$ 3,806$ & $\$ 0$ & $\$ 0$ & $\$ 22,838$ \\
\hline Fringe Benefits & $\$ 5,449$ & $\$ 5,449$ & $\$ 5,449$ & $\$ 5,449$ & $\$ 7,086$ & $\$ 7,086$ & $\$ 7,086$ & $\$ 7,086$ & $\$ 7,086$ & $\$ 7,086$ & $\$ 5,449$ & $\$ 5,449$ & $\$ 75,213$ \\
\hline Contracted Services & $\$ 0$ & $\$ 0$ & $\$ 0$ & $\$ 0$ & $\$ 1,500$ & $\$ 1,500$ & $\$ 1,500$ & $\$ 1,500$ & $\$ 1,500$ & $\$ 0$ & $\$ 0$ & $\$ 0$ & $\$ 7,500$ \\
\hline Rent/Lease & $\$ 400$ & $\$ 400$ & $\$ 400$ & $\$ 400$ & $\$ 400$ & $\$ 400$ & $\$ 400$ & $\$ 400$ & $\$ 400$ & $\$ 400$ & $\$ 400$ & $\$ 400$ & $\$ 4,800$ \\
\hline Telephone/Internet & $\$ 250$ & $\$ 250$ & $\$ 250$ & $\$ 250$ & $\$ 250$ & $\$ 250$ & $\$ 250$ & $\$ 250$ & $\$ 250$ & $\$ 250$ & $\$ 250$ & $\$ 250$ & $\$ 3,000$ \\
\hline Supplies & $\$ 200$ & $\$ 200$ & $\$ 200$ & $\$ 600$ & $\$ 600$ & $\$ 600$ & $\$ 600$ & $\$ 600$ & $\$ 600$ & $\$ 200$ & $\$ 200$ & $\$ 200$ & $\$ 4,800$ \\
\hline Printing and Copying & $\$ 42$ & $\$ 42$ & $\$ 42$ & $\$ 42$ & $\$ 42$ & $\$ 42$ & $\$ 42$ & $\$ 42$ & $\$ 42$ & $\$ 42$ & $\$ 42$ & $\$ 42$ & $\$ 500$ \\
\hline Equipment Upkeep & $\$ 0$ & $\$ 0$ & $\$ 0$ & $\$ 500$ & $\$ 750$ & $\$ 750$ & $\$ 750$ & $\$ 750$ & $\$ 750$ & $\$ 500$ & $\$ 0$ & $\$ 0$ & $\$ 4,750$ \\
\hline Utilities and Maintenance & $\$ 3,070$ & $\$ 3,070$ & $\$ 3,070$ & $\$ 3,205$ & $\$ 4,284$ & $\$ 4,284$ & $\$ 4,284$ & $\$ 4,284$ & $\$ 4,284$ & $\$ 3,961$ & $\$ 3,070$ & $\$ 3,070$ & $\$ 43,932$ \\
\hline Marketing and Communications & $\$ 150$ & $\$ 150$ & $\$ 150$ & $\$ 150$ & $\$ 150$ & $\$ 150$ & $\$ 150$ & $\$ 150$ & $\$ 150$ & $\$ 150$ & $\$ 150$ & $\$ 150$ & $\$ 1,800$ \\
\hline Conferences and Programs & $\$ 1,000$ & $\$ 1,000$ & $\$ 1,000$ & $\$ 1,000$ & $\$ 1,000$ & $\$ 1,000$ & $\$ 1,000$ & $\$ 1,000$ & $\$ 1,000$ & $\$ 1,000$ & $\$ 1,000$ & $\$ 1,000$ & $\$ 12,000$ \\
\hline Travel and Lodging & $\$ 200$ & $\$ 200$ & $\$ 200$ & $\$ 200$ & $\$ 200$ & $\$ 200$ & $\$ 200$ & $\$ 200$ & $\$ 200$ & $\$ 200$ & $\$ 200$ & $\$ 200$ & $\$ 2,400$ \\
\hline Professional Development & $\$ 100$ & $\$ 100$ & $\$ 100$ & $\$ 100$ & $\$ 100$ & $\$ 100$ & $\$ 100$ & $\$ 100$ & $\$ 100$ & $\$ 100$ & $\$ 100$ & $\$ 100$ & $\$ 1,200$ \\
\hline Insurance & $\$ 83$ & $\$ 83$ & $\$ 83$ & $\$ 83$ & $\$ 83$ & $\$ 83$ & $\$ 83$ & $\$ 83$ & $\$ 83$ & $\$ 83$ & $\$ 83$ & $\$ 83$ & $\$ 1,000$ \\
\hline Total Expenditures & $\$ 23,534$ & $\$ 23,534$ & $\$ 23,534$ & $\$ 24,569$ & $\$ 32,841$ & $\$ 32,841$ & $\$ 32,841$ & $\$ 32,841$ & $\$ 32,841$ & $\$ 30,368$ & $\$ 23,534$ & $\$ 23,534$ & $\$ 336,808$ \\
\hline
\end{tabular}




\section{Acknowledgments}

The preparation of these plans has been funded by a grant from the National Science Foundation Division of Biological Infrastructure. Additional support was provided by the Rubenstein School of Environment and Natural Resources, the Vermont Center for Ecostudies, the Vermont Monitoring Cooperative, the Vermont Department of Forests, Parks and Recreation, the UVM Offices of the Provost and Vice

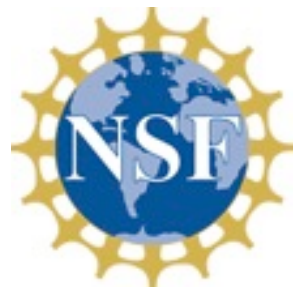
President for Research, and the Vermont Ski Areas Association. Dan Lambert wrote and edited the text with contributions from James Duncan (Data Coordinator, Vermont Monitoring Cooperative), Tyler Scott (Architect, Scott and Partners Architecture), Cara Hanson (UVM Facilities Design and Construction) and the following members of the Mansfield Center Leadership Team: Nancy Mathews (Dean, Rubenstein School of Environment and Natural Resources), Rick Paradis (Director, UVM Natural Areas Center), Jennifer Pontius (Principal Investigator, Vermont Monitoring Cooperative), Chris Rimmer (Executive Director, Vermont Center for Ecostudies), Allan Strong (Associate Dean, Rubenstein School of Environment and Natural Resources), Nathan Fry (graduate student, Rubenstein School of Environment and Natural Resources), David Kaufman (Director, UVM Parks, Recreation, and Tourism Program), Carl Waite (Program Coordinator, Vermont Monitoring Cooperative), and Sandy Wilmot (Forest Health Specialist, Vermont Department of Forests, Parks and Recreation). Dan prepared the first draft of the business plan for "Entrepreneurship in Recreation and Tourism", a resource management course at the Rubenstein School.

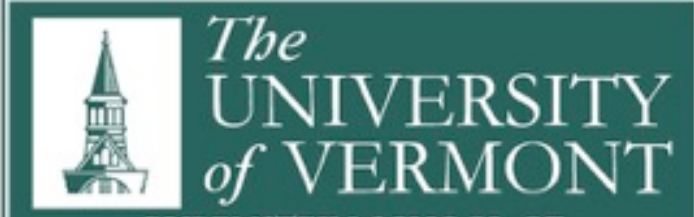

RUBENSTEIN SCHOOL OF

ENVIRONMENT AND NATURAL RESOURCES

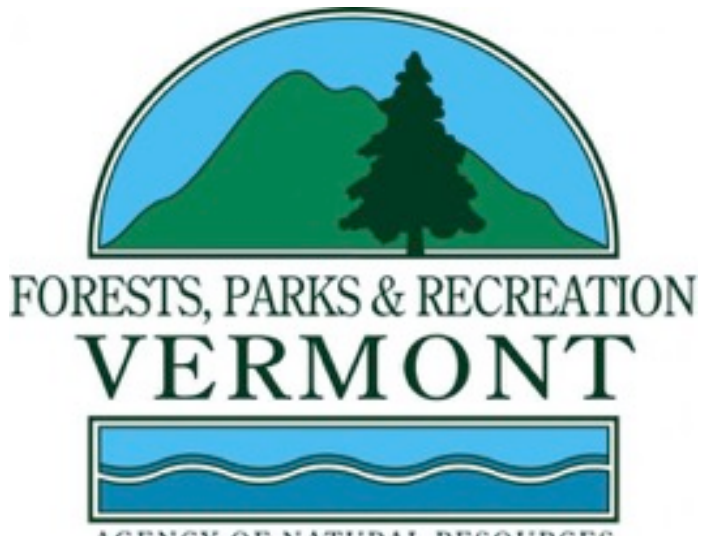

AGENCY OF NATURAL RESOURCES
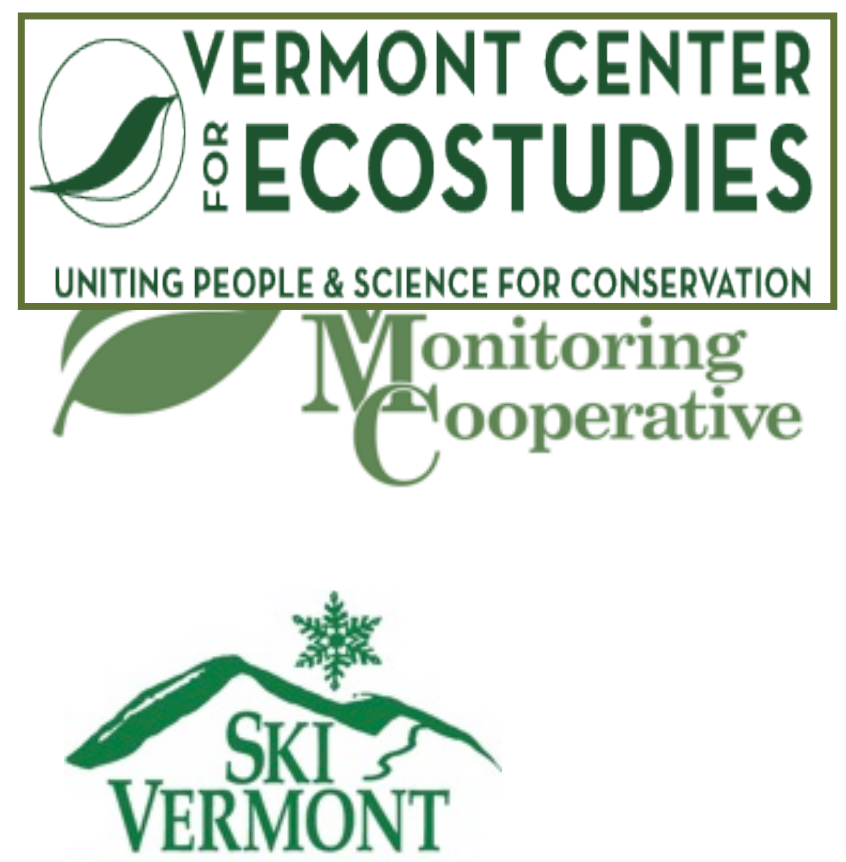

Winter in its Oriqinal State. 